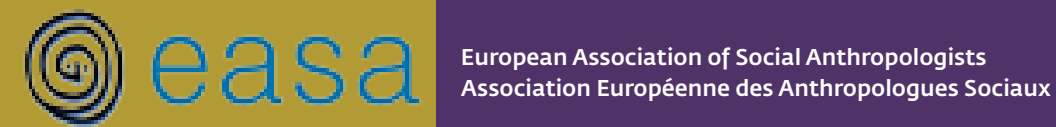

THE ANTHROPOLOGICAL CAREER IN EUROPE:

A complet

EASA mem

Martin Fotta, Mariya Ivancheva \& Raluca Pernes

(2)

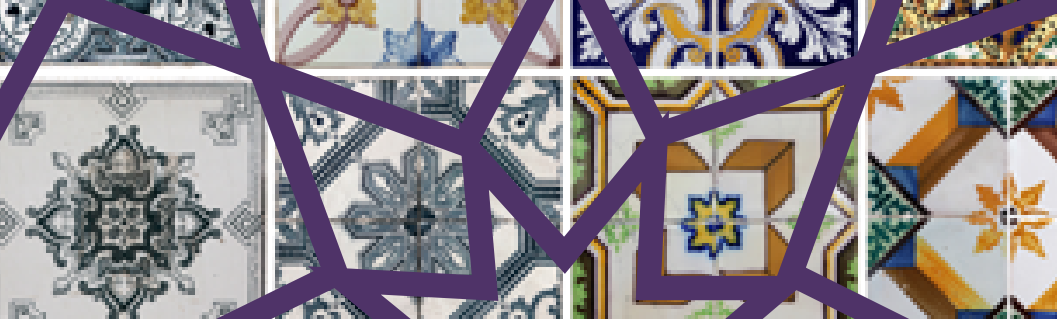

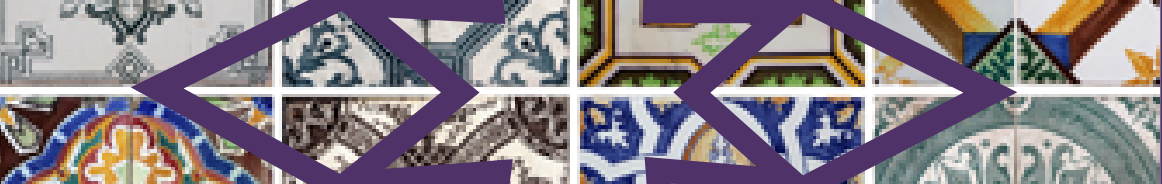
cr.

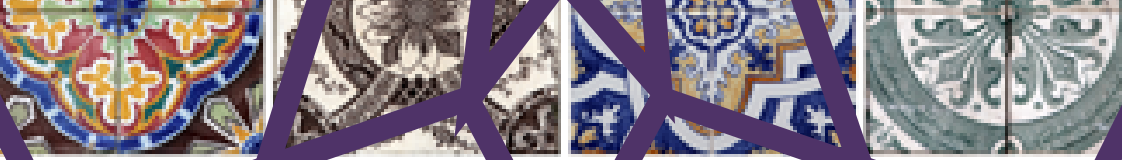

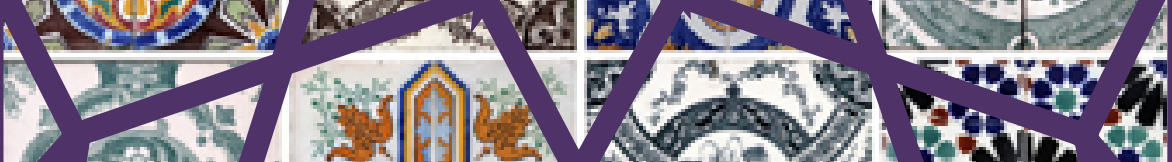

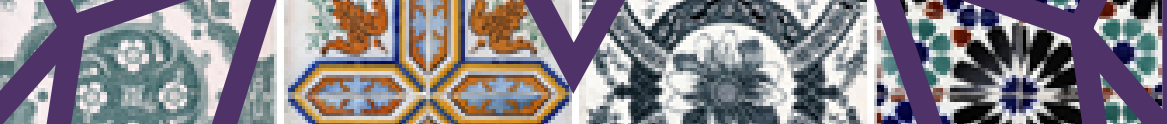

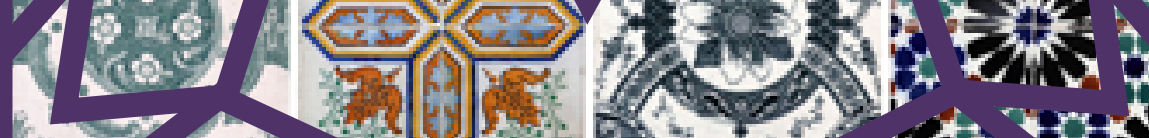

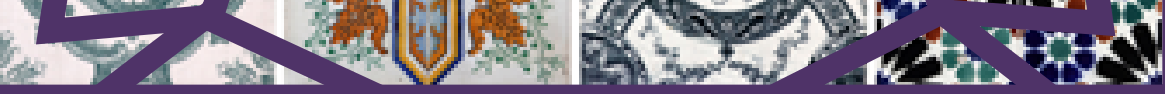


This report was written by Martin Fotta, Mariya Ivancheva and Raluca Pernes for the PrecAnthro Collective and was commissioned by the European Association of Social Anthropologists. Any part of this report may be copied, translated, or adapted with permission from the authors, provided that the parts copied are distributed free or at cost (not for profit) and the authors are acknowledged.

Any commercial reproduction requires prior written permission from the authors.

The Internet links contained in this report were active at the time of the publication.

This report is published in English.

Copy-editing: Andrew Hodges

Cover design and layout: Kirsten El

(c) 2020 European Association for Social Anthropologists

https://doi.org/10.22582/easaprecanthro

EASA is a Charity registered in England and Wales

Registered Office: c/o RAI, 50 Fitzroy St, London W1T 5BT, UK

https://easaonline.org

This publication should be cited as: Fotta, Martin, Mariya Ivancheva and Raluca Pernes (2020) The anthropological career in Europe: A complete report on the EASA membership survey. European Association of Social Anthropologists.

https://doi.org/10.22582/easaprecanthro 


\section{THE ANTHROPOLOGICAL CAREER IN EUROPE: A complete report on the EASA membership survey}

Martin Fotta, Mariya Ivancheva \& Raluca Pernes 


\section{Contents}

Acknowledgements $\quad 6$

Executive summary $\quad 7$

$\begin{array}{ll}\text { Findings } & 7\end{array}$

Recommendations $\quad 8$

How to read the report $\quad 8$

1. Key findings 9

2. Background 14

2.1 Rationale $\quad 15$

3. Methodology and the research sample 19

4. Basic characteristics of EASA survey participants 21

5. Employment and academic career 25

5.1 Contracts and employment 25

5.1.1. Contracts in academia $\quad 25$

5.1.2 Fixed-term contracts 26

5.1.3 Percentage of fixed-term contracts $\quad 29$

5.1.4 Permanent contracts 30

5.1.5 Employment history 33

5.1.6 Gender and academic career $\quad 36$

5.1.7 Employment satisfaction $\quad 37$

5.1.8 Summary $\quad 39$

5.2 Kinds of jobs and tasks 40

5.2.1 Working hours $\quad 41$

5.2.2 Unpaid overtime $\quad 41$

5.2.3 Applying for jobs $\quad 44$

5.2.4 Writing funding applications $\quad 45$

5.2.5 Career development work $\quad 48$

5.2.6 Summary 49

5.3 Subjective views on employment and career prospects 49

5.3.1. Views on employment prospects 49

5.3.2 Pursuing careers 50

5.3.3 Views on the academic environment 52

5.3.4 Summary 53

6. Combining work and private lives $\quad 54$

6.1 Income $\quad 54$

6.1.1 Sources of income $\quad 54$

6.1.2 Income averages $\quad 55$

6.1.3 Employment-related benefits 58

6.1.4 Income and quality of life $\quad 59$

6.1.5 Summary 62

6.2 Combining work and family life $\quad 62$

6.2.1 Academics' family situation $\quad 62$

6.2.2 Class background 63

6.2.3 Subjective evaluations $\quad 65$ 
6.2.4 Summary 69

7. Mobility 70

$\begin{array}{ll}7.1 \text { Workplace commuting } & 70\end{array}$

$\begin{array}{ll}\text { 7.1.1 Commuting frequency } & 70\end{array}$

$\begin{array}{ll}\text { 7.1.2 Forms of commute } & 71\end{array}$

7.1.3 Commuting time $\quad 72$

7.1.4 Commuting costs $\quad 73$

$\begin{array}{ll}\text { 7.1.5 Long-distance commuting } & 74\end{array}$

7.1.6 Air travel $\quad 74$

$\begin{array}{ll}\text { 7.1.7 Summary } & 75\end{array}$

7.2 Academic mobility $\quad 76$

7.2.1 International mobility $\quad 76$

$\begin{array}{ll}7.2 .2 \text { Interdepartmental mobility } & 78\end{array}$

7.2.3. Views on international mobility $\quad 79$

7.2.4 Moving countries and life satisfaction $\quad 81$

7.2.5 Summary 82

8. Workplace $\quad 83$

8.1 Academic departments $\quad 83$

8.2 Workspace 83

8.2.1 Employer-provided services and infrastructure 83

8.2.2 Sufficiency of the workspace, access

to facilities, and career development 84

8.2.3 Student support and workspaces $\quad 85$

8.3 Summary 86

9. Discrimination $\quad \mathbf{8 7}$

9.1 Experiences with discrimination, unfair treatment,
harassment or abuse within academia

9.2 Other reasons for discrimination, unfair treatment,
harassment and abuse within academia

9.3 Witnessing discrimination, unfair treatment,

harassment or abuse within academia 89

9.4 Power and inequality in academia 90

9.5 Summary 92

10. Representation of interests 93

10.1 Representation of interests in one's department 93

10.2 Trade unions 94

10.2.1 Union membership $\quad 94$

10.2.2 Reasons for not joining a union 95

10.2.3 Summary 96

10.3. Raising complaints 96

10.4 The role of EASA 98

11. Conclusions and recommendations 101 


\section{Acknowledgements}

We wish to thank the following:

The PrecAnthro Collective, especially Ana Ivasciuc and also Dan Hirslund.

NomadIT's Rohan Jackson and Triinu Mets specifically for their initial push for PrecAnthro to become a central event and not just a parallel lab at EASA2016, and for their robust logistical and moral support ever since.

The previous and current EASA execs - especially the Presidents Thomas Hylland Eriksen and Valeria Siniscalchi for entering into the conversation with us fully, and for taking academic precarity seriously since 2016, and Sarah Green for encouraging this work to continue and for new directions of inquiry to emerge under her presidency. David Mills and Prem Kumar Rajaram for engaging with this report in more than one way and to all other EASA executivecommittee members for their encouragement and feedback. And especially Sabine Strasser and Georgeta Stoica, who were PrecAnthro liaisons between 2016 and 2018. They were central to organising the survey: they contributed to the development of the questions, organised the EASA Bern 2017 AGM around political and labour precarity, and spent hours with us identifying central questions to be explored in the analysis.

Janine Widmer for setting and running the online survey, and for the initial analyses; and to University of Bern for resourcing Janine's work and allowing us to use their survey licence.

Andrew Hodges and Kirsten El for their assistance with copyediting and graphic design, respectively.

Countless and unnamed precarious anthropologists who did not leave us without food for thought and spite with their stories and struggles.

Our families and friends who did not give up on us even when we brought academic precarity into their lives not just as a conversation topic, but also as a lived reality. 


\section{Executive summary}

This report presents the results of the survey conducted among EASA members in 2018. The survey was a collaboration between EASA and the PrecAnthro Collective, whose members have worked together and mobilised since 2016 to raise awareness about the challenges of developing an academic career in anthropology. The themes explored in the survey reflect existing academic research on changes to the academic profession and the casualisation of labour in Europe and beyond.

The survey enquired into the extent to which and how trends already documented in other disciplines, and in academia as a whole, affect anthropologists. These trends include a growing division between research and teaching, the deprofessionalisation of academic labour through multiple contract types, the imperatives of international mobility and cyclical fundraising, and weak labour unions.

This report captures overall trends as well as regional differences in the anthropological profession in Europe.

\section{Findings}

Anthropology in Europe is increasingly a precarious profession. Half of the survey respondents worked on fixed-term contracts. Not including fieldwork travel, anthropologists spend on average five or more years after the PhD before gaining tenure, and often move between institutions, contracts and countries.

Regardless of their contract type, anthropologists in Europe spend a large number of hours engaged in overtime and unpaid work. An ever-growing proportion of this work is dedicated to writing up papers from already-finished research projects while also doing new fieldwork and applying for new project funding: such arrangements are a large waste of human resources as most applications are unsuccessful.

PhD students in anthropology - a discipline characterised by its requirement for long-term immersive fieldwork - are dissatisfied with their funding situation as they are increasingly required to support themselves through their studies, fieldwork and career development.

Despite growing awareness of issues that concern discrimination, harassment and inequality in their workplace, which includes power asymmetries created by big grants from the EU and national agencies, yet with growing stratification between those on permanent and those on precarious contracts, many anthropologists do not find adequate support in existing trade unions, where they exist at all. 


\section{Recommendations}

A framework is needed for career progression and tenure for anthropologists across the continent, which would encourage receiving tenure following a certain number of teaching or research contracts. Employers should take on the responsibility of guaranteeing career progress inside institutions.

Cyclical project funding must be reduced to a minimum, with a discrete budget granted to universities to develop long-standing, well-resourced research programmes. Departments should reduce overtime workloads and be aware of the risks of creating exploitative working environments.

Governments and institutions should ensure PhD programmes have resources to provide employment contracts and salaries to all PhD students. They should be granted access to fieldwork, conference and career development funds. Student fees and debt-inducing loans should be discouraged.

Professional organisations and learned societies as EASA - while not legal bodies or trade unions in their own right - could and should increasingly engage in lobbying activities and introduce standards of good practice to be observed by institutions that adhere to our professional values.

\section{How to read the report}

The report begins with a detailed summary of the key findings. It then provides more detail on the background context and survey design, and discusses each of the key areas in depth. A full set of recommendations are also provided at the very end of the report. 


\section{Key findings}

A total of 809 EASA members completed the questionnaire. They comprised $35.2 \%$ of all members in 2018. Respondents were spread across 59 nationalities. Most of them resided in the West and North of Europe - only 9.7\% were residents of East Central and South East Europe. In total, 65.9\% declared themselves to be 'employed in academia' (at a university, research institution or similar) as their primary job. Most worked in social-science departments and two thirds of them in departments of anthropology, ethnology or similar.

While the survey attests to the great variety of experiences and significant country differences, the most typical respondent (and, by extension, EASA member) is a woman aged around 40 who works in academia. She has likely been educated in either the UK or Germany and is very likely to work in the UK, Germany or Italy. She is possibly in a relationship but has no children. She is probably dissatisfied with her current employment and her work-life balance, which is very likely due to the fact that she works on a fixed-term contract and as the years go by, her chances of obtaining a permanent contract decrease.

\section{Fixed-term employment as a norm for anthropologists}

- Academic precarity: Among those who identified 'employed in academia' as their primary status, only $44.3 \%$ had a permanent contract, and only $31.3 \%$ were on permanent and full-time contracts. This means that over two thirds of all academic anthropologists in Europe are in some form of precarious employment.

- Country differences: In the three countries in which one third of all survey respondents held their primary job, less than $50 \%$ of all respondents had permanent contracts: Germany $-12.1 \%$, Italy $-28 \%$, and the United Kingdom - $49.4 \%$. For those who had ultimately been offered a permanent contract, the number of years it took them after obtaining their PhD also varied: Germany -8.8 years, Italy -8 years, UK -4.6 years. The highest proportion of fixed-term contracts were in Central Europe (including Germany and Austria) and Russia where the Habilitation or Doktor nauk tenure path prevails.

- Gender differences: While men and women were equally represented among those on fixed-term contracts, women held a higher proportion of very short-term contracts, i.e. under six months. Women were also less likely to be in senior positions (29\% of men versus $19 \%$ of women). There are more women than men in permanent jobs in the West/North but not in the South/East of Europe. Yet, overall, while men comprise $24 \%$ of doctoral students, they represent $42 \%$ of full professors in our sample.

- Generation differences: The average age of those on permanent contracts was 49.9 years. Those who secured such contracts took on average five years following the PhD before gaining tenure. Of the lecturers and assistant professors, only $37.3 \%$ had permanent full-time contracts, while of the full professors, associate professors and senior lecturers, $72.1 \%$ had such contracts. The chances of gaining a permanent contract after the PhD and of getting a job in academia decrease over time. 


\section{Job and grant applications and other work-related overtime}

- Job applications: Early career researchers in particular spent an excessive amount of time at work applying for jobs: many felt this to be a full-time job in its own right. Half of all respondents spent more than one month a year applying for jobs. Less than $10 \%$ had not applied for a job in 2018.

- Funding and job applications: Unless applying for funding was their primary job responsibility (20\%), respondents spent less time writing funding proposals than applying for jobs. A total of $17 \%$ spent more than one month a year working on job applications, including those in secure positions. As many as $60 \%$ of full professors wrote proposals for big projects during the last 12 months.

- Pastoral care and administrative work: While in other disciplines women report taking on more administrative and pastoral-care-related work, among the EASA membership, men reported doing more committee work and equal amounts of supervision.

- Academic career development: On average, $65 \%$ of respondents reported they spend about 6.5 hours a week on average doing work that is not directly required or recognised by their job, such as peer-reviewing publications or working on projects for which funding streams had already ended.

- Overtime: Up to one quarter of all work remains uncompensated. Permanent workers spent slightly more unpaid overtime on tasks that are part of their jobs. However, the fewer the contract hours, the greater the unpaid overtime: adjunct faculty received a wage for approximately only two thirds of the time required to fulfil their contractual obligations. Many PhD students reported working on their thesis during overtime - only after having finished teaching or doing other tasks requested by their supervisors.

\section{Job and studies-related satisfaction and prospects}

- Studies-related satisfaction: Less than half of the students in the sample were satisfied with their education situation; the number of students who were completely dissatisfied with their situation was twice as large as the number who were completely satisfied.

- Job satisfaction: A total of $53 \%$ of all respondents were dissatisfied with their current employment, their education situation or both. A permanent contract contributes to positive job satisfaction. However, almost 70\% did not regard academia as a careerenabling environment.

- Job prospects: Most respondents were pessimistic, with two in three anthropologists who wanted a permanent job believing that this would be unlikely within the foreseeable future. Yet only $4 \%$ were planning on leaving academia within the next five years and most remained committed to advancing their academic careers by accepting temporary, 
part-time jobs, and changing workplaces and even countries, or working a significant amount of overtime to achieve such a goal.

\section{Financial stability and the ability to plan for emergencies and the future}

- Income differences: Only in eight out of 21 countries were respondents' average monthly incomes - i.e. academics' income as highly skilled professionals - above national averages. The survey suggests persisting divides: academics in East Central and South East Europe said their incomes did not meet their needs, and that they were unable to save or manage unexpected expenses.

- Income stream(s): Only $42.7 \%$ of respondents reported covering their living expenses solely from the wages of one full-time job. Respondents often had to rely on sources and streams of income other than wages to cover their monthly expenses. Even when students were excluded from the sample, the numbers remained high: a total of $22 \%$ depended on support from a partner and $9.7 \%$ from relatives, and $25.5 \%$ depended on more than one employment contract.

- End of the month/emergencies: Only one in four anthropologists had money left at the end of the month. While $60 \%$ of respondents said they were able to handle a major unexpected expense, worryingly, $27 \%$ were 'not at all' able to do so. Temporary teaching fellows or instructors were the most vulnerable: of these, $68.8 \%$ said their income did not cover their needs, $80.7 \%$ had no money left at the end of the month, only $6.2 \%$ were 'completely' in a position to deal with an unexpected expense, and $53.1 \%$ were 'not at all' able to do so.

- Having a family: Only $45.3 \%$ who were below the age of 40 said they were provided with parental leave, which might make it difficult to decide freely and responsibly on the number, spacing and timing of their children. Women, and those with partners and small children also shared anxieties around managing the work-life balance, commuting and moving country.

- Family background: Two thirds of respondents came from middle-class families. This calls for reflection on how students from working-class backgrounds are encouraged and provided (or not) with the resources to pursue university education, doctoral degrees and academic careers in anthropology.

\section{Work-life balance and (hyper)mobility}

- Work-life balance: While respondents saw a healthy work-life balance as central to their life projects, approximately only $41 \%$ were more or less satisfied with their existing work-life (or study-life) balance. Women, people in relationships and those with children under ten years of age experienced difficulties in maintaining a healthy work-life balance. 
- Commuting: A total of $68 \%$ commuted to their workplace daily or several times a week, although women commuted less frequently. Most commutes were via land, especially using public transport (40\%) and bicycles (34\%), while $8 \%$ reported an aeroplane commute and one third of the respondents travelled several times a month. On average a respondent spends $€ 123$ per month on commuting.

- International mobility: More than $50 \%$ of respondents had moved between countries in the five years before 2018 . Almost $20 \%$ had changed countries three or more times. Among those aged 31-35 years, only one third had not left their countries for work or education (excluding fieldwork), while a quarter had changed countries for work three or more times over the last five years. Overall, however, such movements were related not to age but to the type of employment contract: of workers on fixed-term contracts, $39 \%$ did not move country in this period, but $63.3 \%$ of tenured staff stayed put.

- Inter-institutional mobility: A total of $72.1 \%$ of academics did not work at the department in which they received their highest degrees. Only $14.5 \%$ of respondents had never left their alma mater. A total of $13.4 \%$ returned to their alma mater after a period spent elsewhere. There were, however, significant differences between countries.

\section{Workplace facilities and relations}

- Workspaces: While most respondents had been provided with some sort of workspace by their employer, $29.4 \%$ considered their workspace insufficient. Many of them were frequent commuters. Almost half of the graduate students in our sample were either not provided with a workspace or deemed it in-sufficient.

- Funding and facilities: Many PhD students and academics reported not being provided with computer facilities, career training, research, conference or publication funds.

- Discrimination, harassment, unfair treatment: More than half of the respondents had personally experienced discrimination, unfair treatment, harassment, bullying, verbal, physical or emotional abuse. Two out of three had witnessed such treatment in the case of a colleague or a student in their immediate context. The most prominent grounds were gender or citizenship, but among 'other' reasons given, respondents often reported bullying and mobbing along power and status differentials, which arises from the academic hierarchies.

- Representation: Up to half of the respondents do not feel that their interests are sufficiently represented in their academic context. A total of $15.9 \%$ reported that there was nobody who represented their interests, and $18.6 \%$ were unaware of the presence of representatives. They even saw benevolent representatives as not in a position to defend them adequately. 
- Trade-union membership: EASA members in Nordic countries were among the most unionised. German-speaking countries and South West Europe lie below the sample average, and the countries of East Central Europe are on the whole, with a few exceptions, much below the average. Precariously employed academics did not join unions because they felt that unions did not represent their interests as the unions were dominated by senior faculty or administrative staff. Insecurity regarding staying in academia or in the country of employment was another reason for not joining. 


\section{Background}

The present survey, initially entitled 'Survey of the European Association of Social Anthropologists on Employment and Academic Precarity', was distributed among members of the European Association of Social Anthropologists (EASA) in 2018. It was organised by EASA's Executive Committee and members of the PrecAnthro Collective, a pressure group that emerged to thematise precarity as an issue in the profession. The survey was conducted at a specific time in the history of the association, of anthropology as a profession, and of academia as a labour market, namely, during a period in which a number of issues intersected with various consequences. Some of these issues have been discussed at PrecAnthro and EASA meetings.' These debates - and other sources, such as publications, blogs and events - are reflected in the survey design, the questions that were asked, and the analytical framework. The survey does not cover the more recent developments in academic careers and casualisation caused by the outbreak of the COVID-19 pandemic. We believe, however, that the trends presented here are of even greater interest and concern vis-à-vis the effects of the pandemic on the academic labour market.

The survey consisted of seven parts. Part I gathered basic data about the respondents' employment and education. Part II asked about working conditions and pay. Part III focused on the quality of workplaces. Part IV considered the overall context of the departments in which EASA members were active. Part $\mathbf{V}$ was about experiences, especially with labour unions, and further levels of representation regarding their rights. Part VI gathered demographic information. In Part VII we asked the participants if they would be potentially interested in sharing their stories with us in follow-up interviews.

We were guided by a need to explore several topics in particular:

- the rise of precarity;

- geographic mobility and work-life boundaries;

- old and new hierarchies in the academic profession;

- divisions within Europe and beyond;

- anthropology, the academic profession, and life 'beyond' it;

- job satisfaction and expectations;

- mobilising inside and outside trade unions.

These topics were reflected in the selection and wording of specific questions.

The survey aimed to understand how these tendencies are reflected in anthropology as a profession (across Europe in particular) and how this impacts anthropology as a discipline. The next sections describe the rationale behind the survey design, the chosen methodology and the basic characteristics of the membership according to the survey and in light of the

' On politics and precarities in academia: anthropological perspectives, 16th-17th November 2017, Institute of Social Anthropology, University of Bern https://www.easaonline.org/about/agm/agm2017.shtml. 
data we have from EASA. These sections are followed by chapters that detail all data, and a concluding part that offers some tentative recommendations.

This report is a complete report that includes all analyses of the data collected by the survey and completed to date. Instead of summarising tendencies or providing an overall picture, the report contains detailed statistics, often in tables rather than charts. This is a deliberate move: the report should also be understood as an archive that documents not only commonalities and typical traits found among respondents, but also a rich variety of circumstances and experiences.

\subsection{Rationale}

As several of us set up the survey, that is, the authors and members of the PrecAnthro Collective, it reflected some of our shared awareness - arising from personal experiences, political activity and academic research - of the casualisation of the academic labour force in Europe and beyond. The trend towards casualisation has been reinforced by processes welldiscussed in the academic literature on the subject, such as the division between research and teaching, and the deprofessionalisation of academic labour through the proliferation of multiple types of contracts for those studying for or having graduated from a PhD (such as different levels of 'academia-related' management roles, research-only pre- and postdoctoral positions, and teaching-only 'atypical' contracts), combined with a decrease in public funding for research. ${ }^{2}$ For instance, a study of research staff found out that in 2011 , $80 \%$ of all the 5,202 post-doctoral researchers in Irish institutions of higher education were on temporary contracts. ${ }^{3}$ In Germany, $80 \%$ of research staff are on fixed-term appointments 4 - this includes $93 \%$ of those under 45 , who are mid-level faculty (Mittelbau), i.e. neither PhD students nor full professors. ${ }^{5}$

When we began this survey, we were aware that many respondents would not even fit into the data reported by institutions or national agencies: the number of precarious staff is difficult to report, as data on casualisation are only available to institutions and discreet, fractional contracts are often reported, summed up as full-time equivalents. ${ }^{6}$ It was also clear that many people - in precarious and permanent positions alike - 'wear more than one hat' professionally. They complete different tasks, many of which come in the form of various precarious 'gigs' across academic institutions and beyond. We also started from a paradox that we have seen evolving around us: teaching-only contracts often come to replace highly

\footnotetext{
2 See University and College Union (UCU). (2013). Over half of universities and colleges use lecturers on zero-hour contracts, Retrieved from http://www.ucu.org.uk/G749; UCU. (2016). Precarious work in higher education. Retrieved from https://www.ucu.org.uk/media/8384/Precarious-work-in-higher-education-November-2016-update/pdf/ucu_ precariouscontracts_hereport_nov16_.pdf.

${ }_{3}$ Loxley, A., Seery, A., \& Walsh, J. (2016). Knowledge workers of the world unite? Work practices and career aspirations among postdoctoral researchers in Irish universities. Paper presented at the Inequality in Irish Higher Education, UCD, December Gth Dublin. (p.128).

${ }_{4}$ Wissenschaftsrat. (2014). Hintergrund: Zu Karrierezielen und -wegen an Universitäten. Retrieved from

http://www.wissenschaftsrat.de/download/archiv/hginfo_2014.pdf (p.5).

5 BuWiN, Bundesbericht Wissenschaftlicher Nachwuchs. (2017). Statistische Daten und Forschungsbefunde zu

Promovierenden und Promovierten in Deutschland. WBV. Retrieved from https://www.bmbf.de/files/buwin_2017.pdf (p.127).

${ }^{6}$ Courtois, A., \& O'Keefe, T. (2015). Precarity in the ivory cage: Neoliberalism and casualisation of work in the Irish higher education sector. Journal for Critical Education Policy Studies, 13(1), 43-66.
} 
visible-and-cited VIP researchers who attract students to 'top-ranked' departments. These students then end up being taught by their precarious 'buy-outs' while the VIPs fundraise, or manage PhDs and post-docs in large research projects instead. ${ }^{7}$ In some cases teaching is increasingly done by post-graduate students ${ }^{8}$, and in others, by underpaid teaching fellows ${ }^{9}$, that is, by a precarious workforce composed primarily of women and members of ethnic minorities. ${ }^{\circ}$ As post-docs or TAs, many of us have experienced first-hand these metric-driven hierarchies between research and teaching, but the proliferation of such contract types has made it difficult to strike a balance between individual cases and overall tendencies across the discipline.

The reason that we wished to address this and sought assistance from EASA was that during our conversations at the PrecAnthro meetings at EASA's conferences in Milan (2016) and Stockholm (2018), as well as from our watchdog activity, it became clear that the commitment of institutions and departments to staff members on precarious contracts has been weak. This became even more evident with the little or no protection that faculty members in such positions have received during the COVID-19 pandemic so far. We hoped that learning of the different conditions that EASA members face would help us and the respective departments, institutions, national and international decision-making bodies look for ways to tackle the challenge of academic precarity in anthropology on a systemic level. We also had a unique opportunity to look at differences between countries across the continent through the survey carried out among EASA's membership across Europe.

Another axis we wished to explore was the growing deprofessionalisation of academic positions, the standardisation of tasks, the fragmentation of job descriptions and the ever lower professional status, recognition and remuneration given to 'tasks' and job types that were previously considered academic", and if, as well as how, these changes affected anthropology. During the PrecAnthro meeting at the EASA conference in Milan 2016, people expressed concerns about how the widening of existing divisions between teaching, research and service has increasingly placed many in new job positions with descriptions that turn those with doctoral degrees into lower-ranked and lower-paid workers, such as 'casual researchers', ${ }^{22}$ post-doctoral 'interns'13 etc. In this process, contracts are becoming ever shorter, and when they accept these positions, recent PhD graduates in anthropology

\footnotetext{
7 Ivancheva, M. (2018). Enough outsourcing of precarity. Member Voices, Fieldsights, March 21. Retrieved from https://culanth.org/fieldsights/enough-outsourcing-of-precarity.

8 Cidlinská, K., Fárová, N., Mař́ková, H., \& Szénássy, E. (2018). Akademici a akademičky 2018: Zpráva z kvalitativní studie veřejných akademických a výzkumných pracovišt'. Sociologický ústav AVČR, v. v. i. Retrieved from

https://www.soc.cas.cz/publikace/akademici-akademicky-2018-zprava-z-kvalitativni-studie-verejnych-akademickychvyzkumnych.

9 Dyer, S., Walkington, H., Williams, R., Morton, K., \& Wyse, S. (2016). Shifting landscapes: From coalface to quick sand?

Teaching geography, earth and environmental sciences in UK higher education. Area, 48(3), 308-316

${ }_{10}$ Megoran, N., \& Mason, O. (2O2O). Second class academic citizens: The dehumanising effects of casualisation in higher education. University College Union. Retrieved from

https://www.ucu.org.uk/media/10681/second_class_academic_citizens/pdf/secondclassacademiccitizens.

"Demailly, L., \& de la Broise, P. (2009). The implicătions of deprofessionalisation: Case studies and possible avenues for future research. Socio-Logos, 4. Advance online publication. https://doi.org/10.400o/socio-logos.2307; Macfarlane, B. (2011). The morphing of academic practice: unbundling and the rise of the para-academic. Higher Education Quarterly, 65(1), 59-73. https://doi.org/10.1111/j.1468-2273.2010.00467.x.

12 Ivancheva, M. (2015). The age of precarity and the new challenges to the academic profession. Studia Europaea, LX(1), 39-47. 13 British Library. (2019). Medieval Manuscripts Post-Doctoral Internship, The British Library. Mary Jaharis Center for Byzantine Art and Culture. Retrieved from

https://maryjahariscenter.org/blog/medieval-manuscripts-post-doctorial-internship-the-british-library.
} 
can possibly - and based on PrecAnthro's watchdog observations, often - end up not only providing their expertise, but also giving uninhibited access to their whole networks of research participants and trust, as well as analytical ideas for projects in which they are not even given authorship rights. ${ }^{14}$ In teaching-only jobs, graduates become 'fractional', 'occasional' or 'seasonal' lecturers. In Germany in 2016 there were around 100,000 sessional lecturers paid per hour taught, who often offered compulsory courses, compared with 50,000 full professors. ${ }^{15}$ In the UK, academics increasingly work on zero-hour contracts ${ }^{16}$ as 'content curators', 'online-forum discussants' and in further roles that morph academic practice beyond recognition. ${ }^{17}$ Yet, we were also aware that these processes need further scrutiny as they remain undocumented and invisible, given that the most precarious academics often do not come to campus for more than a few hours a week. They often share a workspace with others (if they have any space at all). This invisibility is deepened as both institutions and national agencies report full-time equivalent positions without any more granular data, let alone discipline-specific information. ${ }^{18}$ As this reality is often not presented in mainstream representations of academic work by university management and granting institutions, this survey offers a 'counter-representation' of such mainstream constructions of academic 'reality'. Thus, it is important to see both the realistic situation in the discipline and also the extent to which colleagues are aware of these processes.

Another dynamic that we knew of anecdotally and from the literature was the blurring of work-life boundaries in academia and the rise of a work-family conflict. ${ }^{19}$ We also wanted to explore whether anthropologists were equally susceptible to the (often gendered) pressures of self-promotion, constant geographic mobility and the often gendered division of labour in academia. ${ }^{20}$ Another topic of interest was whether and to what extent anthropologists were affected by the reported increased (often unpaid) working hours, with early career academics also being on the lookout for jobs and potential sources of funding, such as the ever scarcer sources of funding that are quite important for developing professional networks in the early stages of academic careers. ${ }^{21}$

Given unique national trajectories across Europe, we also wished to explore whether the East-West and North-South divides in Europe can be applied to pay-scale and contractual permanence, as well as how these arrangements relate to benefits that are all but standardised across countries. We thus wanted to see to what extent anthropologists across Europe are entitled to healthcare provision, pension systems, childcare benefits, redundancy,

\footnotetext{
14 Tilche, A., \& Astuti, R. (2019). Draft of good practice guidelines in collaborative research. EASA. Retrieved from https://www.easaonline.org/newsletter/75-0120/guidelines.shtml.

15 Gallas, A. (2018). Precarious academic labor in Germany: Termed contracts and new Berufsverbot. Academic Labor: Research

and Artistry, 2(1). Retrieved from https://digitalcommons.humboldt.edu/alra/vol2/issi/8.

${ }^{16}$ Courtois \& O'Keefe (2015)

17 Macfarlane (2011).

18 Ivancheva, M., Lynch, K. \& Keating, K. (2019) 'Precarity, Gender and Care in the Neoliberal Academy'. Gender, Work \&

Organization 26 (4): 448-62. https://doi.org/10.1111/gwao.12350.

19 Zábrodská, K., Mudrák, J., Šolcová, I., Květon, P., Blatný, M., \& Machovcová, K. (2018). Burnout among university faculty:

The central role of work-family conflict. Educational Psychology, 38(6), 800-819.

20 Ivancheva et al. (2019).

${ }^{21}$ Kendzior, S. (2012). The closing of American academia. Al Jazeera. Retrieved from

https://www.aljazeera.com/opinions/2012/8/20/the-closing-of-american-academia/.
} 
parental leave and so on, and if these are their rights as workers or merely as citizens or noncitizen residents in different European countries. Access to welfare programmes has been thematised especially because the rise of fixed-term (temporary) contracts has reportedly made academics look for employment outside their country of origin and exposed them to the loss of kinship and friendship networks that provide care where such care is not centrally accessible. ${ }^{22}$ This could limit career choices, especially for women who have to make employment decisions, especially given age limits related to childbirth and childcare. ${ }^{23}$

We wanted to also explore whether anthropology across Europe - as a profession as well as a discipline with its presumably critical views - goes against or follows the findings of national or international-level surveys ${ }^{24}$ showing that women and members of ethnic minorities do more of the teaching-only work often on precarious contracts, and are thus more exposed to low earnings, overwork, burnout and ultimately, quitting academia ${ }^{25}$ for non-academic jobs in the corporate sector. ${ }^{26}$ We wished to know whether these tendencies, observed in the US, are also part of the experience of those practicing anthropology as an academic profession in Europe.

Last but not least, we wished to see whether and how anthropologists are involved in initiatives that are fighting some of the developments well documented in neoliberal academia: in other words, what is the role of academic trade unions and other forms of institutional and self-organising across the continent? Is the reported national-level challenge of trade unions to defend the prerogatives of permanent fee-paying members against those of precarious faculty, and the push in many national union structures away from collective bargaining towards case work ${ }^{27}$ also reflected in our discipline? Do workers in such a social-justice-oriented field such as anthropology, manage to self-organise, or as elsewhere, are they 'claimants' confined to taking individual cases in isolation from the community and under the threat of being deemed 'trouble-makers'? ${ }^{28}$ We know it too well: inequality, exploitation, bullying and harassment are still difficult to report, and as the HAU debate revealed, ${ }^{29}$ improvements are difficult to achieve when structural positions are affected. Thus, it was imperative for us to ask which workers (do not) join unions and what their experience of non-membership is. We also wished to know whether they find ways of challenging existing conditions when they believe injustices exist, as the PrecAnthro Collective is trying to do through mobilising within EASA.

\footnotetext{
${ }_{22}$ Stalford, H. (2005). Parenting, care and mobility in the EU: Issues facing migrant scientists. Innovation: The European Journal of Social Science Research, 18(3), 361-380. https://doi.org/10.1080/13511610500186805.

${ }_{23}$ ESF, European Science Foundation. (2009). Research Careers in Europe Landscape and Horizons. ESF. Retrieved from http://webcache.googleusercontent.com/search?q=cache:oxXA7UHlyiUJ:archives.esf.org/fileadmin/Public_documents/24 Advance, H. E. (2018). Equality in higher education: Statistical report 2018. Retrieved from

https://www.advance-he.ac.uk/knowledge-hub/equality-higher-education-statistical-report-2018.

${ }_{25}$ Dunn, S. (2013). Why so many academics quit and tell. Chronicle of Higher Education. Retrieved from

https://community.chronicle.com/news/216-why-so-many-academics-quit-and-tell.

${ }_{26}$ Platzer, D., \& Allison, A. (2018). Academic precarity in American anthropology. Retrieved from

https://culanth.org/fieldsights/academic-precarity-in-american-anthropology.

${ }_{27}$ Ivancheva, M., \& 'O'Flynn, M. (2016). Between career progression and career stagnation: casualisation, tenure, and the contract of indefinite duration in Ireland. In S. Gupta, J. Habjan, \& H. Tutek (Eds.), Member Voices, Fieldsights, February 12

(pp. 167-184). Palgrave Macmillan UK. https://doi.org/10.1057/978-1-137-49324-8_10.

${ }_{28}$ Ahmed, S. (2018). The time of complaint. Feministkilljoys. Retrieved from

https://feministkilljoys.com/2018/05/30/the-time-of-complaint

${ }^{29}$ AllegraLab. (2018). Hautalk Archives. Allegra. Retrieved from

https://allegralaboratory.net/category/thematic-threads/hautalk/.
} 


\section{Methodology and the research sample}

To address all the above-mentioned issues, the PrecAnthro Collective conducted the present survey under the aegis and with the support of EASA's Executive Committee. ${ }^{30}$ The survey was carried out online between 18 June 2018 and 22 July 2018 and contains the responses of 809 EASA members from 59 countries. These dates were chosen in order to increase the sample size: before every EASA biennial conference, which that year was scheduled for early August, the number of EASA members almost doubles, as being a member is a requirement for participation.

An invitation to take part in the survey and two follow-up reminders were sent by EASA to its members via email. The invitation and encouragement to participate was also posted on the EASA and PrecAnthro Twitter and Facebook pages, and forwarded through several different anthropology-related mailing lists and through EASA's thematic networks. The survey was implemented using EFS survey software from QuestBack Unipark. The invitation contained a unique link to the consent form and the questionnaire, and the system ensured that respondents cannot be identified.

All EASA members (2291 in 2018) received invitations to participate in the survey. Given that internal surveys usually achieve a response rate of between 30 and $40 \%,{ }^{31}$ the $35.2 \%$ response rate to the survey can be considered adequate. We are aware that respondents might have self-selected based on various criteria. Yet, while not technically constructed as a representative sample, the pool of respondents is large enough in terms of both absolute number and proportion from the membership population to give us meaningful - and generalisable - information about the EASA membership.

Categorised by country of 'primary employment, studies, fellowship and so on, or where you receive unemployment benefits, pension or similar', there were 24 countries for which we had at least five respondents, and two countries - Germany and the UK - for which we had more than 100 respondents. Bearing methodological precautions in mind, we considered that it was worth looking at the indicators more closely only for countries with five cases or more in order to gain information about anthropologists and anthropology in those countries, rather than just about the individuals in the overall sample.

\footnotetext{
30 Since 2016, PrecAnthro has been a collective of activist anthropologists operating as a pressure group within EASA, but whose ultimate aim is to organise collectively towards a transnational anthropological union in Europe and beyond. See the Acknowledgments section for people involved at various stages.

${ }^{31}$ The Complete Guide to Acceptable Survey Response Rates, Retrieved from

https://www.genroe.com/blog/acceptable-survey-response-rate-2/11504.
} 
Only one question - on EASA membership - was compulsory. Since we had no control over who received the link to the online questionnaire, this enabled us to focus the analysis on EASA members only.

As with all self-completed questionnaires, there was a significant non-response rate for many questions, which is signposted in the analysis in places where it seemed important by noting the number of respondents.

The survey consisted of questions proposed originally by the PrecAnthro Collective and further developed alongside the EASA Executive Committee..$^{32}$ It was extensively discussed and improved during the EASA AGM in Bern in October 2017. It was also piloted before it was administered. Certain questions, and, indeed, the idea for the survey itself, first arose during the PrecAnthro meeting in Milan in 2016. Other questions were inspired by other surveys that have been conducted nationally among anthropologists (e.g. in Denmark and Australia), or that drew on the research and activist interests of the survey authors.

The data were analysed using SPSS, Excel and QGIS.

32 As a response to the PrecAnthro meeting called at the EASA 2016 conference in Milan, EASA appointed two PrecAnthro liaisons, a position that was then renamed as 'Precarity and Lobbying Officer'. One of the results was the position paper on precarity: EASA (2019) Combatting Precarious Job Conditions in Academia,

https://www.easaonline.org/downloads/other/EASA\%20Position\%20Paper\%20Precarity.pdf. 


\section{Basic characteristics of EASA survey participants}

A total of 804 (99.4\%) survey respondents answered the question about gender. They identified respectively as female(62.9\%), male(32.4\%), while $0.6 \%$ self-described in alternative non-binary ways (e.g. female but masculine performing, genderqueer or non-binary). Of the respondents, $4.1 \%$ chose not to identify their gender. Due to the small sample size, alternative identification or non-identification is often grouped together under the category of in this report. The survey's gender composition roughly corresponds to the overall composition of EASA: when renewing their membership in 2018, 61.8\% of EASA members identified as female, $35.5 \%$ as male and $2.7 \%$ chose not to say.

Most respondents (69.7\%) were under the age of 45 , while for EASA in 2018 the proportion was $65.4 \%$. The table below gives the percentages of different age cohorts. The biggest differences in EASA's overall age structure in 2018 are in cohorts: 30 and below (many of whom possibly joined EASA only in order to attend the 2018 biennial conference), 41-45, 3640 and 56-65. Our dataset is thus slightly skewed towards early career researchers: people aged between 31 and 45 comprise $59.1 \%$ of the survey sample, as compared with $51.5 \%$ of EASA's membership in 2018.

Table 1: Age structure of respondents and of EASA members in 2018, as percentages

\begin{tabular}{|lcc|}
\hline Age group & Survey sample & EASA 2018 \\
\hline $\mathbf{3 0}$ and below & 10.6 & 13.9 \\
\hline $\mathbf{3 1}$ to $\mathbf{3 5}$ & 21 & 18.5 \\
\hline $\mathbf{3 6}$ to $\mathbf{4 0}$ & 21.7 & 19.6 \\
\hline $\mathbf{4 1}$ to $\mathbf{4 5}$ & 16.4 & 13.4 \\
\hline $\mathbf{4 6}$ to $\mathbf{5 5}$ & 17.3 & 18.4 \\
\hline $\mathbf{5 6}$ to $\mathbf{6 5}$ & 9.6 & 11.7 \\
\hline above 65 & 3.4 & 4.5 \\
\hline
\end{tabular}

Note. $\mathrm{N}=792$

As earlier mentioned, the respondents were of 59 nationalities. ${ }^{33}$ Most respondents resided in West and North Europe. Respondents residing in the countries of East Central and South East Europe represented $9.7 \%$ of the analysed sample.

In total, there were 24 countries of residence for which we had at least five respondents (i.e. $0.6 \%$ of the sample). Almost one third of respondents resided in two countries - Germany

33 In total, $14.9 \%$ are nationals of a country in East Central and South East Europe. This UN-defined geographic division consists of the following countries: Albania, Bosnia and Herzegovina, Bulgaria, Croatia, Cyprus, Czech Republic, Georgia, Greece, Hungary, Montenegro, Poland, Romania, Serbia, Slovakia, Slovenia, North Macedonia, Turkey, and Ukraine. http://ecseed.zrc-sazu.si. 
(15\%) and the UK (14.4\%). ${ }^{34}$ These two countries are followed by Italy (6.7\%), Portugal (4.4\%), Switzerland (4.4\%), Spain (4.3\%) and the Netherlands (4.3\%). ${ }^{35}$

\begin{tabular}{|c|c|c|c|}
\hline Country & $\begin{array}{c}\text { Number: Survey } \\
\text { sample } \\
\text { (EASA 2018) }\end{array}$ & \multirow{2}{*}{$\begin{array}{c}\text { Percentage: Survey } \\
\text { sample } \\
\text { (EASA 2018) } \\
15(15.3)\end{array}$} & \multirow{2}{*}{$\begin{array}{c}\text { Rank: Survey } \\
\text { sample } \\
\text { (EASA 2018) } \\
1(1)\end{array}$} \\
\hline Germany & 119 (350) & & \\
\hline United Kingdom & $114(343)$ & $14.4(15)$ & $2(2)$ \\
\hline Italy & $53(135)$ & $6.7(5.9)$ & $3(3)$ \\
\hline Portugal & $35(53)$ & $4.4(2.3)$ & $4-5(14-15)$ \\
\hline Switzerland & $35(82)$ & $4.4(3.6)$ & $4-5(7-8)$ \\
\hline Netherlands & $34(96)$ & $4.3(4.2)$ & $6-7(5)$ \\
\hline Spain & $34(82)$ & $4.3(3.6)$ & $6-7(7-8)$ \\
\hline United States & $30(107)$ & $3.8(4.7)$ & $8(4)$ \\
\hline Norway & $27(75)$ & $3.4(3.3)$ & 9) \\
\hline France & $26(75)$ & $3.3(3.3)$ & $10(10-11)$ \\
\hline Denmark & $25(87)$ & $3.2(3.8)$ & $11-12(6)$ \\
\hline Sweden & $25(81)$ & $3.2(3.5)$ & 11-12 (9) \\
\hline Austria & $24(70)$ & $3(3.1)$ & $13(12)$ \\
\hline Finland & $21(53)$ & $2.7(2.3)$ & $14(14-15)$ \\
\hline Poland & $20(68)$ & $2.5(3)$ & $15(13)$ \\
\hline
\end{tabular}

Note. $\mathrm{N}=791$

The top 15 countries in the survey sample according to residence are the same as the countries of residence of EASA members in 2018.36 Indeed, the order of the first three countries does not change across the two sets, and most countries move up or down only one or two places. We can only speculate why the response rate across individual countries differed significantly, ranging from Portugal (66\%) and Italy (49\%) to Denmark (29\%) and the

\footnotetext{
${ }^{34}$ This is possibly because these are two of the countries in Europe with the largest populations and the biggest number of university programmes in anthropology and its kindred disciplines (ethnology, sociology, cultural studies etc.) in Europe. It also reflects the fact that the third biggest country, France, is somewhat underrepresented at the level of EASA - a question that may be a matter for EASA to further reflect on.

35 Apart from Poland, only five countries from East Central and South East Europe had more than five respondents or residents: Greece (15), Czech Republic (13), Romania (10), and Slovenia (6).

${ }^{36}$ Members' mailing addresses were here to mean 'residence'. Of course, this should be taken with caution.
} 
US (28\%). As earlier noted, the survey-sample response rate was $35.2 \%$ and that of the top 15 countries was $35.4 \%$. For instance, concerns with unemployment, not only of academics, and declining real wages in South West Europe may have motivated respondents from Italy, Spain and especially Portugal, with the result that their proportions in the survey are somewhat higher than within EASA in 2018. Or, it is possible that many US academics joined as EASA members only to attend the 2018 conference, but otherwise identified only weakly with the association.

In terms of primary employment, studies, fellowships and so on, or of unemployment benefits, pension or similar (hereafter 'employment etc'.), the list of the 15 most-represented countries is comparable, although as mentioned the order changes slightly. Besides the lower response rate for the question regarding employment etc., this suggests a certain split between countries of residence and employment. Once again, certain generalisations are possible for only 24 countries.

Table 3: The top-ten countries according to primary employment, studies, fellowship
etc. of respondents, or where unemployment benefits, pension or similar are received etc. of respondents, or where unemployment benefits, pension or similar are received

\begin{tabular}{|lcc|}
\hline Country & Number of respondent & Proportion of the total (as percentages) \\
\hline Germany & 119 & 15.2 \\
\hline United Kingdom & 107 & 13.7 \\
\hline Italy & 50 & 6.4 \\
\hline Switzerland & 43 & 5.5 \\
\hline Netherlands & 35 & 4.5 \\
\hline Portugal & 35 & 4.5 \\
\hline United States & 32 & 4.1 \\
\hline Norway & 29 & 3.7 \\
\hline Spain & 29 & 3.7 \\
\hline Sweden & 27 & 3.4 \\
\hline France & 25 & 3.2 \\
\hline Poland & 24 & 3.1 \\
\hline Austria & 24 & 3.1 \\
\hline Denmark & 23 & 2.9 \\
\hline
\end{tabular}

Note. $\mathrm{N}=784$

Only $10.5 \%$ of respondents in the sample are primarily employed or study etc. in a country of East Central and South East Europe. There are more than five cases for only four of these countries: Poland (24), Czech Republic (13), Greece (13) and Romania (12). 
The most frequently reported primary status of respondents is: (1) employed in academia $-65.9 \%$; (2) doctoral students - 15\%, and (3) unemployed (with or without benefits) - 5.6\%.

The academic position of respondents was as follows:

Table 4: Primary academic positions, as a number and percentage (\%)

\begin{tabular}{|lcc|}
\hline Academic position & Number & Percentage \\
\hline Doctoral student & 46 & 7.6 \\
\hline Student assistant/teaching assistant or similar & 4 & 0.7 \\
\hline Research assistant (without PhD) & 20 & 3.3 \\
\hline Research fellow/post-doc or similar (with PhD) & 167 & 27.7 \\
\hline Teaching fellow/instructor or similar & 34 & 5.7 \\
\hline Assistant professor/lecturer & 118 & 19.6 \\
\hline Associate professor/senior lecturer/reader & 104 & 17.3 \\
\hline Full professor & 77 & 12.8 \\
\hline Other & 32 & 5.3 \\
\hline
\end{tabular}

Note. $\mathrm{N}=602$ 


\section{Employment and academic career}

\subsection{Contracts and employment}

The following section describes the respondents' employment situation. It examines their employment stability by looking into types of contracts, the length of contracts and future expectations.

\subsubsection{Contracts in academia}

A total of $80.7 \%$ (653) of survey respondents have at least one employment contract within or outside academia. Of these, $74.5 \%$ have one contract, $18 \%$ have two contracts, $5.4 \%$ have three and $2.1 \%$ have four or more contracts. A quarter of those employed in academia thus hold more than one contract.

Table 5: Average number of contracts for selected countries (students excluded)

\section{Country of residence}

Austria

Portugal

Switzerland

Italy

Poland

France

Germany

UK

Norway

Netherlands

\section{Number of contracts (av.)}

1.9

1.7

1.6

1.4

1.4

1.6

1.3

1.3

1.3

1.1

A closer look at two countries with values at opposite ends of the spectrum - the Netherlands and Austria - reveals two very different structures. In Austria 37.5\% of respondents held one contract, but $29.2 \%$ held two, $25 \%$ three and $4.2 \%$ four (non-response rate: $4.2 \%$ - four individuals). In the Netherlands, $62.9 \%$ held one employment contract, while only $8.6 \%$ held two and $5.7 \%$ held three contracts. It should be noted, however, that the non-response rate was high $(22.9 \%$ - nine individuals).

A total of $78.5 \%(635)$ held at least one contract in academia - academic employment was either their primary or secondary employment status. 
Only $29.7 \%$ of all respondents had permanent contracts in academia, $3.2 \%$ had permanent contracts outside academia, $46.8 \%$ had fixed-term contracts in academia, and $7.3 \%$ had fixed-term contracts outside academia.

When students were left out of the analysis, 34.9\% had a permanent contract in academia and $3.2 \%$ of non-students had a permanent contract outside academia. A total of $49 \%$ had fixed-term contracts in academia and $6.9 \%$ had fixed-term contracts outside academia.

A total of $\mathbf{6 5 . 9 \%}$ (533) declared their primary status as 'employed in academia (at a university, research institution or similar)'. Of the women, $63 \%$ declared a primary employment status in academia, as did $70 \%$ of men, $75.8 \%$ of those who prefer not to declare their gender and $60 \%$ of those who prefer to self-describe in (an) alternative way(s).

Table 6: Primary status, as percentages (\%)

\section{Status}

\section{Employed in academia}

Doctoral student

Unemployed

Employed outside academia

Self-employed

Non-employed, receiving a stipend

Retired

Master's student

Other

\section{Percentage}

65.9

15

5.6

4.3

2.5

1.7

1.6

0.9

2.5

The table above clearly shows that - as far as the sample goes - EASA is an association of academic anthropologists. Only $4.3 \%$ of respondents worked primarily outside academia. Given that most current members who hold fixed-term contracts will never obtain a permanent status in academia and $4 \%$ of respondents planned to leave academia within 5 years (below), EASA might want to address whether it is interested in more proactively involving anthropology PhDs working outside academia, for instance.

\subsubsection{Fixed-term contracts}

Fixed-term contracts were common. Of those who viewed employment in academia as their primary status, $71.1 \%$ (379) held at least one temporary contract.

This pattern is correlated with higher job insecurity. Much corridor talk at the 2014, 2016 and 2018 EASA conferences, and many informal chats during the online-only 2020 conference were neither about the latest ground-breaking study nor even about the latest careerbreaking scandals, but rather about the lack of career prospects, which ultimately prevents highly skilled scholars from conducting ground-breaking academic work. 
When master's and doctoral students were removed from the sample - as $29.2 \%$ of doctoral students were employed as members of staff at their departments or within projects the proportion remained high. Almost one half (49\%) of all non-students employed in academia worked on fixed-term contracts (334 individuals). Of these, $60.5 \%$ were women, $34.4 \%$ were men and $4.5 \%$ were 'Other'. A total of $14.2 \%$ of non-students were on part-time fixed-term contracts (97 individuals), while $32.3 \%$ of non-students were on fulltime fixed-term contracts (220 individuals). ${ }^{37}$ Many people held several fixed-term contracts.

Overall, fixed-term contracts predominated among early career researchers and younger cohorts.

Chart 1: Fixed-term contracts in academia by age, as percentages (\%)

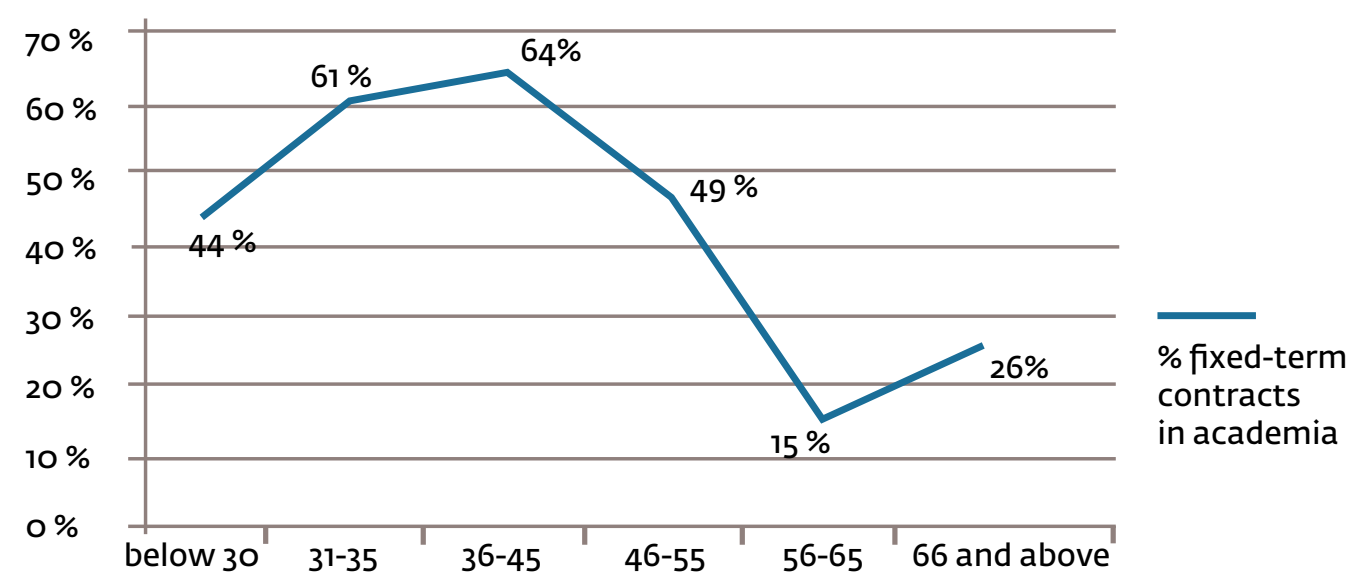

When we removed students, who have a time-limited status by definition, from analysis, the tendency of the proportion of fixed-term contracts to decrease with age remained, and the proportions of fixed-term to permanent contracts inverted between the cohorts aged 31-35 and 56-65.

Chart 2: Fixed-term contracts in academia excluding students by age, as percentages

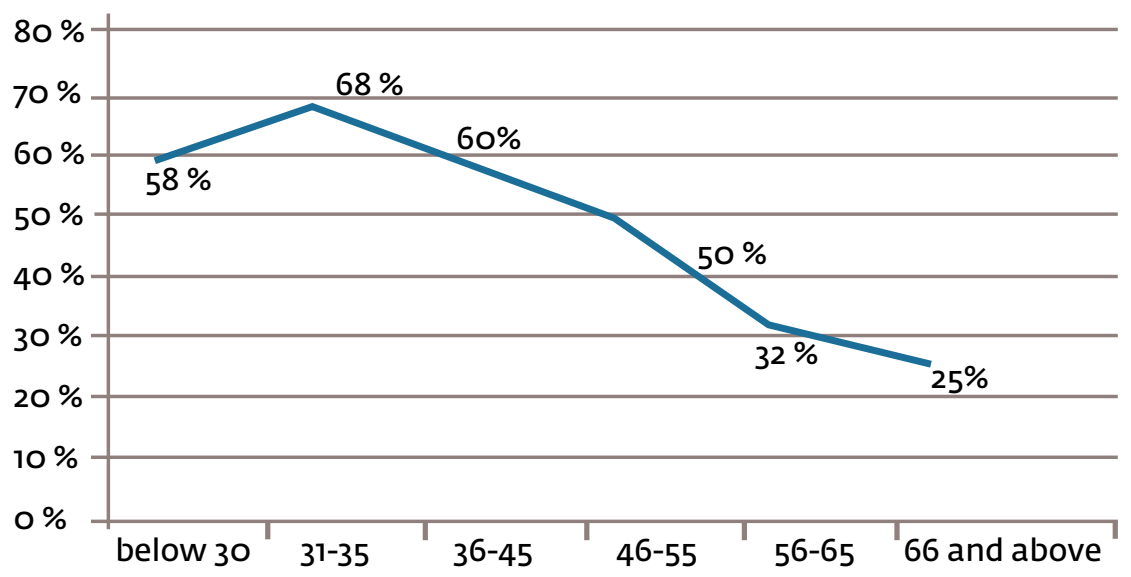

${ }^{37}$ In total, 17 respondents did not answer whether they worked part- or full-time. 
As concerns gender categories, $48.3 \%$ of non-student women held fixed-term contracts, $51.1 \%$ of men and $48.4 \%$ of those who identified otherwise or who preferred not to report a gender identity. The initial assumption that a higher proportion of women would be temporarily employed compared with men was thus not confirmed.

The average duration of a fixed-term contract was 26 months.

Based on the answers of 367 respondents and 493 fixed-term contracts that these respondents shared among themselves, we can observe that very short contracts of six months and below, and those lasting three years were the most common: they each constituted $22 \%$ of all fixed-term contracts. ${ }^{38}$

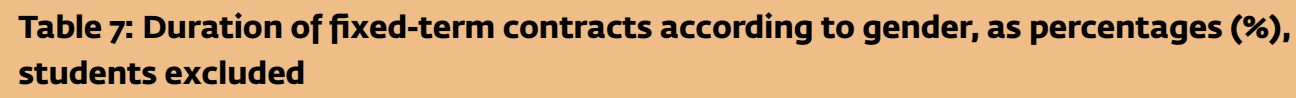

\begin{tabular}{|c|c|c|c|c|}
\hline Contract duration & Total & Women & Men & Other \\
\hline 6 months and below & 21.9 & 25.4 & 18.3 & 6.7 \\
\hline 7-11 months & 4.7 & 3.7 & 7.3 & \\
\hline one year & 16.2 & 17.4 & 14 & 16.7 \\
\hline 13-23 months & 6.1 & 6 & 7.3 & \\
\hline two years & 11 & 13.7 & 6.1 & 10 \\
\hline 25-35 months & 2.2 & 2 & 3 & \\
\hline three years & 21.9 & 19 & 25 & 33.3 \\
\hline above three years & 16 & 12.7 & 18.9 & 33.3 \\
\hline
\end{tabular}

Note. $\mathrm{N}=493$

A total of $38 \%$ of contracts were for three years or more. Unless 2018 was an exceptional year, work needs to be done, but permanent posts are not being created. In general, contracts that women held tended to be somewhat shorter: almost $30 \%$ of temporary contracts held by women were for periods shorter than one year and $32 \%$ were for three years and above, while for men the proportions were $26 \%$ and $44 \%$ respectively.

A different look at fixed-term contracts reveals that while, in total, 60.6\% (299) of such contracts were held by women, women held $70.4 \%$ of contracts below 6 months, but only $52 \%$ of three-year contracts and $48 \%$ of contracts longer than three years. Fixed-term contracts held by men (164) comprised $33.3 \%$ of all temporary contracts, but $38 \%$ of threeyear contracts and $39 \%$ of contracts that last three years or more. Remember that the length of contract influences academic productivity and thus career prospects: when a scholar

${ }^{38}$ Three years may represent an emerging European standard at doctoral and post-doctoral levels. Short-term contracts are typical of adjunct positions, such as seasonal teaching posts that are typically course based. 
has to worry about her contract ending in six or 11 months, she is going to have different priorities to those on a contract of three years or more (i.e. she will likely spend most of her time applying for jobs and worrying about her research-funding applications).

The geographic distribution of average lengths of fixed-term academic contracts per country of primary employment etc. is represented on the following map:

\section{Chart 3: Map of fixed-term contracts in academia}

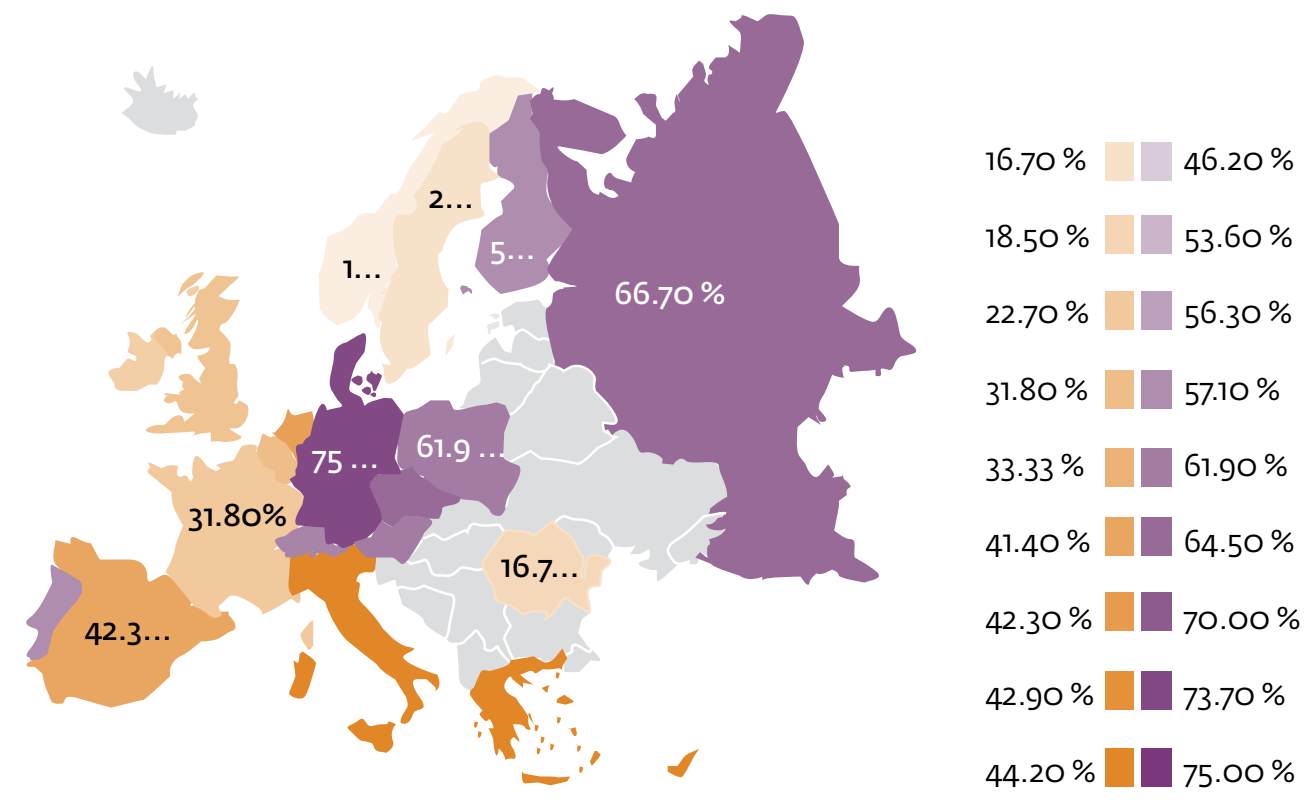

Note. Countries with 5 cases or more

Although we do not have enough data to generalise for all countries, as the map above show, fixed-term contracts were most prevalent in the countries of Central Europe and Russia, many of which still have a Habilitation or Doktor nauk path towards a full professorship.

\subsubsection{Percentage of fixed-term contracts}

Survey respondents were also asked to estimate the proportion of academic staff working on fixed-term contracts in their departments or divisions. Although these are clearly only subjective estimates, they are revealing of how EASA members view the structure of employment in academia and the environment within which they assess their career prospects. 
Table 8: Respondents' estimation of temporary contracts at their departments as percentages $(\%)$

Percentage of temporary contracts

Up to $10 \%$

$11 \%$ to $30 \%$

$31 \%$ to $50 \%$

$51 \%$ to $70 \%$

$71 \%$ to $90 \%$

Above $90 \%$
Percentage of estimates

13.5

20.3

19.1

21

17.6

8.5

Note. Responses to the question: 'Could you estimate for us the proportion of academic staff that is working on fixed-term contracts in your department/division?'

More than one quarter of respondents reported that over $70 \%$ of staff members in their departments or divisions worked on a fixed-term basis, and more than $8 \%$ of respondents estimated that $\mathbf{9 0 \%}$ of their colleagues were working on temporary contracts. The perceptions of EASA members need to be corroborated by official statistics from departments, university HR offices or national statistical agencies and highereducation authorities. However, as these usually release information only about full-time equivalents, the true number and percentage of part-time and fixed-term contracts remains insufficiently researched and difficult to study. ${ }^{39}$ Clearly, however, the perception is alarming as anthropologists across Europe observe that a significant proportion of those who do teaching and research in the discipline are not offered stable jobs.

\subsubsection{Permanent contracts}

A total of $\mathbf{2 9 . 6 \%}(240)$ of respondents were employed on permanent contracts in academia.

Among those who identified with 'employed in academia' as their primary status, 44.3\% had a permanent contract. There were no differences between men and women.

Table 9: Permanent contracts among respondents 'employed in academia' according to gender, as percentages (\%)

$\begin{array}{cccc}\text { Overall } & \text { Women } & \text { Men } & \text { Other } \\ 44.3 & 43.3 & 43.4 & 57.1\end{array}$

Note. $\mathrm{N}=533$

39 See, for example, Courtois \& O'Keefe. (2015). 
Of all the respondents, $\mathbf{2 6 . 5 \%}$ (214) had permanent and full-time contracts. These are the kinds of contracts to which most aspire and that are seen as the most stable.

Table 10: Permanent and full-time contracts according to gender, as percentages

$(\%)^{40}$

\section{Overall}

26.5
Women

24.3
Men

27.7
Other

42.1

Note. $\mathrm{N}=214$

When doctoral students are removed from the sample, the proportion of permanent and full-time contracts increases only slightly - to 31.3\%.

When only those who confirmed that they held any kind of contract in academia (619) are selected, that is, when the unemployed, the retired and those on stipends are removed, the numbers are as follows: $38.7 \%$ of those with some kind of employment contract in academia were on permanent contracts, $34.5 \%$ were on permanent and full-time contracts, and $2.5 \%$ of respondents were employed on at least one permanent and one fixed-term contract simultaneously.

Among those who identified 'primarily employed in academia' as their primary status, $40.1 \%$ were employed on a permanent and full-time basis.

Table 11: Permanent and full-time contracts split according to primary academic positions, as percentages $(\%)^{41}$

\begin{tabular}{|lcccc|}
\hline Academic position & Overall & Women & Men & Other \\
\hline $\begin{array}{l}\text { Research fellow/post-doc } \\
\text { or similar (with PhD) }\end{array}$ & 6.6 & 5.6 & 5.8 & 16.7 \\
\hline $\begin{array}{l}\text { Teaching fellow/instructor } \\
\text { or similar: }\end{array}$ & 5.9 & 9.1 & 0 & 0 \\
\hline Assistant professor/lecturer & 37.3 & 39 & 30.3 & 42.9 \\
\hline $\begin{array}{l}\text { Associate professorl } \\
\text { senior lecturer/reader }\end{array}$ & 72.1 & 71.4 & 69.8 & 100 \\
\hline Full professor & 89.6 & 94.7 & 81.3 & 100 \\
\hline Other & 34.4 & 39.1 & 16.7 & 0
\end{tabular}

Note. "A total of $79 \%$ of teaching fellows had PhDs.

As could have been expected, academic seniority correlates with employment stability. More stable jobs - permanent and full-time employment - were typical for professors and

40 Of the 214 respondents who held a permanent and full-time contract, 211 responded to the question about gender.

${ }^{41}$ There was only one case of a doctoral student and teaching assistant with a permanent contract in academia. We left these two cases out of this overview. 
associate professors. These comprised 30\% of all respondents. Most respondents labour under temporary and frequently part-time contracts. In fact, the dividing line of precarity lay between lecturers/assistant professors and senior lecturers/associate professors: whereas only $37.3 \%$ of the former had permanent and full-time contracts, among the latter the number increased to $72.1 \%$.

When focused on ERC countries,42 the proportion of permanent contracts was comparable with the overall average: $38.8 \%$. As the table below shows, however, there were great differences between regions, with German-speaking countries having the lowest percentages of permanent contracts. Bearing in mind that percentages refer only to the survey sample and may, or may not, correspond to values for a particular region. For instance, in the sample, there were only 27 individuals who worked primarily in South East Europe. It is possible, then, also given the context of austerity, that permanent and salaried positions are over-represented in the survey (and possibly among EASA members).

\section{Table 12: Permanent contracts according to gender in ERC countries grouped into regions, as percentages (\%)}

\begin{tabular}{|lcccc|}
\hline Region & Overall & Men & Women & Other \\
\hline $\begin{array}{l}\text { German-speaking Countries } \\
\text { (including Switzerland) }\end{array}$ & 17.4 & 13.7 & 19.8 & 14.3 \\
\hline $\begin{array}{l}\text { West \& North Europe (not } \\
\text { including the UK and Ireland) }\end{array}$ & 49.6 & 52.4 & 46.2 & 83.8 \\
\hline $\begin{array}{l}\text { UK \& Ireland } \\
\text { South West Europe }\end{array}$ & 50.6 & 50 & 50 & 60 \\
\hline \begin{tabular}{l} 
(including Italy) \\
\hline $\begin{array}{l}\text { South East Europe } \\
\text { (including Turkey) }\end{array}$
\end{tabular} & 34.7 & 40.7 & 32.6 & 0 \\
\hline East Central Europe & 70.4 & 81.8 & 62.5 & - \\
\hline \begin{tabular}{l} 
Other ERC countries \\
\hline
\end{tabular} & 30 & 23 & 29.2 & 66.7 \\
\hline
\end{tabular}

Among the three countries in which more than one third (34.1\%) of survey respondents worked (had their primary employment etc.), the percentages of permanent contracts varied significantly: they were very low in Germany, at $12.1 \%$. In Italy the rate was $28 \%$. Almost half $(49.4 \%)$ of the survey respondents employed in the United Kingdom held permanent contracts. However, for many other countries there were only a few respondents, and so generalisations by country cannot be made. 43

\footnotetext{
${ }_{42}$ There are $28 \mathrm{EU}$ countries and 16 associated countries. There were no cases for the following countries: Luxembourg, Cyprus, Albania, Montenegro, Bosnia and Herzegovina, Serbia, North Macedonia, Moldova, Ukraine, Tunisia, Georgia, Armenia, Israel, and the Faroe Islands.

43 EASA membership rates may also vary across certain segments (e.g. due to costs, membership may be less appealing to early career researchers in some countries more than others). Nevertheless, at least some rates seem more-or-less comparable: for instance, in Czech Republic in 2018, 34.3\% of academics worked on permanent contracts at universities and $29.3 \%$ at the Czech Academy of Sciences. See Vohlídalová, M. (2018). Akademici a akademičky 2018: zpráva z dotazníkového šetření akademických a vědeckých pracovnic a pracovníků ve veřejném sektoru. Institute of Sociology, Czech Academy of Sciences (p.6). This corresponds to our values for East Central Europe.
} 
A note on percentages by gender: in our sample, $62.5 \%$ of respondents were female, $32.1 \%$ male, $4.1 \%$ preferred not to say, $0.6 \%$ preferred to self-describe and $0.6 \%$ did not answer. We do not have reliable data about the gender percentages present in the population of anthropology professionals. This data would help us assess whether one gender is overrepresented in the sample and by how much (although we do know that the gender profile of the sample is comparable with that of the EASA membership as a whole). ${ }^{44}$

\subsubsection{Employment history}

A respondent with a permanent academic job was on average 49.9 years old and was therefore likely to be an advanced scholar. Those who worked on permanent contracts reported being offered them on average within five years of obtaining their PhDs. There were no notable gender-based differences when viewed through this parameter (women who were employed on a permanent basis were offered such contracts on average within 4.98 years and men within 4.97 years). .45

A total of $64.2 \%$ of those on permanent contracts, or $29.7 \%$ of the actual total sample $(28.9 \%$ when students are left out), signed a permanent contract within five years of finishing their PhDs. Of those working on permanent contracts, $64.2 \%$ were offered a first such contract within 5 years of obtaining their PhD degrees and $86.8 \%$ within 10 years.

\begin{tabular}{|lcccc|}
$\begin{array}{l}\text { Table 13: Number of years after a PhD degree until the first permanent contract, } \\
\text { according to gender, as percentages (\%) }\end{array}$ \\
\begin{tabular}{|l}
\hline \\
Years after PhD
\end{tabular} & Overall & Men & Women & Other \\
\hline $\mathbf{0}$ & 19.1 & 21.5 & 18.2 & 12.4 \\
\hline $\mathbf{1 - 5}$ & 45.1 & 41.8 & 47.4 & 43.8 \\
\hline $\mathbf{6 - 1 0}$ & 22.6 & 24.1 & 19.7 & 43.8 \\
\hline $\mathbf{1 1 - 1 5}$ & 9.8 & 10.1 & 10.9 & \\
\hline More than 15 & 3.4 & 2.5 & 3.6 & \\
\hline
\end{tabular}

For $19.1 \%$ of those employed on permanent contracts it took less than one year after finishing their PhD to be employed in such a manner. ${ }^{46}$ They might have been working on one during their PhDs. The possibility of attaining such contracts seems to be diminishing:

\footnotetext{
44 Taking into account data from a handful of national-level studies that consider not just women in employment but the difference between those in permanent and precarious jobs, and where men still usually hold more permanent positions than women, it would be interesting to see if further studies engage in exploring whether anthropology in North West Europe shows real advancement in terms of gender parity. See for instance Dubois-Shaik, F., \& Fusulier, B. (2015). Academic careers and gender inequality: leaky pipeline and interrelated phenomena in seven European countries. GARCIA project working paper. Retrieved from

https://eige.europa.eu/sites/default/files/garcia_working_paper_5_academic_careers_gender_inequality.pdf; Megoran, N., \& Mason, O. (2020). Second class academic citizens: the dehumanising effect of casualisation in higher education. University College Union. Retrieved from

https://www.ucu.org.uk/media/10681/second_class_academic_citizens/pdf/secondclassacademiccitizens

45 Since only two of the respondents who did not identify either as men or women or who did not declare their gender in the survey answered this question, no conclusions were possible for this category.

${ }_{46}$ The cases were as follows: 6 - UK, 4 - US, 3-Canada, 3-Netherlands, 3 -Norway, 3 - Portugal, 3 - Romania, 3-Sweden,

2 - Germany. The rest had one case per country.
} 
While in the age group 56-65 there were 16 individuals and in the $46-55$ cohort, there were 12 individuals, the number goes down for the age groups 41-45 and 36-40 (both with five respondents). ${ }^{47}$ Among those aged 35 and younger, there were only two individuals.

While in the age group 56-65 there were 16 individuals and in the $46-55$ cohort, there were 12 individuals, the number goes down for the age groups 41-45 and 36-40 (both with five respondents). Among those aged 35 and younger, there were only two individuals.

The above data reveals a certain irony and an 'unwritten rule' that needs to be clearly communicated to aspiring scholars and recent graduates: despite the promise of transnational mobility and the increasing prevalence of project-based work - as we have seen, the highest proportion are those on temporary contracts lasting 3 years or more (45.9\%) - the chances of being offered a permanent contract after attaining a PhD degree decrease over time. That is, the longer the post-doctoral phase lasts or the more extensive project funding one has, the lower the chances of gaining a permanent job. As context, note how section 5.3.1 shows that the majority of those on temporary contracts aspire for permanent ones - less than $3 \%$ of respondents do not want a permanent contact while planning to remain within academia.

For comparison, the following table represents the average time it took respondents with permanent contracts to obtain such a contract, divided according to age cohort. It has to be taken into account that not all the age brackets are of the same size, and that there are older members who received their PhDs more recently. On average, younger people had also received their PhDs more recently (to put it bluntly, 10 or 15 years could not have passed for them, unlike for older respondents who on average received their PhDs earlier).

\section{Table 14: Years after PhD until the first permanent academic contract according to age, as percentages (\%) (absolute numbers in brackets)}

\begin{tabular}{|c|c|c|c|c|}
\hline \multirow[t]{2}{*}{ Age } & \multicolumn{4}{|c|}{$\begin{array}{c}\text { Years from PhD to } \\
\text { permanent post in academia }\end{array}$} \\
\hline & $0-5$ & $6-10$ & $11-15$ & $15+$ \\
\hline 30 and younger & $100(2)$ & 0 & $\mathrm{O}$ & 0 \\
\hline 31-35 years old & $100(8)$ & $\mathrm{O}$ & 0 & 0 \\
\hline $36-40$ years old & $76.7(23)$ & $23.3(7)$ & $\mathrm{O}$ & $\mathrm{O}$ \\
\hline 41-45 years old & $66(31)$ & $21.2(10)$ & $12.8(6)$ & 0 \\
\hline $46-55$ years old & $58(41)$ & $28.2(20)$ & 12.7 (9) & $1.4(1)$ \\
\hline 55 and older & $61.1(44)$ & $19.4(14)$ & $11.1(8)$ & $8.3(6)$ \\
\hline
\end{tabular}

${ }_{47}$ For respondents above 65 there were four, but many of these are already retired, so we disregard it here. 
What the table does not capture is the increasing number of applicants for one position. It also does not reflect the overall proliferation of temporary contracts - in our sample, as we saw, $32 \%$ of those aged $56-65$ years held such contracts, compared with $68.2 \%$ of those aged 36-45. In other words, although for 40-year olds who eventually obtain permanent contracts, it may not have taken longer on average than for their Go-year old colleagues, the attrition rate has increased as the system as a whole has come to depend on temporary staff for teaching and research and the proportion of permanent contracts in academia has decreased. ${ }^{48}$

In fact, given the low absolute values, it is more than likely that many would never be offered a permanent contract. As an example, let us take the cohort of those aged between 41 and 45 , that is, those who are somewhere between five and ten years after their PhD:49 at the time of the survey just over one third had attained a permanent contract (among those between 46 and 55 it is slightly more than one half). As the values for preceding generations also show, it is clear that most of the remaining two thirds will never attain a permanent position. As one respondent observed when asked if they considered academia to be an enabling environment for pursuing their academic career: 'There are many social scientists with a PhD that after 10, 15 or 20 years of professional work within academia are still in fixedterm and precarious contracts'. The table thus does not reflect worsening overall prospects and the fact that the probability - discussed above - that one gets a job only if one remains in academia long enough (five years) has been decreasing.

When focusing on ERC countries the average time it takes to obtain a permanent job after finishing the PhD was 5.3 years. As the table below shows, in countries with the habilitation system (the German-speaking countries and East Central Europe) it takes longer for an individual to obtain a permanent job in academia.

\section{Table 15: Years from the PhD degree until the first permanent contract in ERC countries grouped into regions, according to gender ${ }^{\circ}$}

\section{Region}

German-speaking countries (incl. Switzerland)

West \& North Europe (not incl. UK and Ireland)

\section{Overall}

7.3

4.8

4.5

\section{Men}

7.9

5.6

4.6

4.8

UK \& Ireland
4
7.7

\footnotetext{
${ }^{48}$ For example, in the UK, since $2011-2012$ there has been a $33 \%$ increase in teaching-focused staff and a $21 \%$ increase in research staff. Teaching and research staff (lecturers and professors) have grown by only $7 \%$. See Megoran \& Mason Ibid. 49 This is an approximation for the average age of receiving a PhD in Europe, EUI Academic Career Observatory (2018) Average Age when Achieving Position/Degree, EUI, (Accessed 24/20/2020) We, of course, assume that PhD graduation ages are comparable within anthropology and ignore country differences for this exercise (e.g. in the two countries most represented in the survey, Germany and the UK, the average age for receiving a PhD was 26-27 and 33, respectively).

${ }^{\circ}$ We did not include calculations for other and undeclared genders, since there are very few cases and averages would not have made sense.
} 


\section{Region}

South West Europe (incl. Italy)

South East Europe (incl. Turkey)

East Central Europe

Other ERC countries

\section{Overall}

5.4

3.5

7.4

3.8
Men

4.2

2.9

8.7

5
Women

6.4

4.1

6.3

3.3

In the three countries where more than one third (35.3\%) of survey respondents worked, the average number of years it took to be offered permanent contracts after finishing the PhD varied: Germany -8.8 years, Italy -8 years, United Kingdom -4.6 years (In Italy and Germany, the habilitation remains a necessary qualification for full or sometimes even assistant professorship).

\subsubsection{Gender and academic career}

Academic career seems to be still strongly determined by gender. If we disaggregate primary academic positions according to gender and assume that the academic career progresses from the doctoral studies stage, through the post-doctoral and lectureship stages to full professorship, it becomes clear that women are still underrepresented in the most senior positions. These positions, as we have discussed above, are also the most stable - permanent and full-time. While the percentage of women overall was similar to their representation in such positions in the survey sample (62.9\%; for EASA in 2018 it was similar - 61.8\%), it was $10 \%$ lower at the highest two levels, which best correspond to the position titles of associate professor, senior lecturer, reader or full professor. Given that among those at professor level in our sample there was a relatively high rate of refusal to identify with any gender, this finding cannot be taken at face value. Nevertheless, more than $40 \%$ of assistant and full professors or similar identified as men, which is a proportion significantly higher than both the survey sample (32.4\%) or EASA in 2018 (35.5\%).

The data could also be read differently: while men compose $\mathbf{2 4 \%}$ of doctoral students, they represent $\mathbf{4 2 \%}$ of full professors; clearly, however, the survey was not designed to capture the changes in the discipline over the last decades (one has to keep in mind that most full-time jobs are obtained relatively early, within the first 10 years after the PhD). The data for doctoral students seems to suggest that the overall proportion of women and individuals who identify or express their gender outside the culturally dominant gender binary may be increasing, at least among doctoral students and lower-ranking positions, and we can only hope (yet seriously doubt) that the hiring pattern will reflect these changes. 
Table 16: Distribution of academic positions, according to gender, as percentages (\%)

\begin{tabular}{|c|c|c|c|c|c|}
\hline Academic position & Women & Men & $\begin{array}{l}\text { Prefer not } \\
\text { to say }\end{array}$ & $\begin{array}{l}\text { Prefer to } \\
\text { self-describe }\end{array}$ & Missing \\
\hline Doctoral student & 67.4 & 23.9 & 4.3 & 4.3 & 0 \\
\hline $\begin{array}{l}\text { Student assistant / } \\
\text { teaching assistant or similar }\end{array}$ & 75 & 25 & O & $\mathrm{O}$ & O \\
\hline $\begin{array}{l}\text { Research assistant } \\
\text { (without PhD) }\end{array}$ & 60 & 30 & 10 & o & 0 \\
\hline $\begin{array}{l}\text { Research fellow / post-doc } \\
\text { or similar (with PhD) }\end{array}$ & 64.1 & 31.1 & 3.6 & 0 & 1.2 \\
\hline $\begin{array}{l}\text { Teaching fellow / } \\
\text { instructor or similar }\end{array}$ & 64.7 & $35 \cdot 3$ & O & O & $\mathrm{O}$ \\
\hline Assistant professor / lecturer & 65.3 & 28 & 5.9 & $\mathrm{O}$ & 0.8 \\
\hline $\begin{array}{l}\text { Associate professor / senior } \\
\text { lecturer / reader or similar }\end{array}$ & 53.8 & 41.3 & 2.9 & 1.9 & $\mathrm{O}$ \\
\hline Full professor or similar & 49.4 & 41.6 & 7.8 & 0 & 1.3 \\
\hline Other & 71.9 & 18.8 & 6.3 & 3.1 & $\mathrm{O}$ \\
\hline
\end{tabular}

\subsubsection{Employment satisfaction}

A total of $53 \%$ of individuals were dissatisfied with their current employment, education situation, or both - to a lesser or greater extent. The pie chart below shows how they evaluated the statement 'I am completely satisfied with my current employment and/or education situation'.

\section{Chart 4: Job or study satisfaction}

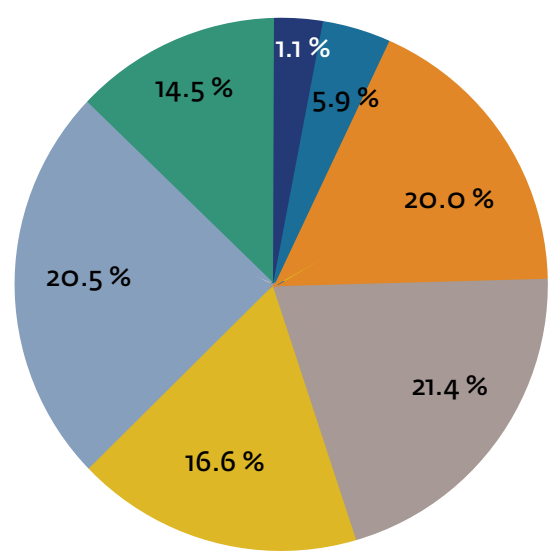

All respondents

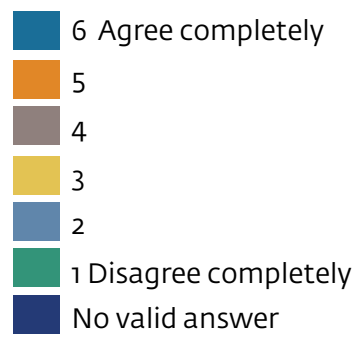

Note. 'I am completely satisfied with my current employment and/or education situation' 
The degree of dissatisfaction varied according to gender. Men were on average less dissatisfied - $48 \%$ of men disagreed with the above statement ( $10 \%$ completely), $53 \%$ of women ( $17 \%$ completely) and $59 \%$ of those with another or undeclared gender ( $17 \%$ completely).

Not unexpectedly, the level of dissatisfaction differed according to the type of contracts respondents were employed on: $14.2 \%$ of those on fixed-term contracts, $4.2 \%$ of those on permanent contracts, and $\mathrm{\%}$ of those on permanent, full-time contracts disagreed completely with the statement. In other words, not having a permanent contract adds to job dissatisfaction.

Having a permanent contract contributes to job satisfaction - those employed on permanent contracts were more satisfied than those who were not.

\section{Chart 5: Job satisfaction among the permanently employed}

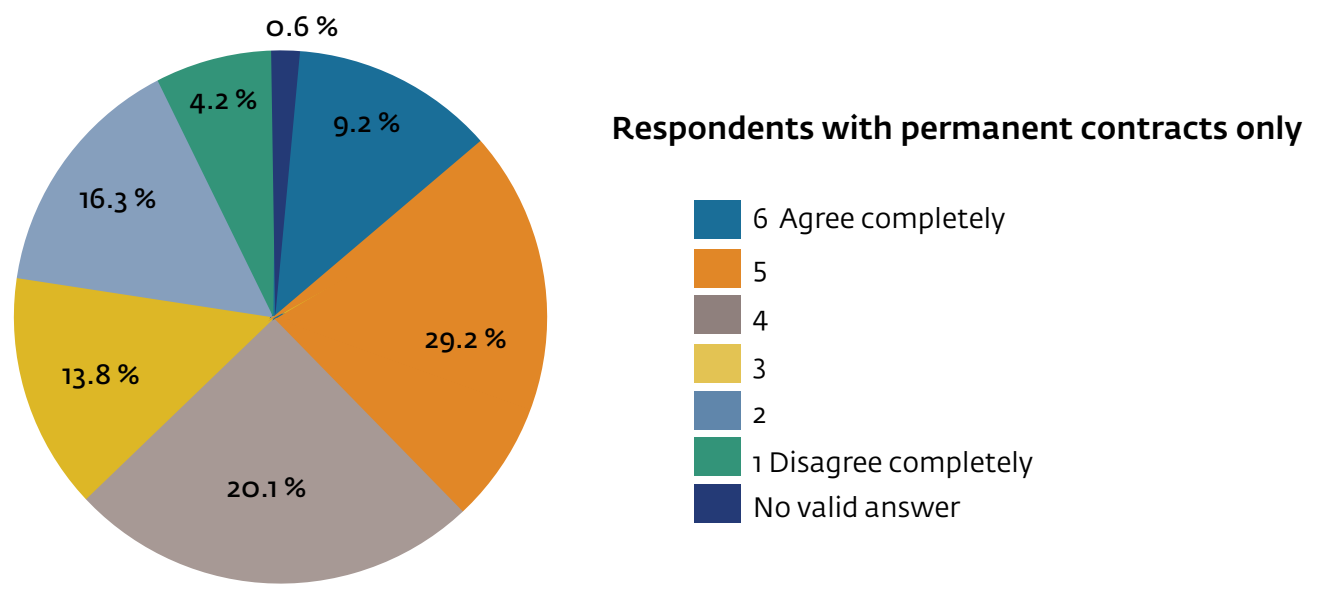

Note. 'I am completely satisfied with my current employment and/or education situation'

\section{Chart 6: Job satisfaction among those not holding a permanent contract}

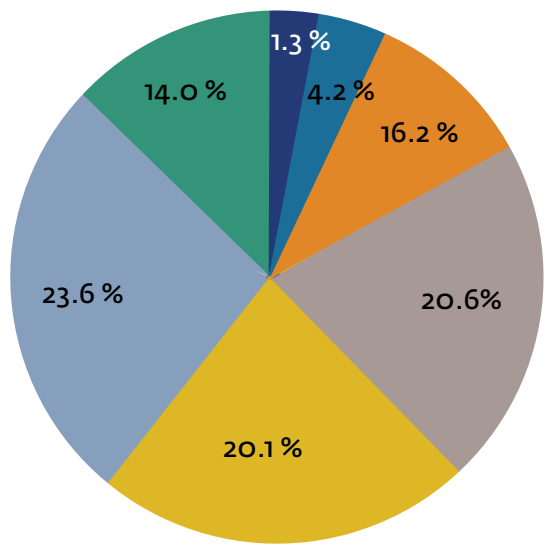

\section{Respondents without permanent contracts only}

Note. 'I am completely satisfied with my current employment and/or education situation' 
Less than half of the students in the sample were satisfied with their education situation. Twice as many were completely dissatisfied with their situation as were completely satisfied. Further research into doctoral training in anthropology is therefore advisable.

\section{Chart 7: Student satisfaction with their education situation}

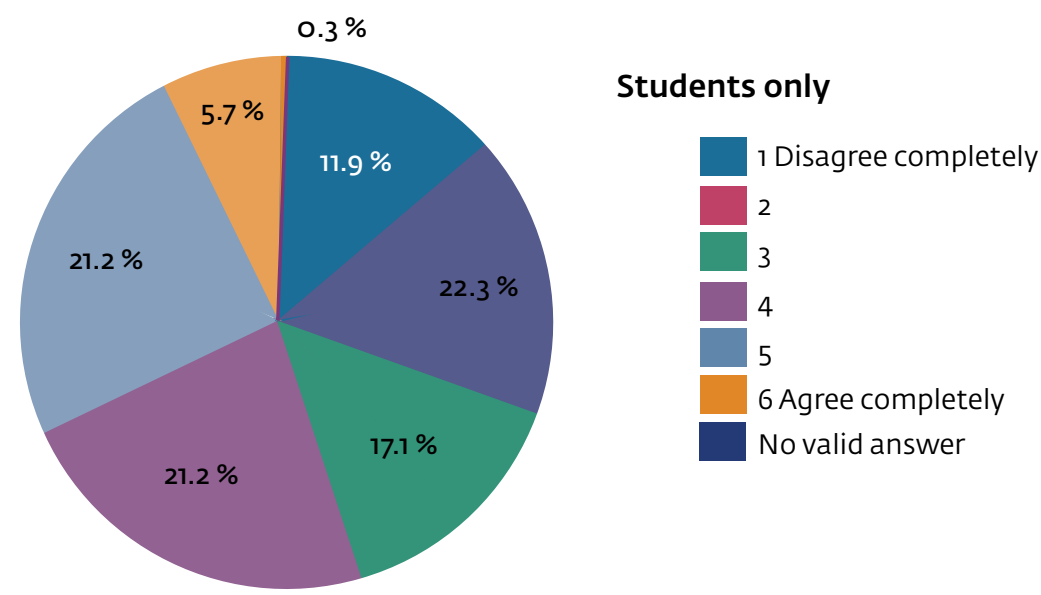

Note. 'I am completely satisfied with my current employment and/or education situation'

\subsubsection{Summary}

The analysed data show a troubling tendency towards casualisation and decreased job satisfaction for those working in anthropology in academia and outside.

Only $29.7 \%$ of all respondents had a permanent contract. Even when MA and PhD students were removed, the figure was still only $38.7 \%$. A total of $26.5 \%$ of all respondents have permanent and full-time contracts. Of the respondents, 65.9\% (533) declared their primary status as 'employed at a university, research institution or similar)'. Fixedterm employment is a norm with $71.1 \%$ (379) of those who saw employment in academia as their primary status working on temporary contracts (this became $49 \%$ or 334 when MA and PhD students were removed, albeit many of them do work as graduate teaching assistants). A total of $53 \%$ of individuals were dissatisfied with their current employment, education situation, or both, and having a permanent contract contributes significantly to job satisfaction (or decreases dissatisfaction, which is particularly high among students).

Fixed-term contracts were not evenly distributed geographically among gender groups and across ages:

- Geographically, they are most prevalent in the countries of Central Europe and Russia. In the three countries that employ $34.1 \%$ of survey respondents, the percentage of permanent contracts was under $50 \%$ in all cases, but the rates varied significantly (Germany - 12.1\%, Italy - 28\%, United Kingdom - 49.4\%).

- In gender terms, anthropology is somewhat of an anomaly compared with nationallevel surveys of all professions: in our sample women are slightly more likely to be 
permanently employed, especially in the Western and Northern countries. However, women on fixed-term contracts end up working on shorter contracts than men.

- In terms of age, a respondent with a permanent academic job was on average 49.9 years old. Permanent contracts are being offered on average within 5 years after obtaining a $\mathrm{PhD}$, but not all will be offered such a contract. Again, the rates varied between the three countries employing $34.1 \%$ of survey respondents (Germany -8.8 years, Italy -8 years, United Kingdom -4.6 years).

- In terms of seniority, among lecturers and assistant professors, $37.3 \%$ had permanent and full-time contracts, while the figure was $72.1 \%$ for those in senior lecturer or associate professor positions.

\subsection{Kinds of jobs and tasks}

One of the reasons why some academics may not be moving along the career-1adder at the same pace as others - if they are moving at all - could be that they are engaging in various teaching-related and research activities that are necessary for guaranteeing the academic ethos and purpose of the discipline, but which do not count for much within the current systems for evaluating academic work. A typical example is the gendered nature of service work - traditionally, women have been involved more than men in administrative and committee work in their departments, or have been expected to provide pastoral care to students. ${ }^{51}$ Similarly, academics of colour and minority academics are often by default expected to provide emotional, psychological and spiritual care to students of colour or of a minority background. When combined with family obligations, within families where the imperative to care still falls predominantly on women, and within lower-income families with less access to welfare and paid care, as is more often the case with minority background families, this may leave little time or energy for research work, publication and fundraising.

Another significant split may be between those who are temporarily employed and those on permanent contracts. As is discussed below, $41 \%$ of respondents feel that 'all they do is apply for jobs'. This is not an overstatement, but points to a structural issue. As the previous section showed, the average duration of the fixed-term academic contract is 26 months. An average EASA member on a temporary contract (i.e. the majority of EASA members) therefore has to start looking for a job or to start writing funding applications just a few months into their new position. This takes valuable time away from their current projects and slows down the process of completing publications (especially when combined with family obligations). Given the gendered nature of family obligations, this often means that women cannot be equally productive across the duration of short-term contracts, and they therefore enter job-application cycles at an initial disadvantage as compared with men.

The third major cleavage is more recent. It has to do with the funding structure and the nature of post-doctoral work. First, there is a growing split between the teaching and

${ }^{51}$ See, for instance, Ivancheva et al. (2019). 
research staff. Those involved in teaching as, for instance, temporary research fellows who take over the teaching responsibilities of those who receive big research grants, are not only underpaid, but their work is also not something that gets recognised when they eventually apply for permanent posts. ${ }^{22}$ Second, there is a growing evidence of inequalities and outright exploitation within big grants ${ }^{53}$ on which many, especially early career researchers, depend as post-docs.54 Often they have to work on projects that have been developed by more senior and better-connected PIs, under conditions specified by those projects (while already thinking of new positions to apply for, as noted above). Understandably, then, many such positions provide an important career stepping stone or stumbling block for early career researchers. It may make PIs feel that they, almost by default, are helping junior scholars by offering them work and contracts, but equally it may also make PIs feel threatened and personally offended in cases of conflicts and the post-doc's non-compliance with their leadership. Due to this power asymmetry, through its watchdog activity the PrecAnthro Collective has been made aware of numerous cases. 55 There have been cases in which early career scholars have not had control over their data and have not been able to publish from projects that they have worked on for years (while the projects have often used their contacts and built on trust gained from their previous projects). Once again, this is reflected poorly on precarious researchers' CVs.

\subsubsection{Working hours}

On average, the respondents work 33.4 hours per week according to their current contracts. Although there are some variations between countries, those employed on full-time contracts are generally expected to work 40 hours a week, a European standard.

The average working time for those on part-time contracts only (156 cases) is 22.9 hours. Contracts of 20 hours a week (23 cases) are common, that is 0.5 of the European FTE, and 30 hours a week (21 cases), that is 0.75 of the European FTE. A total of 29 cases are contracted for up to 10 hours per week. There were 33 individuals, i.e. $21.1 \%$ of those on part-time contracts, who work more than 30 hours per week. Due to the survey design we unfortunately cannot say whether they did so on one or several contracts.

\subsubsection{Unpaid overtime}

In addition to contracted working hours, respondents reported spending $\mathbf{1 0 . 4}$ hours of uncompensated overtime working on tasks that were related to their jobs. On average, men reported working overtime two hours longer than women (11.7 hours versus 9.7 hours). Since the average weekly working hours specified by respondents' contracts was 33.4 hours, in reality they worked on average 43.8 hours to complete all job-related work

\footnotetext{
52 See, for instance, Ivancheva (2016).

53 See for instance Tilche \& Astuti (2019).

54 See, for instance, Laudel, G., \& Gläser, J. (2008). From apprentice to colleague: The metamorphosis of early career researchers. Higher Education, 55(3), 387-406. https://doi.org/10.1007/s10734-007-9063-7.

55 Due to the delicate nature of this work, we will not give examples, for risk of identifying vulnerable early-career academics. However, some of these cases were discussed during the PrecAnthro 2018 meeting at EASA in Stockholm and in Tilche \& Astuti's workshop held at LSE in 2019, from which the authorship guidelines were produced (TIche \& Astuti 2019 ). Some of these queries were also submitted as free-text responses to our question on having taken up cases against employers and agreeing to follow-up interviews. These are beyond the scope of this study.
} 
(e.g. to keep courses going). In other words, when comparing these two average sums, we find that almost $24 \%$ of work as required by employers remained uncompensated. Survey respondents were working more than one day a week unpaid. This is 'structural overtime', with consequences not only for one's professional life and relationships (due to burnout and reasons for increased levels of sick leave), but also for academics' personal lives. ${ }^{56}$

To be more precise, we approached the problem in two ways:

In the first, we calculated the average of the individual proportions of respondents' uncompensated working hours: this is what was used throughout. In this manner (based on 560 cases for which we had both answers - regarding overtime and contracted hours), we found that $21.91 \%$ of all working hours of those employed in academia was uncompensated. By comparison, $16.10 \%$ of all working hours of anthropologists employed outside academia was also uncompensated (based on 64 cases).

In the second, we added together all hours for the sample as a whole and calculated the proportion of overtime. We found that $27.67 \%$ of the total number of hours worked by respondents with academic jobs was uncompensated, as a cumulative total across the entire sample. For those with jobs outside academia this figure was 15.97\%.

Depending on the method chosen, somewhere between one fifth and one quarter of work that needs to be done to fulfil tasks for which one was hired remains uncompensated. This represents a direct value captured by academic employers (in the context of often shrinking real wages across the sector and, in some countries, growing student fees).

As regards gender, according to the average of the individual percentages, for women $21.22 \%$ of their total working hours were uncompensated in academia ( 338 cases) and $13.62 \%$ outside academia (41 cases). The percentages are slightly higher for men $-23.32 \%$ in academia (187 cases) and $20.23 \%$ outside academia (20 cases).

Those without a permanent contract worked on average 9.05 hours per week as uncompensated overtime on tasks required by their employer (27.7\% did not report working uncompensated hours). Importantly, landing a permanent position did not lead to a decrease in such work, but rather the opposite - an increase in comparison with the average: those on permanent contracts reported working $\mathbf{1 2 . 4}$ hours of uncompensated overtime on tasks required by their jobs (and only $14.8 \%$ did not report working overtime). As a group, $23.97 \%$ of all the hours they worked were uncompensated (220 cases).

What did make a significant difference was the number of hours specified in individuals' contracts. Those without full-time contracts worked an average of 10.2 hours of uncompensated overtime ( $24.7 \%$ did not work uncompensated hours). Those with full-time contracts worked an average of 10.4 hours of uncompensated overtime (22.8\% did not work

\footnotetext{
${ }^{56}$ See the report on 'structural overtime' at Dutch universities: Jongsma, M., Sanders, W., \& Weeda, C. (2O20). Survey of the extent and effects of structural overtime at the Dutch universities. WOinActie. Retrieved from

https://www.aob.nl/wp-content/uploads/2020/o1/WOinActie-Survey-of-the-Extent-and-Effects-of-StructuralOvertime-at-Dutch-Universities.pdf.
} 
uncompensated hours). While in absolute terms those on full-time contracts seem to do the same amount of overtime, it is clear that it matters whether the overtime is compared against 1.o FTE or against its fraction. Indeed, there is a direct correlation, which a closer look at the relationship between contracted hours and the number of uncompensated hours as necessary for the complete fulfilment of respondents' job-related obligations reveals.

\section{Chart 8: Proportion of unpaid work to contracted hours, as percentages (\%)}

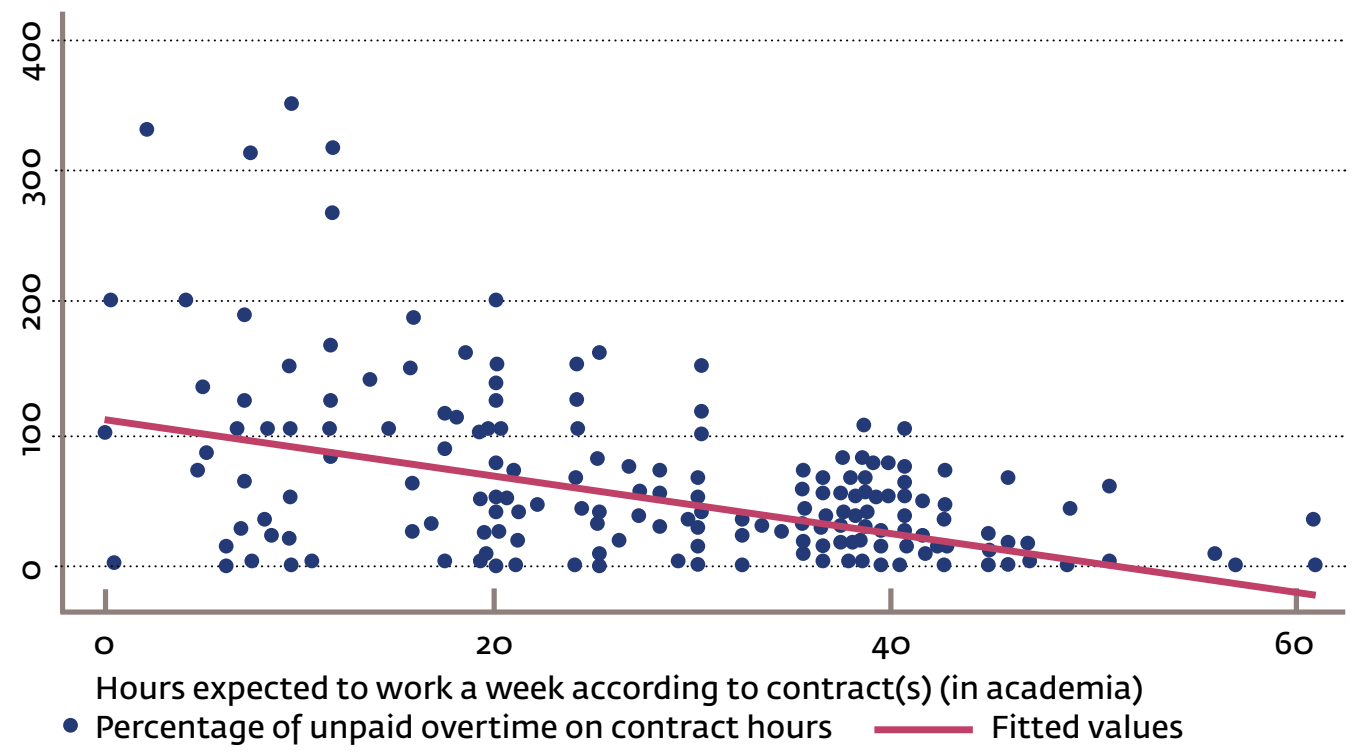

Note. 556

The red line in the chart (regression line) illustrates that the fewer the hours contracted officially (and remunerated), the higher the percentage of unpaid overtime. ${ }^{57}$

To be more specific, those on full-time academic contracts complete $19.63 \%$ of their working hours as uncompensated overtime (410 cases). The proportion of uncompensated work is $17.27 \%$ for part-time workers in academia (20 cases), $34.95 \%$ for agency workers in academia (4 cases), $29.60 \%$ for casual workers in academia (71 cases), while those on zero-hour contracts in academia are uncompensated for $21.50 \%$ of the work needed to get the job done (12 cases). Casual workers - sessional, seasonal or adjunct workers who comprise almost $14 \%$ of the academic workforce in our sample and are responsible for the bulk of teaching and research done at universities - get paid for about $70 \%$ of their hours.

A similar pattern affects employed doctoral students (often 0.5 or 0.75 FTE), who report primarily working on their theses beyond working hours. They also reported running errands for faculty members, revising faculty members' publications or even writing project proposals for them.

\footnotetext{
57 On the $x$-axis you see the hours expected to work each week according to contract(s). The levels on the $y$-axis indicate the percentage of unpaid overtime on contract hours. The correlation between working hours according to contract and the percentage of unpaid overtime on contract hours is -0.497. That means that there is a medium to strong statistical correlation between these two variables (the more contract hours, the lower the percentage of unpaid overtime hours).
} 
Table 17: Reasons for overtime needed for the fulfilment of duties as required by current jobs, according to gender, as percentages (\%)

\begin{tabular}{|lllll|}
\hline Reason for overtime & Overall & Women & Men & Other \\
\hline Writing grant applications & 57.6 & 56.9 & 59.1 & 58.3 \\
\hline Advising students & 49.6 & 51.8 & 47.2 & 41.7 \\
\hline $\begin{array}{l}\text { PR work, open days } \\
\text { and similar }\end{array}$ & 43.3 & 42 & 45.9 & 41.7 \\
\hline Class preparation & 42.0 & 44.5 & 39.6 & 25 \\
\hline Committee work & 41.7 & 38 & 50.3 & 29.2 \\
\hline $\begin{array}{l}\text { Extracurricular activities } \\
\text { (e.g. fieldtrips) }\end{array}$ & 36.5 & 35 & 39 & 37.5 \\
\hline Teaching & 18.7 & 16.8 & 19.5 & 33.3 \\
\hline Other & 37.2 & 39 & 32 & 50 \\
\hline
\end{tabular}

Other frequent reasons for overtime included: writing publications, administrative tasks, managerial tasks (e.g. writing accreditation documents), responding to emails (including communication with project partners) and conducting research. Many respondents reported writing references for students, attending conferences or evaluating modules and teaching policies.

\subsubsection{Applying for jobs}

Less than $10 \%$ of survey respondents (79 individuals) had not applied for a job (including postdoctoral positions and fellowships but excluding research funding) during the 12 months prior to the survey.

The following chart illustrates how much time 806 respondents (99.6\%) reported they spent applying for jobs:

\section{Chart 9: Time spent per year applying for jobs}
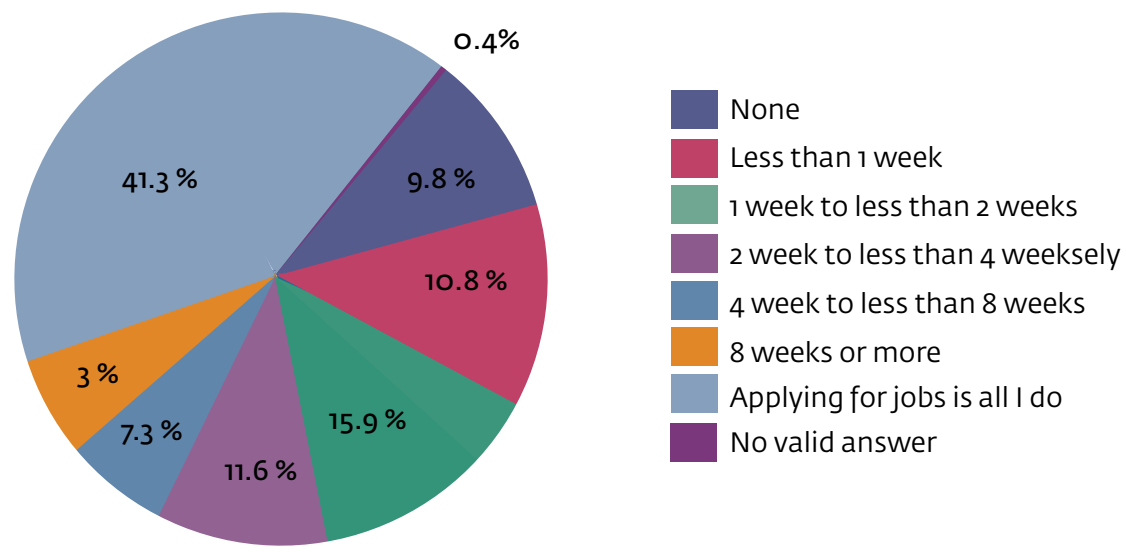

Note. 'In the past 12 months how much time in total did you spend applying for jobs?' 
With hindsight, the last option provided in the survey was a mistake, as it is clear that many (41\%) felt that 'all they did was apply for jobs'. Even more significantly, taken together, 51\% of survey respondents spent more than one month in the preceding 12 months applying for jobs. This is one of the most significant ways in which the current system is wasting the time resources of a highly skilled workforce, and is a trend that can be expected to escalate with redundancies as a result of COVID-19. Moreover, even if the answers were not precise, since it is unlikely that while filling in the survey most respondents went back to their files to check how many applications they wrote and how long it took them, individuals' assessments of how much time was spent writing job applications (most of which were obviously unsuccessful) can be seen as contributing to the overall feeling of despair. It also speaks to a subjective evaluation in how the time is spent or wasted: writing job applications takes away time from other tasks.

We looked at the gender of those who were the busiest applying for jobs (44\%), those who responded that they spent 8 weeks or more per year applying for jobs, or who thought they were doing nothing else. A total of $45.1 \%$ of women are in this category; $41.9 \%$ of men; and $42.1 \%$ of those who preferred not to disclose their gender or who self-identified differently

\subsubsection{Writing funding applications}

Unless applying for funding was their primary job responsibility over the same period, respondents spent less time writing funding proposals than applying for jobs. ${ }^{8}$ Still, only 10\% did not write any funding applications in the preceding year, while $\mathbf{1 7 \%}$ spent more than one month writing them. This is in addition to the $20 \%$ of respondents whose primary responsibility was fundraising (e.g. those employed as a research development officer). In other words, developing grant proposals now belongs firmly on the list of basic scholarly activities.

\section{Chart 10: Time spent per year developing funding applications}

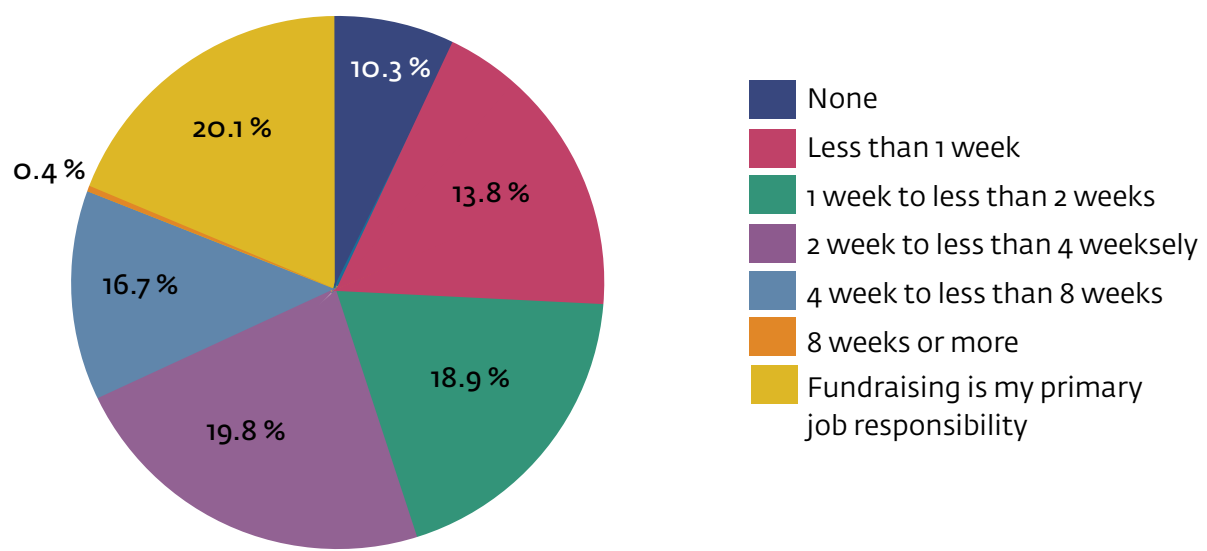

Note. 'In the past 12 months how much time did you spend working on research funding applications?'

${ }^{58}$ Only 3 respondents, $0.37 \%$, spent 8 weeks or more writing grant applications. 
To illustrate what may be at stake: taken together, the respondents combined could have expended as many as 81,000 hours (or 47 working years) writing funding applications in 2018. This experimental assessment suggests how big the scale of the problem is, yet it is invisible when treated at the level of an individual. This is why we have included it. Further research is needed. ${ }^{59}$

There were also differences between countries. Since only three individuals reported spending more than 8 weeks on funding applications, and leaving aside those for whom fundraising was a primary job responsibility, we looked at the category of those who spent between one and two months writing funding applications. Only those countries with more than five responses for this question were included.

Table 18: Respondents who spent between four and eight weeks writing funding applications in selected countries, as percentages (\%)

\begin{tabular}{|lc|}
\hline Country & Percentage \\
\hline Belgium & 0 \\
\hline US & 6.3 \\
\hline Czech Republic & 7.7 \\
\hline France & 8 \\
\hline Spain & 10.3 \\
\hline Australia & 12.5 \\
\hline Poland & 12.5 \\
\hline Norway & 13.8 \\
\hline Italy & 14 \\
\hline Switzerland & 14 \\
\hline UK & 15 \\
\hline Greece & 15.4 \\
\hline Romania & 16.7 \\
\hline Sample Average & 16.7 \\
\hline Germany & 17.6 \\
\hline Netherlands & 22.9 \\
\hline Sweden & 25.9 \\
\hline Ireland & 27.3 \\
\hline Israel & 26.6 \\
\hline Austria & 29.2 \\
\hline Denmark & 30.4 \\
\hline Russia & 42.9 \\
\hline
\end{tabular}

59 If the sample were representative of EASA, for the entire EASA membership this would be 229,558 hours, or 132 years. It was calculated in the following manner: if we turn the answers above into numeric values on a scale from one to eight (from no fundraising to fundraising is my job), we find that the average value is four, i.e. two to four weeks spent on an application. Even for those in that category we do not really know if they spent only slightly more than two weeks or almost four. But let us assume that the average respondent spends three weeks on applications. According to our survey, the average working time of a member is 33.4 hours a week (without overtime). In 2018, the average number of annual hours worked per worker within the OECD was 1735. See OECD (2O20). Average annual hours actually worked per worker. Retrieved from https://stats.oecd.org/Index.aspx?DatasetCode=ANHRS. In fact, the number underestimates the true scope. It does not reflect the time spent by those whose job it was to fundraise - if those $20 \%$ worked, for instanced, 30 weeks on funding applications, then the average length of time spent by respondents would be much higher. 
During the same period, $35.6 \%$ of respondents applied for funding as Principal Investigators (PIs) on projects that included at least one other team member. A total of $24.3 \%$ of women, $27.3 \%$ of men, and $50 \%$ of those who preferred to self-describe differently or who preferred not to state a gender submitted such applications.

From the experience of the authors and other PrecAnthro members, these projects are on average more difficult to design (even if one assumes that conceptually all projects are similarly complex, when you have more than one team member, drafting a budget and schedules or establishing terms of cooperation become more complicated). ${ }^{60}$

Unsurprisingly, senior scholars were more likely to apply for such funding. Those who had recently graduated and those without PhDs are often not eligible or stand only little chance. It is worrying - and revealing of the changing nature of academic labour - that more than half of associate professors and almost two thirds of full professors in our sample put together applications for such 'large' projects over the last 12 months.

Table 19: Funding applications as PIs for projects that included at least one team member over the past 12 months, according to primary academic position, as percentages (\%)

Academic position

Percentage

Research assistant (without PhD)

Student assistant/teaching assistant

O

Doctoral student

O

Research fellow (with PhD)/post-doc

6.5

Teaching fellow/instructor

22.8

Sample Average

23.5

Assistant professor/lecturer

35.6

Other

41.5

Associate professor/senior lecturer/reader

43.8

Full professor

51.9

62.3

\footnotetext{
${ }^{60}$ EASA should consider promoting a modified lottery system among funding agencies (especially the ERC for whom developing a full proposal is notoriously time-consuming, with a low success rate). The overall system is not only inefficient and irrational, but given the number of hours expended by individuals it must by definition be conservative and biased - one does not want to be rejected only because the board misrecognized one's project's merit: 'as applications increase and success rates fall, [...] more adventurous proposals are not funded. Moreover, evidence shows peer review assessments are biased, with women and minorities less likely to secure grants' Avin, S. (2017). Research funding is a gamble so let's give out money by lottery. LSE Impact Blog. Retrieved from

https://blogs.Ise.ac.uk/impactofsocialsciences/2017/03/28/research-funding-is-a-gamble-so-lets-give-out-money-bylottery. On the modified lottery system see: Adam, D. (2019). Science funders gamble on grant lotteries. Nature. https://www.nature.com/articles/d41586-019-03572-7 https://doi.org/10.1038/d41586-019-03572-7 and Roumbanis, L. (2019). Blind Luck - Could lotteries be a more efficient mechanism for allocating research funds than peer review? LSE Impact Blog. Retrieved from

https://blogs.Ise.ac.uk/impactofsocialsciences/2019/12/11/blind-luck-could-lotteries-be-a-more-efficient-mechanismfor-allocating-research-funds-than-peer-review/.
} 
At the same time, the data highlight a growing split within the sample and the profession, and show the likelihood of applications increasing with full-time and permanent employment. First, those on permanent contracts in academia were more likely to apply: $53.8 \%$ of those with permanent contracts in academia submitted funding applications as PIs in comparison with $24.5 \%$ of those on fixed-term contracts. Second, those on full-time contracts were more likely to apply: $39.9 \%$ of those with full-time contracts in academia, $23.7 \%$ of those on part-time contracts, $29.6 \%$ of those on casual contracts and $26.7 \%$ of those on zero-hours contracts submitted funding applications as PIs. As these projects are time- and resourceconsuming, with some including permanent employment as an eligibility requirement, and because permanent posts at present often come with an obligation to submit large funding bids, this is an unsurprising, but none-the-less worrying tendency.

\subsubsection{Career development work}

Career progression requires that academics not only do work (whether compensated or uncompensated) in the workplace. They must also do what can be described as 'career development work' or 'service to the community'. A total of 526 respondents (65\%) reported being involved in these kinds of activities. On average, they spent about $\mathbf{6 . 5}$ hours a week doing academic work that was not directly required by or recognised as part of their job description, but which respondents saw as necessary for furthering their careers.

Table 20: Activities completed that respondents saw as advancing their career, as percentages (\%)

Activity

Reviewing publications

Finishing previous projects

Service to the anthropological community

Applying for jobs

Evaluating theses/dissertations

Advising students

Reviewing grant applications

Other

\section{Responses}

64.2

63.3

58.9

46.2

38.2

36.3

26.6

22.6

Note. Responses to the question 'What 'career development' activities do you usually do?'

There were no significant gender differences to the activities that people completed alongside those demanded explicitly by their jobs; people undertake activities that they understand as contributing to their careers.

For most, this meant that they were either peer-reviewing publications or working on projects. Significantly, some were also working on supplementary tasks that were not part 
of their job descriptions. Besides the job-related tasks, 63\% reported that this 'something extra' was finishing work for their previous projects for which they were no longer paid, or working on projects for which they had no funding to begin with. ${ }^{61}$ At the same time they are probably already working on or applying for other projects. Besides the 'career development' activities listed in the table, people most often reported grant-writing, reading, writing publications and attending conferences. Other common activities were organising book clubs, reading groups and seminars (often for stakeholders outside academia), attending various certification courses and maintaining an online presence (e.g. managing their personal websites, Twitter accounts etc.).

\subsubsection{Summary}

The first main finding of this section is that the fewer hours an academic is hired and paid for, the higher the percentage of unpaid overtime is required to accomplish the task for which they are contracted. An average EASA member spends 50.3 hours a week on academic work, not counting reading: 33.4 hours are paid, 10.4 are unpaid and 6.5 hours are spent doing career development work, which for most means catching up with unfinished work from previous projects, doing unfunded research or peer-reviewing publications.

The second is that $41 \%$ of all members responded that all they felt they did in the year prior to the survey was to apply for jobs (before analysing separately the data for temporary and permanent contract workers), and that in 2018 EASA members spent an enormous amount of time on grant applications. This means that by proliferating precarity, universities are paying salaries for the elaboration of research projects that often do not get sponsored and implemented and are thus wasting time and human resources that can be allocated to more meaningful activities such as actually conducting research. A profound rethinking is needed regarding how to cut the wasting of resources and time spent on job applications and how to give people secure jobs.

\subsection{Subjective views on employment and career prospects}

\subsubsection{Views on employment prospects}

When asked about how they viewed their job prospects, a question that reveals respondents' subjective assessments of their situation, respondents were pessimistic: $68 \%$ of those who wanted a permanent job thought it unlikely $(42 \%)$ or very unlikely $(26 \%)$ that they would find one within five years. Against this negative background, however, only a surprisingly small fraction of $4 \%$ were planning on leaving academia during the same period.

\footnotetext{
${ }^{61}$ In the UK, '[o]ver a quarter of all research carried out in British universities is said to be unfunded'. Moreover, 37 percent of research is cross-subsidised from the teaching income stream. In reality this research is self-funded. See Edwards, R. (2O2O, August 13). Unfunded research: Why academics do it and its unvalued contribution to the impact agenda. LSE Impact Blog. Retrieved from https://blogs.Ise.ac.uk/impactofsocialsciences/2020/08/13/unfunded-research-why-academics-do-itand-its-unvalued-contribution-to-the-impact-agenda/.
} 


\section{Chart 11: Desirability of permanent academic contracts and the likelihood of their attainment}

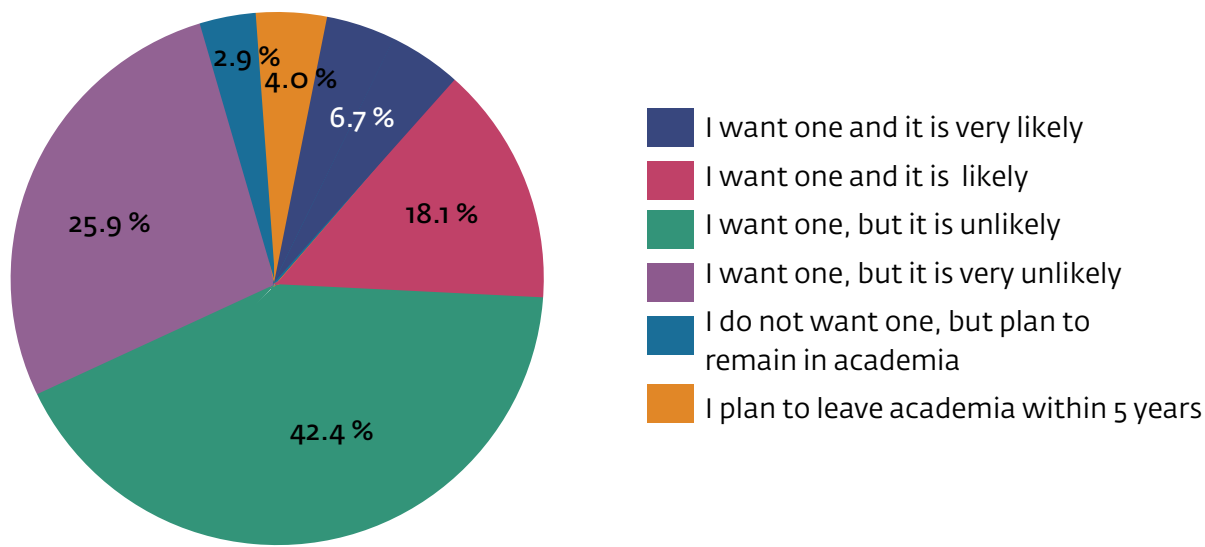

Note. 'Would you like a permanent contract in academia and how likely do you think is it that you will achieve it within 5 years?'

\subsubsection{Pursuing careers}

One of the reasons why anthropologists are willing to work overtime is that, like most scholars, they view their jobs not only as employment, but they value and find pleasure in it beyond the specific tasks at hand. They also see value in research that might not be fundable, but that is beneficial to communities. This is clear from a series of answers they gave to the question: 'When you think about the next five years, how important are the following aspects for your future working life?'

Pursuing their interests at work was crucial for the vast majority of respondents, as the Chart 12 illustrates:

\section{Chart 12: Importance of pursuing one's interests at work}

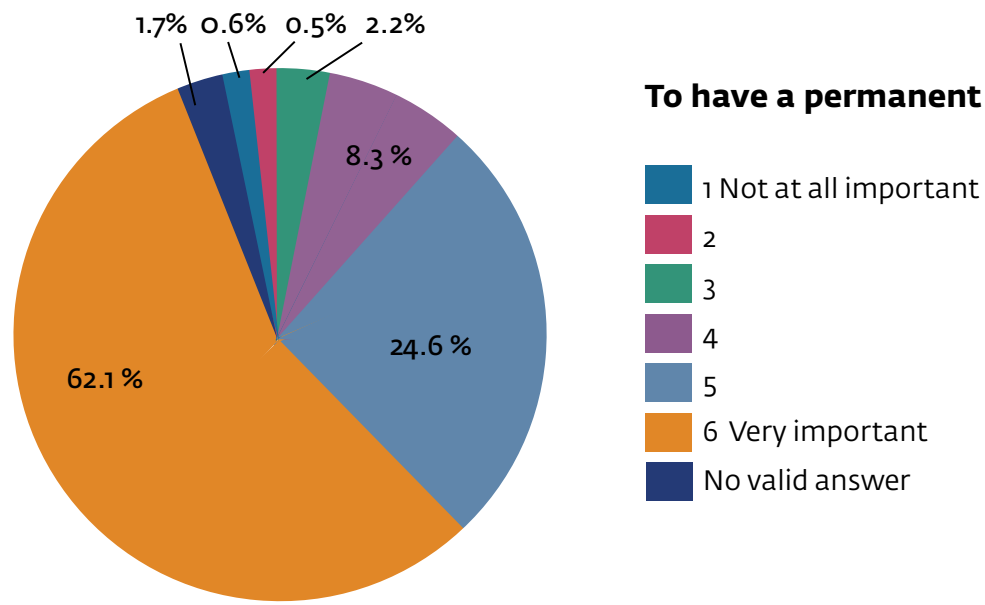

Note. 'When you think about the next five years, how important are the following aspects for your future working life?' 
This leads to a certain paradox. While almost 70\% did not see academia as an enabling environment for pursuing their academic careers, most were still committed to advancing such careers:

\section{Chart 13: Importance of advancing one's professional career}

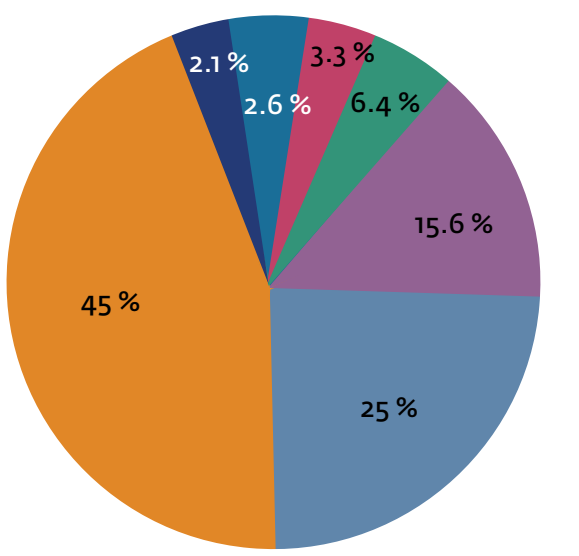

To advance my professional career

Note. 'When you think about the next five years, how important are the following aspects for your future working life?'

Indeed the promise of such advancement might be one of the reasons why respondents accepted temporary - and often part-time - jobs, were willing to change workplaces and even countries, or were prepared to work a significant amount of overtime, whether on tasks that related to their jobs, or that were seen as helping them develop their careers.

Although, as we saw above, almost $70 \%$ of those who would like to have a permanent contract did not think that it was likely that they would gain one within the next five years, the majority of the survey respondents saw having such a contract as central to their future working life. In fact, it appears to be slightly more important than career advancement strictly speaking, as the Chart 14 illustrates:

\section{Chart 14: Importance of gaining a permanent contract}

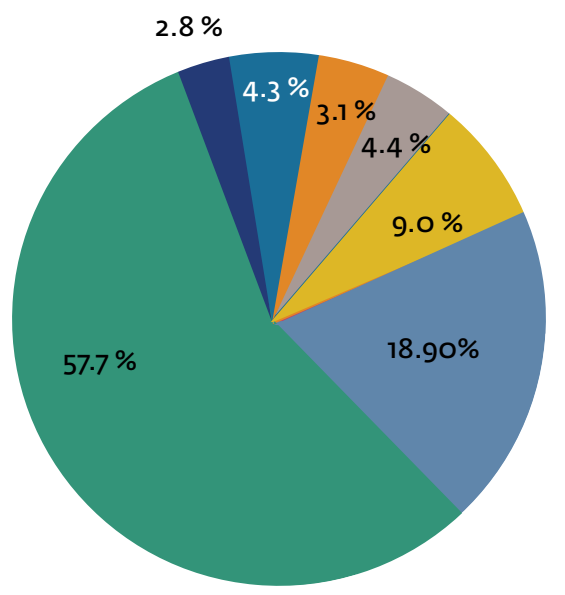

To have a permanent contract

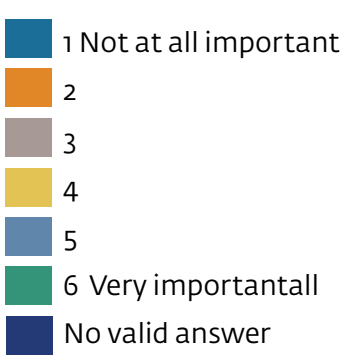

Note. 'When you think about the next five years, how important are the following aspects for your future working life?' 


\subsubsection{Views on the academic environment}

\section{A total of $\mathbf{6 9 . 7 \%}$ of respondents do not view academia as an enabling environment to pursue their academic careers. These are some of the reasons why:}

'Because of labor laws [in my country] requiring that employees who work longer than two years must be hired permanently, there are structures in place that make it very difficult for people to find employment (especially in academia) for longer than two years, because employers are hesitant/don't have the funds to commit to taking anyone and everyone on long-term. Once you receive a permanent position in [my country's] academia, you have a very comfortable situation. But the period of time in between receiving your PhD and/or a post-doc, and finding some kind of secure, stable, long-term employment, is extremely precarious in this country'.

'Although my conditions are very satisfactory right now, precarious employment is a reality for many of my colleagues; rare are those who are still even hoping for a long-term position. I feel more satisfied since I gave up on that idea completely'.

'In [my country], the tendency is now to move towards a more merchandised higher-education system, which is very damaging to the work environment and the potential positions to putative PhDs. As a result, I'm considering if I really will work on a habilitation: where could new doctors be employed in the coming years?'

'Too few employment opportunities for too many persons. Very short-term contracts abound, usually for 2 years'.

'I have received a huge research grant from a funding body, which makes me optimistic about the future. However, this does not guarantee that I will be able to get an associate professorship (in a place of commutable distance from my home and family), but it gives me the possibility of another three years of full-time paid work in academia and the possibility of a paid maternity leave, for I am grateful. It worries me that even associate professorships are increasingly not permanent positions in [my country] and because of cut downs on higher education in [my country], associate professors are also laid off from time to time (several have recently been fired in the department where I am currently employed). So I am secured in the near future, which is a huge relief, but I expect that future employments will continue very uncertain [sic.] and that the workload, which is tough as it is, will only get worse'.

'There are only a few permanent positions, most of them on the level of professorships, and we are a small subject so those positions only seldom become available. In addition, because of the German Wissenschaftszeitvertragsgesetz, after obtaining a MA, one can only be employed in temporary contracts for up to 12 years which de facto for many persons leads to an employment ban after this time has been completed'.

'The academic system in [my country] produces vastly more PhDs than can ever hope to get a permanent position. This means for every job that is advertised, your chance of even getting an interview is very low. This is compounded by the fact that many of the tasks that had been previously done by permanent 
staff (teaching, committee work, etc) are now done by temporary staff, so there is no incentive for universities to hire sufficient permanent staff to meet their needs. This is further complicated by the fact that each hiring cycle is idiosyncratic, in the sense that what counts in a candidate's favour in one case, may be irrelevant or even a liability in another application. These are all structural issues that have been growing for some time and that individuals cannot affect on their own'.

\section{5-3.4 Summary}

The main finding of this section is that in terms of employment prospects most members of EASA are very pessimistic: almost $70 \%$ did not see academia as an enabling environment for pursuing their academic careers. In total, $68 \%$ of those who wanted a permanent job thought it unlikely (42\%) or very unlikely (26\%) that they would secure one within five years. A total of $4 \%$ were planning to leave academia within the same period. Nevertheless, respondents were still committed to advancing their academic careers, and reported accepting temporary, part-time jobs, and willingness to change workplaces and even countries or to work significantly overtime to achieve such a goal. 


\section{Combining work and private lives}

\subsection{Income}

\subsubsection{Sources of income}

To cover their monthly expenses, respondents often had to rely on sources and streams of income other than wages. In the month before the survey, $23.2 \%$ relied on money from their partners and $10.8 \%$ on money from their relatives. The numbers stay comparably high even when students are removed from the sample: $\mathbf{2 2 \%}$ of non-students reported depending on support from their partners and $\mathbf{9 . 7 \%}$ from their relatives. There are no significant gender-based differences, although fewer women than men (a five\% difference) relied on income from one full-time job, an inheritance or endowment (a four\% difference).

Table 21: Answers to the question 'In the last month, how did you cover your living expenses? (Select all that apply)', according to gender, as percentages (\%)

\begin{tabular}{|lccccc}
\hline & & \multicolumn{3}{c}{ Respondents (excl. students) } \\
\hline Overall & Overal & Women & Men & Other \\
\hline Wage from one full-time job & 59.3 & 64.9 & 63.2 & 68 & 61.7 \\
\hline $\begin{array}{l}\text { Wages from more than } \\
\text { one full-time job }\end{array}$ & 3 & 3.2 & 2.4 & 3.6 & 11.8 \\
\hline Wage from one part-time job & 15 & 14.8 & 14.6 & 15.6 & 14.7 \\
\hline $\begin{array}{l}\text { Wages from more than } \\
\text { one part-time job }\end{array}$ & 10.5 & 10 & 11 & 9.3 & 2.9 \\
\hline Benefits or pension & & & & & \\
\hline $\begin{array}{l}\text { Inheritance or endowment } \\
\text { Help from my partner/spouse }\end{array}$ & 4.1 & 4.4 & 3.3 & 7.1 & 0 \\
\hline Support from relatives & 10.8 & 9.7 & 9.1 & 10.2 & 14.7 \\
\hline Support from friends & 0.7 & 0.4 & 0.7 & 0 & 0 \\
\hline Other & 12.2 & 7.6 & 7.9 & 6.7 & 11.7 \\
\hline
\end{tabular}

A total of $12.2 \%$ of respondents chose 'other' sources of income. Unsurprisingly, most of these (around 37\%) constituted diverse scholarships, stipends and fellowships. More worryingly, $21 \%$ relied on their savings from previous employment or projects. This is hardly sustainable in the long run, and several have noted that their savings were 'running dry'. Another significant alternative source of income for respondents (around 13\%) was freelance jobs, such as copyediting, working on NGO projects or writing commercial articles. 
As discussed above, among those employed in academia one quarter (25.5\%) held more than one contract within or outside academia. Indeed, only $\mathbf{4 2 . 7 \%}$ of respondents reported covering their living expenses solely from wages from one full-time job, $4.7 \%$ only from wages from one part-time job, and $2 \%$ reported living only on welfare benefits. We should be mindful, however, that this does not mean that this single stream of income was sufficient to live on - some respondents may have been running up debts, for instance, at the moment of the survey.

\subsubsection{Income averages}

Income was (as it often is) an uncomfortable terrain to survey. A total of 782 respondents gave information regarding their gross monthly income. To make sense of it, this data needs to be looked at in a wider context and comparatively. We converted all local currencies to euros. We selected the countries with at least five valid answers and looked at the distributions of incomes and compared them with (i) the other sets of responses, and (ii) the data on incomes in the respondents' respective countries.

Several observations must be made about the data itself. As is expected with online surveys, the questions on income included many erroneous answers. It is probable, for instance, that some of the respondents gave their annual, rather than monthly income. It is even more likely that some gave their net (after tax), rather than gross monthly income. Yet again, some of the answers were plainly incorrect, due to causes we could not identify (e.g. monthly incomes of 2.4 euro). Ultimately, the number of cases that could be included in the analysis was 540 . Because of the aforementioned issues, the seemingly valid data needs to be taken with a grain of salt.

Once lists for each country had been made, individuals with no income and outliers that were clearly incorrect answers - i.e. values that were too small or far too large to plausibly be a monthly income - were excluded from the analysis. The degree of plausibility was evaluated on a country-by-country basis. There are also limits to the data because different levels of taxation may mean that comparisons between gross incomes are not fully nuanced. Also, we looked at absolute euro values rather than purchasing power parity, thus thinking of our respondents in this line of work as global citizens, rather than as strictly confined within their countries' specific economic conditions. There were large variations in the numbers of cases per country - from six to 97 for the 21 countries. Despite the data's limitations, this was a unique opportunity to gain a glimpse at anthropologists' incomes.

As expected, Russia and the few countries from East Central and South East Europe (those for which there was a sufficient number of cases) had the lowest incomes. At the other end of the spectrum, there are the West and North European countries, and more specifically the Nordic countries. The highest average incomes were in Switzerland.

The average monthly incomes of EASA respondents by country varied between below 1000 euros a month (Russia 899 euros, Czech Republic 935 euros) to more than 4500 euros a month (Denmark 4567 euros, Switzerland 4707 euros). In some countries, these 
averages were below the average monthly income for the country (as mentioned before, this can be affected by the fact that some respondents might have given their net instead of gross income). In others, they were well above country averages.

Chart 15: Average gross monthly income compared with country average incomes

(in EUR)

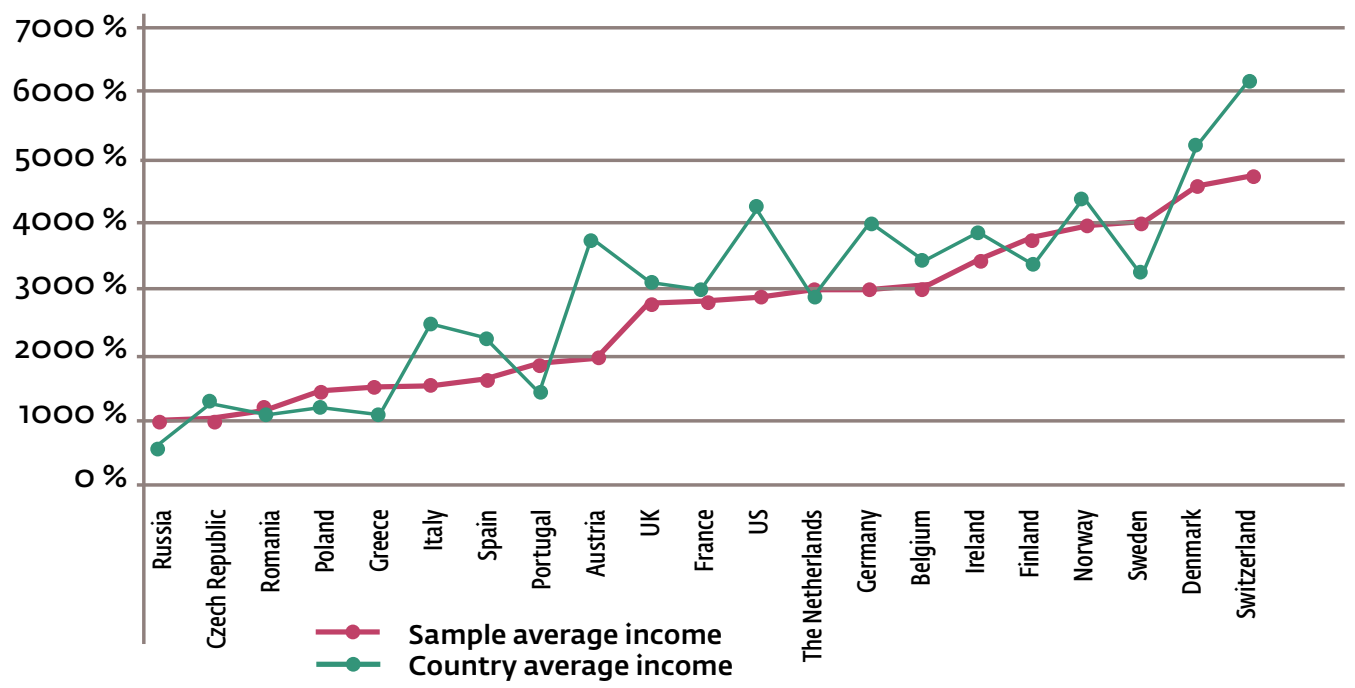

Given the high level of education and highly qualified positions of most EASA respondents, we would expect their average incomes to be consistently above national averages, especially as some of the respondents were well advanced in their careers and we expected professorships, in probably all countries, to be well remunerated. However, the relationship between average EASA incomes and average national incomes varies a lot from one country to another. Only in eight out of 21 countries were our respondents' average incomes above national averages. The differences ranged from 807 euros above the national average in Sweden to 1912 euros below the national average in Austria. Again, given the relatively small number of respondents and the likelihood of people giving net rather than gross incomes, the data should be understood as offering a preliminary insight only. A more nuanced survey focused on income is needed.

Chart 16: Difference between gross monthly income and national average incomes (in EUR)

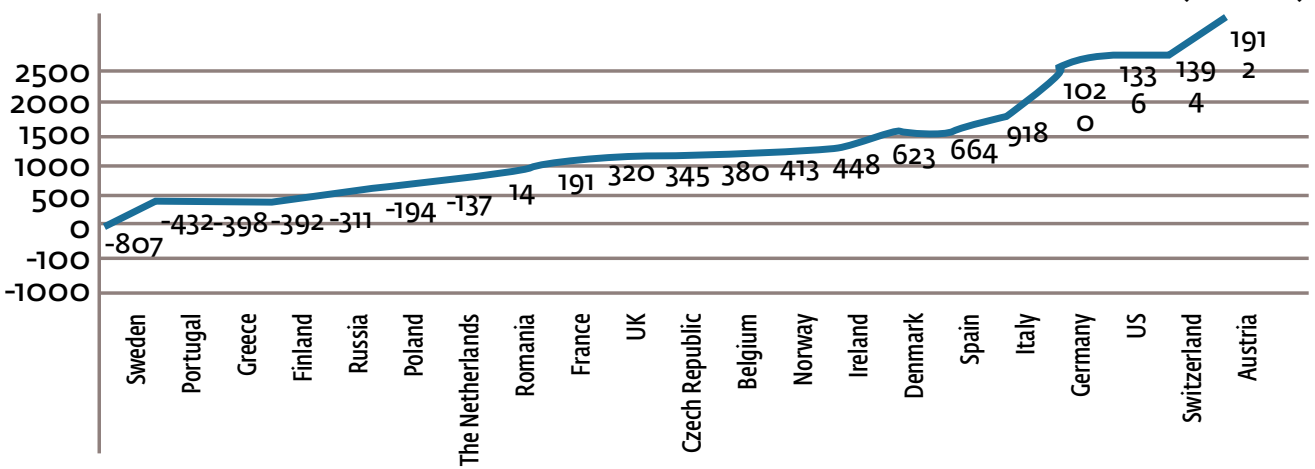


Since salaries, especially in academia, change significantly depending on one's position, the distribution of incomes varies within each country. Mean incomes can hide sets of cases that consist of very low and/or very high incomes that have little connection to the average. A much-needed measure of income inequality is difficult to attain with a small number of cases. The coefficient of variation (CV) was the most appropriate instrument. ${ }^{62}$ The country CVs provided in the table below might appear a little counterintuitive at first sight. For our sample, the most equal countries in terms of income distribution are Sweden, Denmark, Russia, Romania and Finland, i.e. high income countries with low levels of inequality and lower-income countries with high levels of inequality. This is in fact very straightforward: it is likely that the individuals from Russia or Romania who could afford to be EASA members or attend EASA conferences were those already in the higher-income brackets for their country. Therefore, what is being measured here is not the inequality of incomes between anthropologists in Russia and those in Romania, but the inequality in incomes between anthropologists in Russia and those in Romania who were EASA members in 2018 (and who could be expected to be better off). At the other extreme, two other relatively lower-income countries in our sample, Poland and Portugal, seem to have been represented by both lowerincome and higher-income scholars, and this has led to high measures of income inequality.

In other words, given the specificities of the context, for our EASA sample, the CV works as a measure of income inequality for some higher-income countries (in our sample, for high income countries post-doctoral fellows constituted around 30 to $40 \%$ of respondents, and full professors around 10\%), but for many lower-income countries it serves more as a mechanism to show what income categories of anthropologists (can afford to) join EASA and (can afford to) attend EASA conferences.

\section{Chart 17: Income inequality among EASA members, by country, measured through the coefficient of variation (CV)}

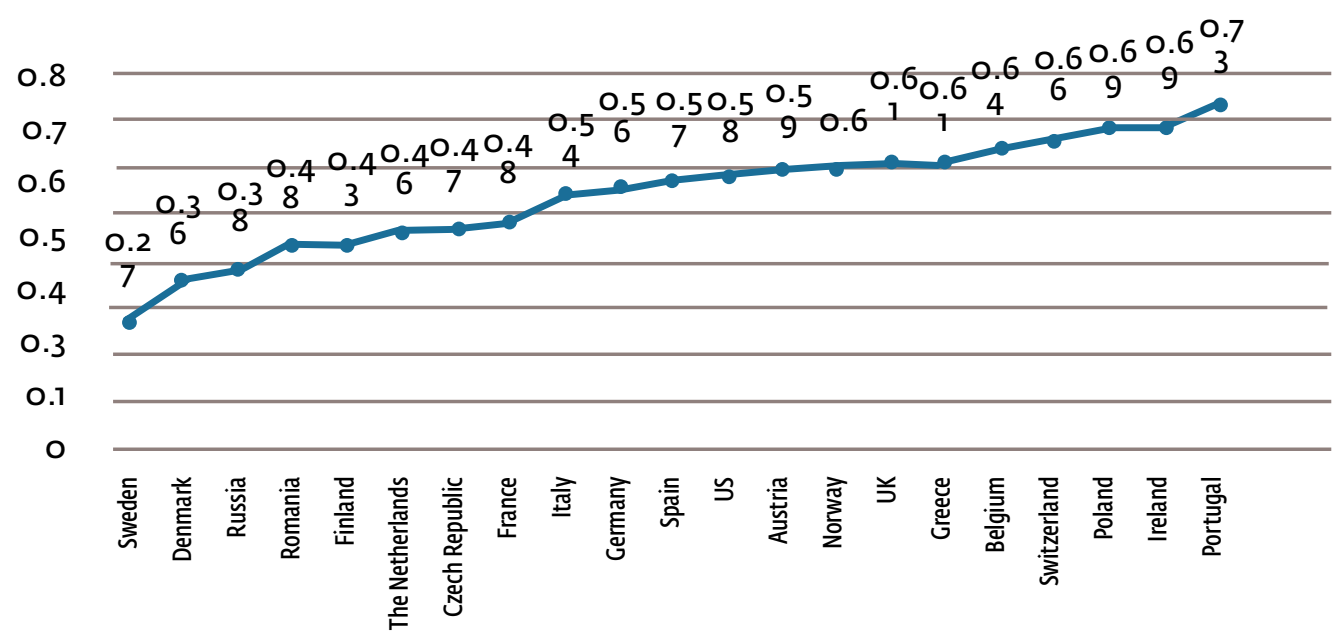

\footnotetext{
62 The coefficient of variation (CV) is a rather straightforward indicator, calculated by dividing the standard deviation (i.e. the mean deviation from the mean) of the income distribution by its mean. The CV rather than standard deviation was used as it provided a standardised measure for each country that was not influenced by the absolute size of income, which was important as incomes are so different among the countries in our sample. Because there is a natural o when it comes to incomes and all cases were measured in the same unit (euros), the CV is quite appropriate for describing our sample's income distribution. The more equal an income distribution is, the lower its standard deviation, and the lower the CV. Conversely, a high CV indicates a very unequal distribution.
} 


\subsubsection{Employment-related benefits}

The survey asked the respondents what benefits their academic contract(s) provided them with.

Table 22: Benefits provided by academic contracts, as percentages (\%)

\begin{tabular}{|l|l|}
\hline Benefit & Responses \\
\hline Healthcare & 56.1 \\
\hline Private health insurance & 10.8 \\
\hline Statutory accident insurance & 31.1 \\
\hline Unemployment benefits & 51.8 \\
\hline Maternity leave & 52.4 \\
\hline Maternity benefits or pay & 37.1 \\
\hline Paternity leave & 32 \\
\hline Paternity benefits of pay & 22.9 \\
\hline Childcare services & 8.4 \\
\hline Pension insurance contribution & 72 \\
\hline Supplementary pension insurance contribution & 18.4 \\
\hline Redundancy payment & 10.6 \\
\hline Sick days & 68.9 \\
\hline 13th/13th \& 14th salary [end of year bonus] & 28.8 \\
\hline Contribution to holidays & 33.8 \\
\hline
\end{tabular}

Certainly, although 604 respondents (74.7\%) answered the above question, it is hard to draw any conclusions from the above, unless one does it on a country-by-country basis, since welfare provisions differ according to countries (e.g. the 13th salary is common in some, absent in others; the NHS in the UK is not funded through insurance). ${ }^{63}$ In addition, there was a $15 \%$ non-response rate to the above questions. Nevertheless, only $65.7 \%$ of those in academia and $62.5 \%$ overall, and $\mathbf{4 5 . 3 \%}$ below the age of 40 said they were provided with parental leave, which might make it difficult to 'decide freely and responsibly the number, spacing and timing of their children'. ${ }^{64}$ In addition, for $28 \%$ of those who responded to the above question, their employment did not come with any contributions towards pensions.

\footnotetext{
${ }^{63}$ Moreover, since the survey did not provide a 'no' option, the percentages only represent those who confirmed they get these specific benefits and we can only make assumptions about the rest.

${ }_{64}$ UNDP. (1968). Resolution XVIII: Human rights aspects of family planning, final act of the international conference on human rights. U.N. Doc. A/CONF. 32/41. (p.15) Retrieved from

https://legal.un.org/avl/pdf/ha/fatchr/Final_Act_of_TehranConf.pdf.
} 


\subsubsection{Income and quality of life}

While the respondents considered that earning a (subjectively estimated) high wage was an important aspect of their work life, it was less important than having a permanent contract (see section 5.3 above) or maintaining a work-life balance (see 6.2 below).

\section{Chart 18: Importance of earning a high wage}

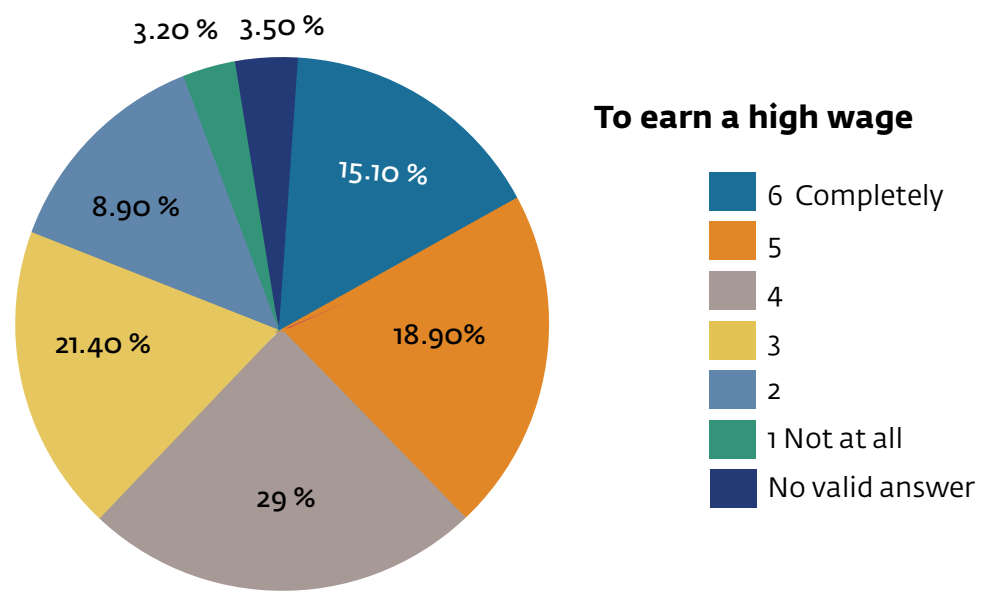

Note. 'When you think about the next five years, how important are the following aspects for your future working life?'

\section{In total, $\mathbf{4 5} \%$ of survey respondents felt that their income did not cover all their needs.}

\section{Chart 19: Income and expenses comparison}

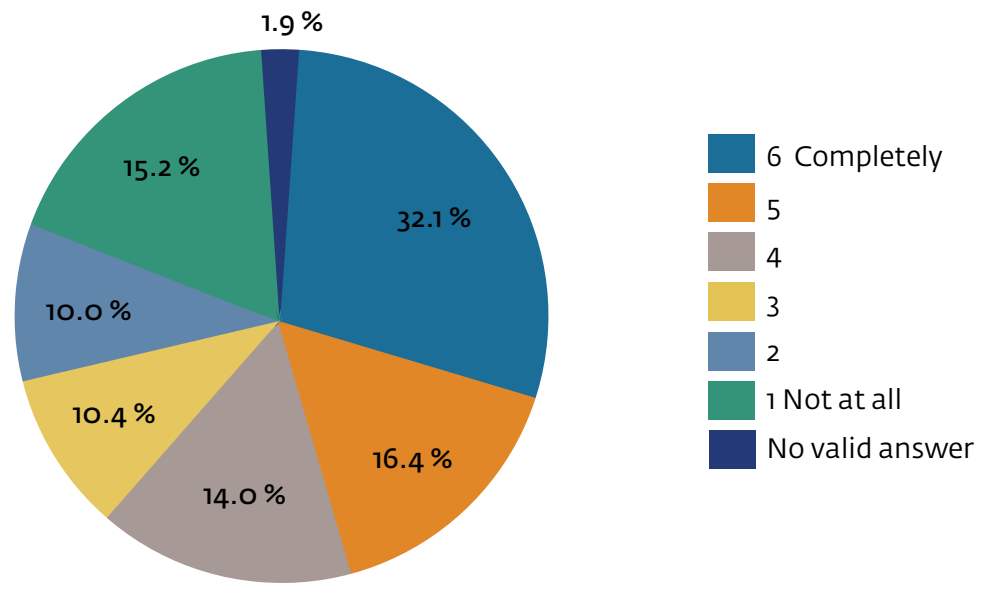

Note. 'My income covers all my needs'

Country scores, that is average values (from $1=$ the statement is not at all true, to $6=$ the statement is completely true) for countries with more than ten cases, which lay on two sides of the spectrum, were calculated. 
According to this country score, respondents living in Germany and Denmark were the most satisfied with how their earnings met their needs (average response value: 4.6), followed by Switzerland (4.5), Netherlands (4.4) and Belgium (4.1). The average for the UK, where a large proportion of respondents worked and lived, was 4.0. Earnings barely, if at all, met the average respondents' needs in Poland (3.4), Portugal (3.3), Czech Republic (3.3), Italy (3.3) and Romania (3.2). Italy, however, is unusual due to its extremes, which suggest a high degree of segmentation according to income in our sample: while $21 \%$ did not agree with the statement at all, $23 \%$ completely agreed with it.

\section{Only $18 \%$ of survey respondents agreed completely with the statement 'I have money left at the end of the month' and almost a further $\mathbf{2 5 \%}$ more or less agreed with this same statement.}

\section{Chart 20: Money left at the end of the month}

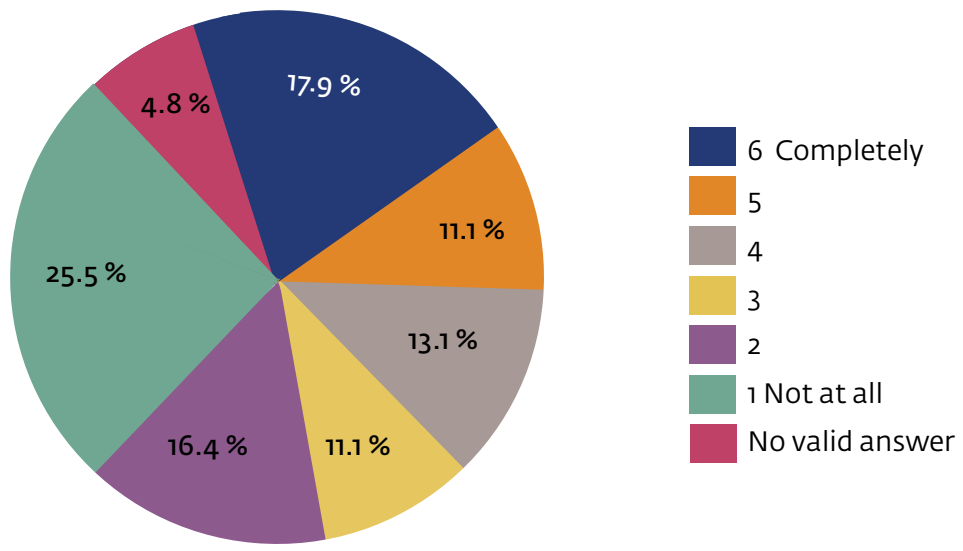

Note. 'I have money left at the end of the month'

Country averages were calculated, with answers scoring from $1=$ not at all agree with the statement 'I have money left at the end of the month', to $6=$ completely agree with the statement. They revealed that the respondents in Denmark were most likely to agree with the statement (country score 4.7), followed by Germany and Switzerland (both 3.6) and Netherlands (3.5). The lowest proportions of those who had savings at the end of the month lived in the Czech Republic (3), Poland (2.8), Italy (2.7), Romania (2.7) and Portugal (2.5). The UK country score was 3.6.

More worrisome, however, is the fact that many respondents - EASA members - were badly positioned to deal with unexpected events, such as disease, accidents, unemployment or situations like the current pandemic. Researching this was not one of our aims when we carried out the survey, but it has impacted significantly on precarious workers in academia. ${ }^{65}$

\footnotetext{
${ }^{65}$ See Zahneis, M. (2020). Covid-19 crisis widens divide between secure and insecure instructors. The Chronicle of Higher Education Retrieved from

https://www.chronicle.com/article/the-covid-19-crisis-is-widening-the-gap-between-secure-and-insecure-instructors/.
} 
A total of $60 \%$ of respondents did not think they would be able to handle a major unexpected expense. A total of $27 \%$ would be 'not at all' able to manage such an expense.

Chart 21: Ability to manage a major unexpected expense

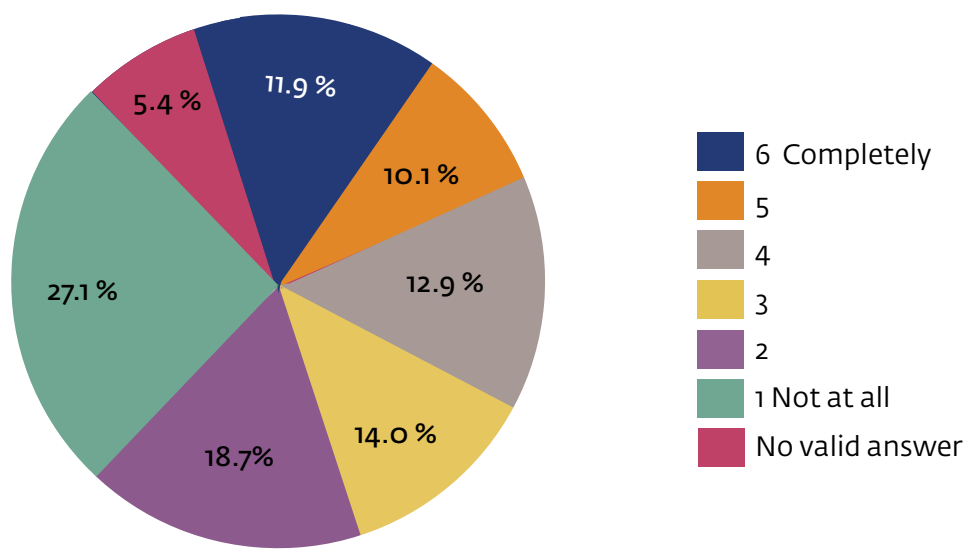

Note. 'I could manage a major unexpected expence'

Country scores (averages) as a proxy for such vulnerability and thus for the lack of savings, reveal that scholars most vulnerable to unexpected events lived in Portugal (1.82), Belgium (1.91) and Greece (2), followed by Poland (2.15) and Romania (2.1). The average value for the Czech Republic is 2.7 and for Italy, it is 2.4 . The least vulnerable respondents lived in the Netherlands (3.7), Denmark (3.68), Switzerland (3.6) and Germany (3.2). The UK country average was 2.78 .

The data suggest the existence of East-West and North-South divides. In terms of the income, what can be done with it, and how much of it can be saved, the worst off were the respondents living in East Central and South East Europe. Portugal, Poland and Romania scored among the lowest five on all three statements. They were followed by Italy and the Czech Republic, which were among the five countries that scored the 'lowest' five on two. Of course, one has to bear in mind that there are exceptions (e.g. Belgian scholars who scored low on the perception of their ability to financially deal with unforeseen events) and that for most countries we did not have enough cases to calculate such averages.

The most vulnerable respondents were temporary teaching fellows or instructors. This is something that departments have to keep in mind when hiring seasonal or hourly paid tutors or lecturers or, even more pressingly in today's context, when reallocating work and otherwise in response to the pandemic. Temporary teaching fellows were more vulnerable than any other cohort, including post-docs or doctoral students. A total of $68.8 \%$ 
of temporary teaching fellows did not agree with the statement 'my income covers all my needs', $28.1 \%$ did 'not at all' agree. In comparison, among post-docs the percentages were $26.9 \%$ and $5.26 \%$, among assistant professors and lecturers they were $36.4 \%$ and $9.3 \%$, among associate professors and senior lecturers they were $24 \%$ and $7 \%$, and among professors they were $5.4 \%$ and $2.7 \%$. Relatedly, $80.7 \%$ of teaching fellows or instructors did not agree with the statement that 'I have money left at the end of the month', and almost half (48\%) did 'not at all' agree with the statement. Similarly, only $6.25 \%$ thought they were 'completely' in a position to deal with an unexpected expense and more than one half $-53.1 \%$ - were 'not at all' in such a position.

\subsubsection{Summary}

This section includes several noteworthy findings. First and foremost, many anthropologists and EASA members need to work multiple contracts to make an income and still many are not able to cover their expenses at the end of the month. Less than half of the respondents reported an ability to cover their living expenses solely with the wages from one full-time job. Over one fifth of EASA members also rely on parents and one tenth on family members to support them in making a living, and over one fifth could not at all face a major unexpected event. The most vulnerable were temporary teaching fellows or instructors, $68.8 \%$ of whom did not agree with the statement 'my income covers all my needs'. Less than half the members below the age of 40 said that they were provided with parental leave, which made having children a difficult choice.

The findings vary between positions on the career ladder, with teaching fellows and instructors being in the most vulnerable positions and barely able to meet their minimum income needs. Furthermore, an East-West and North-South divide persists in anthropology to a very large extent when it comes to income. As a somewhat tentative conclusion, in terms of income and ability to meet basic necessities and unexpected events, the best off were Germany, Switzerland and the Netherlands, and the worst off were the respondents living in Portugal, Poland and Romania. The former three countries scored the highest and the latter three scored the lowest on all three statements (followed by Italy and the Czech Republic, who were among the 'lowest' five in both dimensions). It should be recalled, though, that for most countries we did not have enough cases to calculate such averages.

\subsection{Combining work and family life}

\subsubsection{Academics' family situation}

A total of $80 \%$ of respondents were in a relationship. The survey did not ask if they shared a household with their partner or partners. 
Table 23: Legal marital status, as percentages (\%)

\begin{tabular}{lc} 
Status & Responses \\
\hline Married, registered partnership, civil union or similar & 56 \\
$\begin{array}{l}\text { Single, never married or in (legally recognised) } \\
\text { registered partnership or civil union }\end{array}$ & 35.1 \\
\hline Divorced or dissolved legal partnership status & 8.4 \\
\hline Widowed or surviving civil partner & 0.5
\end{tabular}

A total of $37 \%$ of respondents were regularly responsible for children aged 17 or below, and the average child age was 7.8 years.

In $22.7 \%$ of cases, there were adults aged 18 and above who were financially dependent on respondents (regardless of whether they lived in their household), and in $22.2 \%$ of cases, respondents had caring responsibilities for such adults.

\subsubsection{Class background}

The parents of respondents were educated to levels far above OECD averages. About $60 \%$ of survey respondents' parents had completed tertiary education. ${ }^{66}$ A total of $16 \%$ of fathers/parent 1 and $6.4 \%$ of mothers/parent 2 had a doctoral degree.

Table 24: Educational level of parents, as percentages (\%)

\begin{tabular}{|lcc|}
\hline Educational level & Father/parent 1 & Mother/parent 2 \\
\hline Not completed primary education & 1.5 & 1.7 \\
\hline Primary education & 7.2 & 7.6 \\
\hline Lower secondary education & 10.2 & 9.6 \\
\hline Upper secondary education & 12.6 & 13.6 \\
\hline Post-secondary non-tertiary education & 8 & 8 \\
\hline Short-cycle tertiary education & 3.8 & 8.4 \\
\hline Bachelor's or equivalent & 18.2 & 21.7 \\
\hline Master's or equivalent & 22.4 & 23.0 \\
\hline Doctoral degree or equivalent & 16.0 & 6.4 \\
\hline
\end{tabular}

${ }^{6}$ In 1998, $13.42 \%$ of 55-64 year-olds had completed tertiary education; in 2008, $21.51 \%$ and in 2018, 27.05\%. OECD (2O20). Population with tertiary education (indicator).

https://doi.org/10.1787/ob8fgoeg-en 
These values remain comparable with those among the current students - $56 \%$ of fathers/ parent 1 and $62 \%$ of mothers/parent 2 have completed tertiary education or higher (i.e. more than double the 2018 OECD average).

\section{Table 25: Educational level of parents as percentages, students only}

\begin{tabular}{|lcc|}
\hline Educational level & Father/parent 1 & Mother/parent 2 \\
\hline Not completed primary education & 0 & 0.8 \\
\hline Primary education & 4.7 & 6.3 \\
\hline Lower secondary education & 9.4 & 8.6 \\
\hline Upper secondary education & 18.8 & 15.6 \\
\hline Post-secondary non-tertiary education & 10.2 & 6.3 \\
\hline Short-cycle tertiary education & 3.1 & 7 \\
\hline Bachelor's or equivalent & 15.6 & 14.8 \\
\hline Master's or equivalent & 24.2 & 29.7 \\
\hline Doctoral degree or equivalent & 13.3 & 10.2 \\
\hline N/A & 0.8 & 0.8 \\
\hline
\end{tabular}

If we take the educational level of parents as a proxy for social class, we can conclude that almost two thirds of respondents came from middle-orupper-middle-classfamilies. Although we do not know the ages of parents and we cannot compare their education with that of the general population within the same age brackets, because the percentage of parents with tertiary education stands far above the OECD averages, we can surmise that scholars with a middle-class background are represented within the discipline in levels higher than those found in the overall population. This calls for reflection on two issues: (i) how students from working-class backgrounds are encouraged or discouraged to pursue university education, doctoral degrees and academic careers, not only in anthropology, and (ii) if the previous findings on income-related challenges and meeting expectations and feeling anxious about the future are valid for people from allegedly more secure, middle-class, backgrounds. This gives a rather bleak picture of the situation for working-class anthropologists. ${ }^{67}$

Beyond these points, a broader theoretical point can also be made, namely, that anthropology - as a discipline (e.g. in its liberal sensibilities and how it deals with difference) and also as a profession (e.g. how post-doctoral and doctoral support is organised) - continues to reproduce middle-class biases, and therefore experiences of scholars with working-class backgrounds remain invisible. This might also have to do with the structure of the academic profession that calls for a lot of investment in networking, self-promotion (with its gendered, classed and race-related rules of propriety) and un(der)paid labour ${ }^{68}$ that only those with a

\footnotetext{
${ }^{67}$ On experiences of working-class academics, see for example Crew, T. (2020). Higher education and working-class academics. Precarity and diversity in academia. Palgrave Pivot.

68 See Kendzior 2012; Busso, S., \& Rivetti, P. (2014). What's love got to do with it? Precarious academic labour forces and the role of passion in Italian universities. Recherches sociologiques et anthropologiques, 45(2), 15-37. https://doi.org/10.400o/rsa.1243.
} 
somewhat secure upbringing can afford without falling into debt. Anthropological fieldwork might add to that, given that across Europe fewer and fewer PhD programmes are offering full funding for the whole duration of the studies and support for fieldwork, but this is an open question for further research. Still, as one colleague wrote in the survey: 'Academia is highly homogeneous in terms of class. Colleagues with a middle-class background behave as if they assumed that no colleague can have a working-class background. It is like having an alien identity that only other aliens can see'.

\subsubsection{Subjective evaluations}

Respondents were asked to evaluate their overall satisfaction. Despite the financial insecurity described above, all in all, respondents were on average more or less satisfied with their lives.

\section{Chart 22: Life satisfaction}

$0.70 \%$

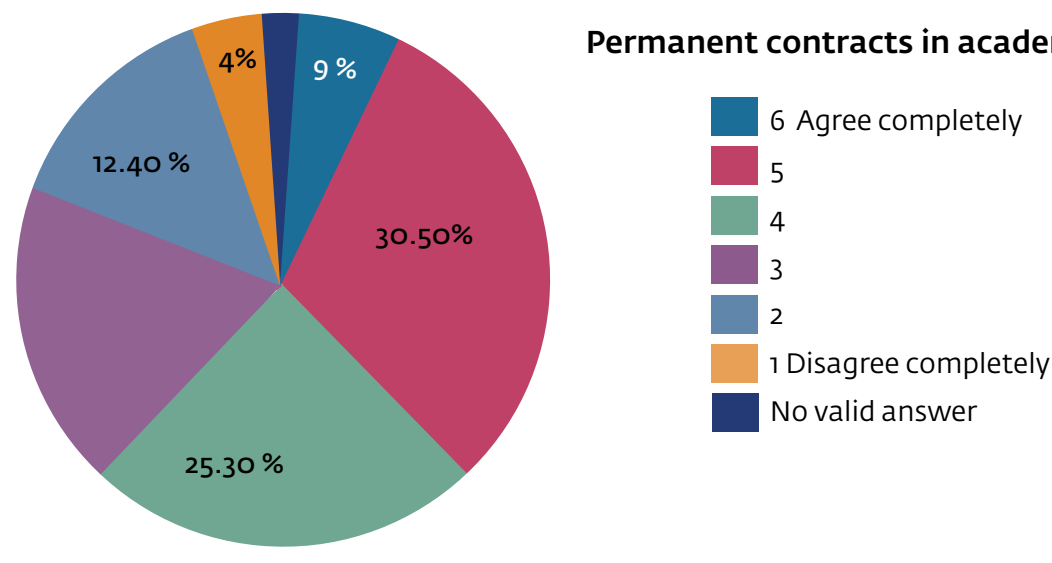

Note. 'I am competely satisfied with my work-life-balance and/or school-life-balance'

\section{Respondents also saw the maintenance of a good work-life balance as central to their life project.}

\section{Chart 23: Importance of a good work-life balance}

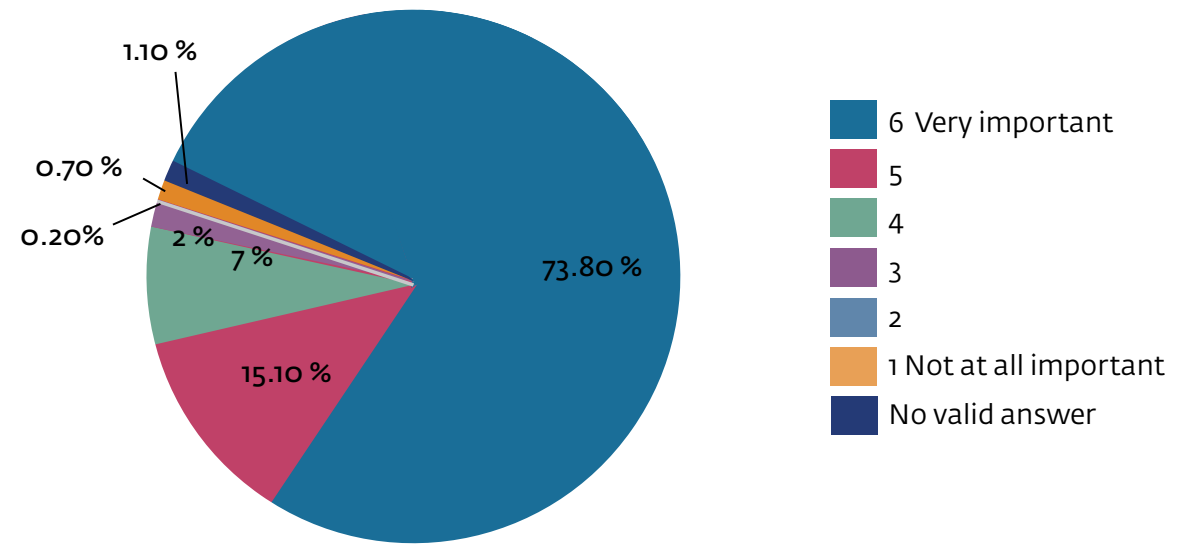

Note.'When you think about the next five years, how important are the following aspects for your future working life?' 
At the same time, this is not something that is easily achieved given the temporary nature of contracts that push scholars to constantly apply for other jobs, the lack of savings, increasing workloads and overtime, and demands on travel. Only around $\mathbf{4 1} \%$ were more or less satisfied with their work-life (school-life) balance.

\section{Chart 24: Satisfaction with the current work-life (school-life) balance}

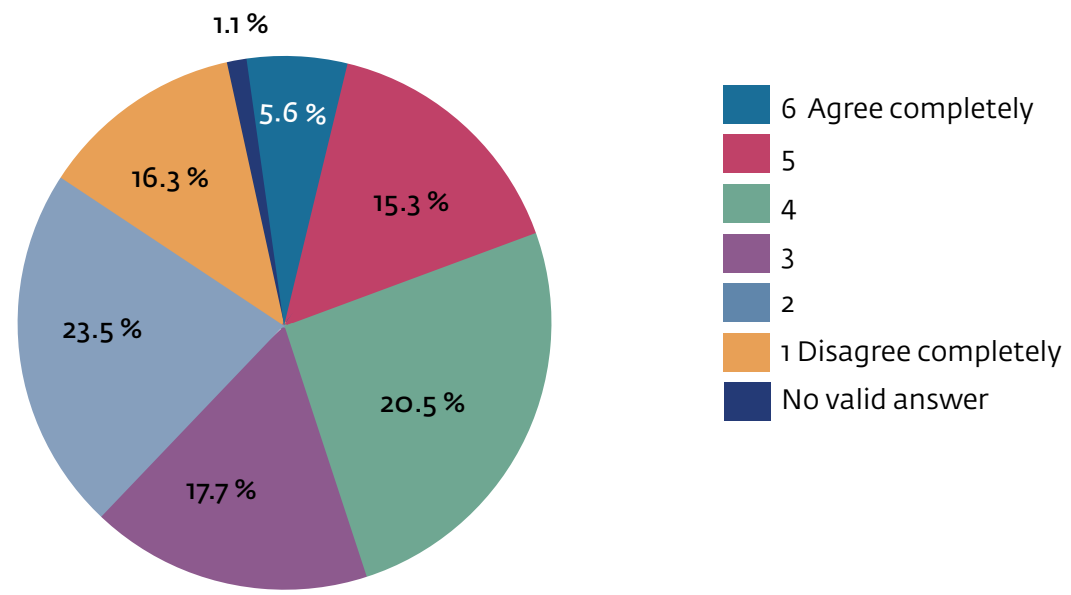

Note. 'I am competely satisfied with my work-life-balance and/or school-life-balance'

There does not seem to be any single strongest predictor for determining who were among the $16.3 \%$ of respondents who were the least satisfied with their work-life balance. These respondents did, however, have certain characteristics for which they lie slightly above or below the sample averages:

- $18.9 \%$ were research fellows/post-docs and $15.9 \%$ were assistant professors/lecturers (there were dissatisfied individuals in all categories, including $3.8 \%$ of full professors) $10.5 \%$ had more than two work contracts

- $40 \%$ did 'career development work' of ten hours or more a week (the sample average was 6.5 hours)

- $33.3 \%$ aspired to a permanent academic contract, but thought it either unlikely or very unlikely within the next 5 years (compared with $68 \%$ in the total sample) $72 \%$ were women (compared with $62 \%$ in the total sample)

- $72.7 \%$ had a partner and $35.6 \%$ had children (compared with $80 \%$ and $37 \%$ in the total sample)

- $63.8 \%$ of those with children had children under 10 years old and $19 \%$ had two or more children

- $4 \%$ were over 40 years old (in the total sample the number was $47 \%$ )

- $58.3 \%$ commuted daily or several times a week (compared with $74.4 \%$ in the total sample). 
Being dissatisfied with one's work-life balance, then, was more common among: women, those who did a lot of career development work, those over 40 years old, and those with no partner. When compared with the general sample, those aspiring to a permanent contract yet viewing it as unlikely, as well as those commuting more than several times a week to work were less commonly found among those with a poor work-life balance. However, this may be changing with the mass introduction of working from home, which may positively affect those without caring responsibilities, but negatively affect those with such responsibilities, thus particularly exacerbating gender inequalities. ${ }^{69}$ Maybe most surprisingly, those least satisfied with their work-life balance are just as likely to have children as not in the overall sample.

When students are removed from the sample, we can see that those on permanent contracts were somewhat more satisfied than those on fixed-term contracts.

\section{Chart 25: Permanently employed academics' satisfaction with their current work-life balance}

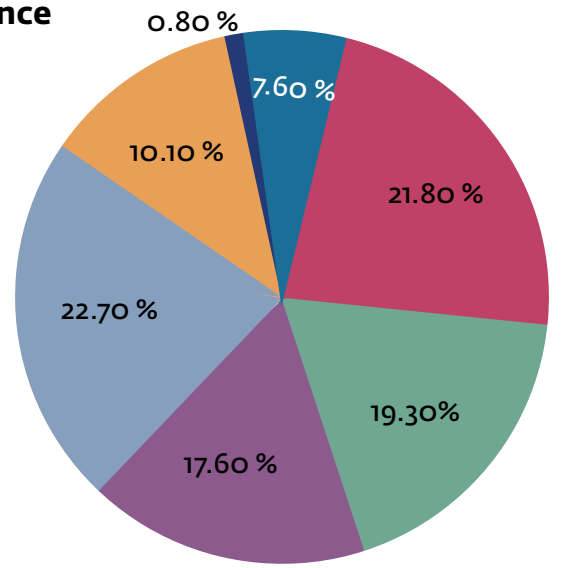

Permanent contracts in academia

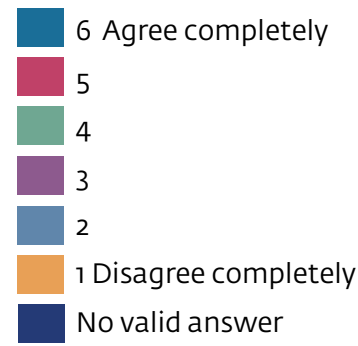

Note. 'I am competely satisfied with my work-life-balance and/or school-life-balance'

\section{Chart 26: Satisfaction with their current work-life balance among academics on temporary contracts (students excluded)}

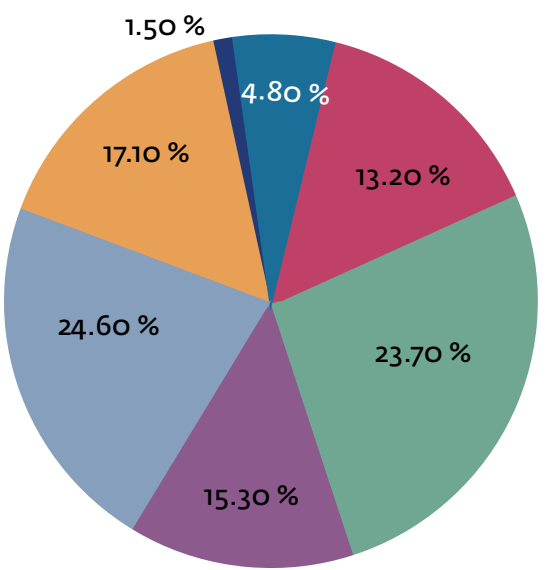

Temporary contracts in academia, non-students only

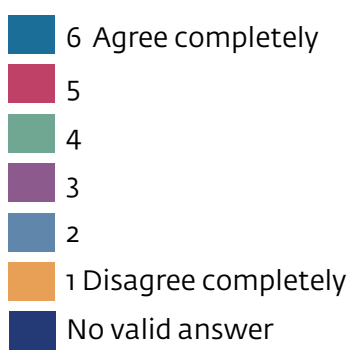

Note. 'I am competely satisfied with my work-life-balance and/or school-life-balance'

\footnotetext{
${ }^{69}$ Viglione, G. (2020). Are women publishing less during the pandemic? Here's what the data say. Nature, 581(7809), 365-366. https://doi.org/10.1038/d41586-020-01294-9. 
On average the gender-based differences are negligible (when answers 1-3 are added up men were somewhat less satisfied with their work-life balance). There are, however, significant differences at the extreme poles. A total of $18.7 \%$ of women were completely dissatisfied with their work-life balance in comparison with $11.1 \%$ of men. ${ }^{70}$ Only $3.8 \%$ of women in comparison with $6.7 \%$ of men were completely satisfied. At the same time, of those who preferred to describe their gender in alternative ways or who preferred not to disclose it ('Other' throughout the survey), over $20 \%$ disagreed completely with the statement, while almost $15 \%$ agreed completely.

\section{Chart 27: Women's satisfaction with their current work-life (school-life) balance}

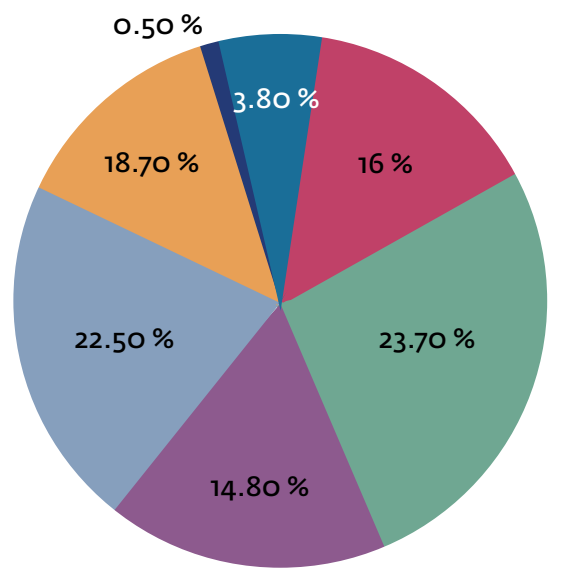

\section{Women}

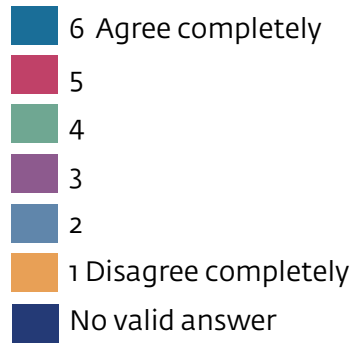

Note. 'I am competely satisfied with my work-life-balance and/or school-life-balance'

\section{Chart 28: Men's satisfaction with their current work-life (school-life) balance}

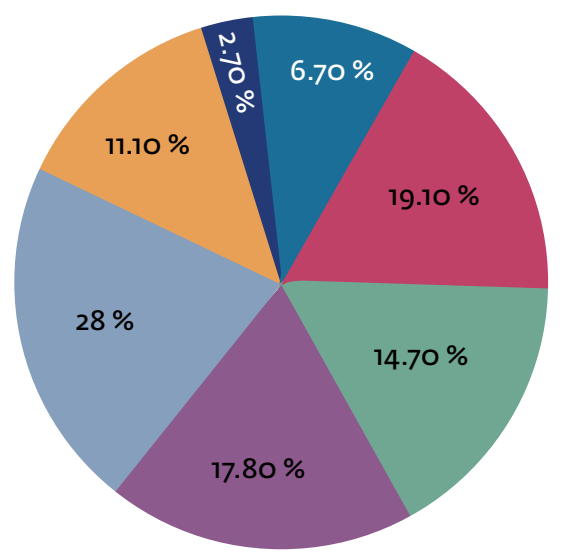

Men

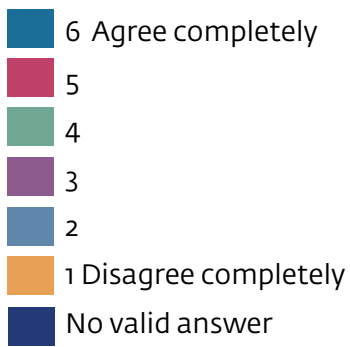

Note. 'I am competely satisfied with my work-life-balance and/or school-life-balance'

\footnotetext{
70 When answers $1 \& 2$ are added up, differences are reduced although women disagree more completely with the statement than men: $41.2 \%$ of women versus $39.1 \%$ men.
} 


\section{Chart 29: Satisfaction with their current work-life (school-life) balance among those who preferred not to disclose gender or who identified their gender as outside the gender binary}

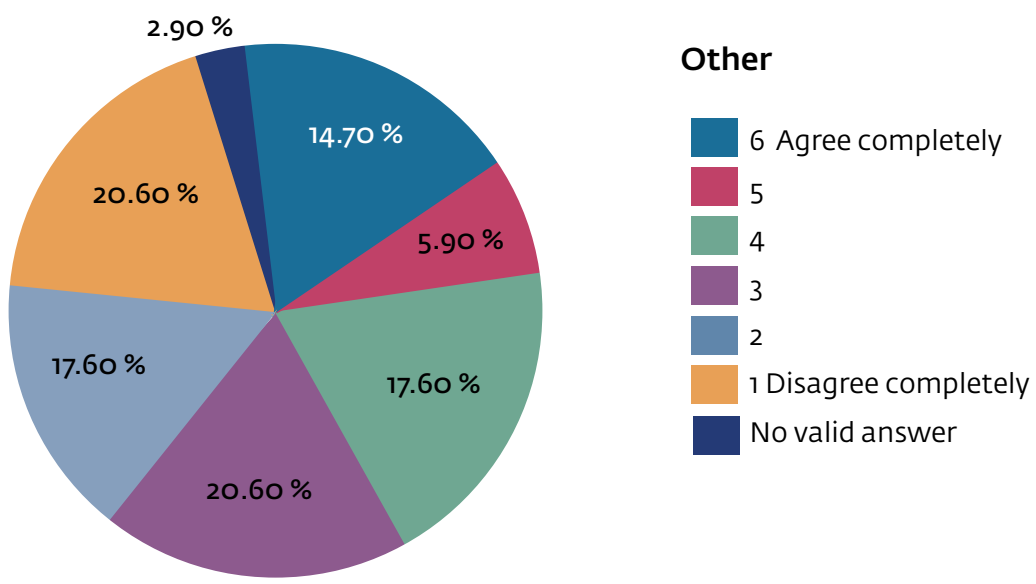

Note. 'I am competely satisfied with my work-life-balance and/or school-life-balance'

\subsubsection{Summary}

Two thirds of respondents came from middle-class families, which is telling of anthropology as a discipline as well as for academia as a career choice. If experiences of insecurity, overwork and anxiety about the future are frequent among those from more secure backgrounds, there should be a greater concern about how little protection, job satisfaction and ability to negotiate workloads those coming from working-class families can afford.

Combined with the increase in student fees and the decrease in support for PhD studies, the costs of conference attendance and fieldwork, as well as the broader cuts that anthropology has experienced in the neoliberal era and with the 2008 crisis, $^{r}$ these findings call for reflection: they posit the serious and urgent question of how students from working-class backgrounds are encouraged or discouraged to pursue university education, doctoral degrees and academic careers, not only in anthropology.

Another important issue relates to work-life boundaries. While the majority of the respondents were relatively satisfied with their lives, many saw the maintenance of a good work-life balance as central to their life project, and they reported experiencing challenges with this. Only around $41 \%$ were more or less satisfied with their work-life (school-life) balance. Women, colleagues with partners and children under 10 years of age, and those commuting to work were among those with the highest levels of dissatisfaction concerning an unhealthy work-life balance.

\footnotetext{
${ }^{71}$ Koch, I. (2018). Towards an anthropology of global inequalities and their local manifestations: Social anthropology in 2017. Social Anthropology, 26(2), 253-268. https://doi.org/10.1111/1469-8676.12520.
} 


\section{Mobility}

The previous section discussed some issues that arise when work is combined with family life. Work-family conflict is one of the most important aspects of job dissatisfaction and the most significant predictor for burnout. An imperative for international mobility, in its various iterations, can contribute significantly to such a conflict.

This section looks at the two main forms of mobility - commuting to work and academic mobility..$^{22}$ For instance, those with caring responsibilities prefer to live within a commuting distance, which may not always be possible. It is expected of academics - especially, but not exclusively, at early stages in their careers - that they gain experience of different workplaces, and international mobility within and beyond the EU has been one of the key priorities in many programmes offered within the union. ${ }^{73}$ While this may be promoted (e.g. via funding streams) as a way of gaining skills and expertise or as a route to further international collaboration, given the predominance of short-term contracts and the simultaneous scarcity of permanent contracts, individuals may in fact have little choice when making a decision to accept another post. At the same time, this may conflict with other life aspirations and put a strain on existing familial and intimate arrangements.

The following sections describe both types of mobility and how the respondents saw them.

\subsection{Workplace commuting}

\subsubsection{Commuting frequency}

A total of $91.6 \%$ of respondents responded to at least one of a series of questions that enquired into how they commuted or otherwise travelled to places of primary academic employment, study, fellowship etc.

The majority $(\mathbf{7 4 . 4 \% )}$ commuted daily or several times a week to their place of academic employment, study, fellowship etc.

Table 26: Frequency of commute to academic workplaces, according to gender, as percentages $(\%)$

\begin{tabular}{|lcccc|}
\hline Frequency & Overall & Women & Men & Other \\
\hline Daily & 35.9 & 32.7 & 41.1 & 41.5 \\
\hline Several times a week & 38.5 & 38.4 & 38.9 & 36.6 \\
\hline Once a week & 6.1 & 7.1 & 4.7 & 2.4 \\
\hline Several times a month & 6.3 & 7.1 & 4.7 & 7.3 \\
\hline Once a month & 3 & 3.5 & 2.1 & 2.5 \\
\hline
\end{tabular}

${ }^{72}$ We should add here that the current pandemic as well as its consequences - such as the push to expand online teaching might ease some of these conflicts, while intensifying existing one, and also giving rise to new forms (e.g. Currie, J., \& Eveline, J. (2011). E-technology and work/life balance for academics with young children. Higher Education, 62(4), 533-550. https://doi.org/10.1007/s10734-010-9404-9).

${ }_{73}$ Tzanakou, C. (2017). Dual career couples in academia, international mobility and dual career services in Europe. European Educational Research Journal, 16(2-3), 298-312. https://doi.org/10.1177/1474904116683185. 


\begin{tabular}{|lcccc|}
\hline Several times a year & 5.9 & 6.5 & 5.1 & 4.9 \\
\hline Once a year & 1.4 & 1.3 & 1.3 & 2.4 \\
\hline Never & 2.9 & 3.4 & 2.1 & 2.4 \\
\hline
\end{tabular}

When only those whose primary status was 'employed in academia (at a university, research institution or similar)' are included, $79.1 \%$ commuted daily or several times a week. While the situation has recently changed radically because of the pandemic and it is hard to predict the post-pandemic future, in 2018 such frequent commutes would have been expected of most academics, at least officially. Men tended to commute to the workplace somewhat more frequently.

Table 27: Frequency of commute to the workplace of those employed in academia as primary employment, according to gender, as percentages (\%)

\begin{tabular}{|lcccc|}
\hline Frequency & Overall & Women & Men & Other \\
\hline Daily & 37.3 & 34.2 & 40.7 & 50 \\
\hline Several times a week & 41.8 & 42 & 42.9 & 32.4 \\
\hline Once a week & 6.8 & 8.5 & 4.9 & 0 \\
\hline Several times a month & 5.4 & 5.6 & 4.9 & 7.1 \\
\hline Once a month & 2.4 & 2.8 & 1.6 & 3.6 \\
\hline Several times a year & 3.2 & 3.4 & 3.3 & 0 \\
\hline Once a year & 0.6 & 0.3 & 0.5 & 3.6 \\
\hline Never & 1.5 & 1.9 & 0.5 & 3.6 \\
\hline N/A & 0.9 & 1.3 & 0.5 & 0 \\
\hline
\end{tabular}

\subsubsection{Forms of commute}

A total of 721 individuals ( $89 \%$ of the survey sample) responded to the question about the means of transport from their place of residence to the place of their primary employment (or study, fellowship and so on). The most frequently used means of transport, either alone or alongside other means, was public transport (40\%) and bicycle (34\%). A total of $6.8 \%$ did not use any means of transport (they presumably only walked).

Table 28: Means of commute to work (singly or in combination with others), as percentages $(\%)$

\begin{tabular}{|lc|}
\hline Means of commute & Responses \\
\hline Local or city public transport & 40 \\
\hline Bicycle & 34 \\
\hline Private car & 21.4 \\
\hline Regional or commuter train & 14.8 \\
\hline Intercity or international train & 10.7 \\
\hline
\end{tabular}




\begin{tabular}{|ll} 
Aeroplane & 8.0 \\
\hline Regional or commuter bus & 4.6 \\
\hline Intercity or international bus & 2 \\
\hline Other & 2.8 \\
\hline I do not use any means of transport & 6.8 \\
\hline
\end{tabular}

\subsubsection{Commuting time}

The average return commuting time between one's house and the workplace or place of study was 1 hour and $\mathbf{4 8}$ minutes. ${ }^{74}$ When air travel is excluded the commuting time decreases to 1 hour and 15 minutes. Gender-related differences were negligible. Those below the age of 30 and those older than 45 tended to live closer to their place of work or study etc. than the sample average ( 1 hour and 29 minutes, and 1 hour and 37 minutes respectively).

Almost half (48.6\%) commuted daily for 30 minutes or less.

From the table below we can see that those who lived further away from their place of work or study etc. tended to commute less frequently. The causality surely goes both ways and some will likely have accepted jobs further away from their homes because of the precarity and insecurity in the job markets, while some decisions may have been also aided by the fact that they were not required to commute frequently because they lived far away. Conversely, those who travelled more than once a week tended to live closer to their workplaces $-65.6 \%$ of those who commuted daily lived less than 30 minutes away.

Table 29: Commuting time (excl. flights), according to frequency

\begin{tabular}{|lcccc|}
\hline Frequency of commute & $\begin{array}{c}\text { 30 mins. or } \\
\text { shorter }\end{array}$ & 31-90 mins. & 91-150 mins. & $\begin{array}{c}\text { 150 mins. or } \\
\text { longer }\end{array}$ \\
\hline Daily & 65.6 & 27.5 & 5.7 & 1.2 \\
\hline Several times a week & 44.7 & 38.5 & 8.7 & 8 \\
\hline Once a week & 12.2 & 19.5 & 22 & 46.3 \\
\hline Several times a month & 28.6 & 11.4 & 17.1 & 42.9 \\
\hline Once a month & 7.1 & 14.3 & 28.6 & 50 \\
\hline Several times a year & 20.0 & 33.3 & 6.7 & 40 \\
\hline Once a year & 66.7 & 33.3 & 0.0 & 0.0 \\
\hline Total & 48.6 & 30.8 & 9.2 & 11.4 \\
\hline
\end{tabular}

74 For comparison, an average European worker spends 1 hour and 24 minutes a day commuting (https://www.sdworx.com/en/press/2018/2018-09-20-more-than-2opercent-of-europeans-commute-at-least-9ominutes-daily). 
On average, respondents spent 123 Euros per month on transportation to work or school. When those who commuted by aeroplane are excluded from the analysis, the average commuting costs decreased to 90 euros per month. A total of $74 \%$ of those who travelled by plane spent more than 100 euros per month, with $57 \%$ spending more than 200 euros.

Costs varied across countries, as could be expected. In some, the largest proportion of commuters spent up to 20 euros per month: Czech Republic - $54.5 \%$, Denmark $-45 \%$, Finland - 40\%, Poland $-44 \%$, Netherlands $-37.9 \%$. In Austria, Belgium and Portugal, the largest percentages spent between 21 and 50 euros per month: $57.9 \%, 50 \%$ and $43.3 \%$ respectively. In France, Norway, Spain and Sweden, the largest percentages of commuters spent between 51 and 100 euros per month: $46.7 \%$ of respondents in France, $41.7 \%$ in Norway, $42.9 \%$ in Spain and $42.1 \%$ in Sweden. Switzerland is notable because it was the most expensive: a quarter (25\%) of commuters spent above 200 euros and $43 \%$ above 100 euros. In Germany and the UK, which each comprised $15 \%$ of all survey respondents, there was no particular concentration in any spending bracket. In Germany, 30.8\% spent up to 20 euros, $22 \%$ between 21 and 50 euros, $18.7 \%$ between 51 and 100 euros, $13.2 \%$ between 101 and 200 euros and $15.4 \%$ spent over 200 euros. In the UK, the percentages were as follows: $25.9 \%, 16 \%, 21 \%, 22.2 \%$ and $14.8 \%$ respectively.

Those who travelled less frequently to their place of work also do so probably because the costs were higher, or because they do not have an office space, the obligation to work in an office, or both. Less than half of those who travelled daily (42.8\%) or several times a week (45.5\%) spent more than 50 euros per month on their commute. Conversely, $71.5 \%$ of those who travelled once a month spent more than 50 euros, with $57.2 \%$ spending more than 100 euros per month. The following table disaggregates respondents' monthly commuting costs according to commuting frequency to give a better overview.

Table 30: Monthly commuting costs (excl. flights), according to frequency, in euros

\begin{tabular}{|lccccc|}
\hline Frequency of travel & $\begin{array}{c}\text { 20 EUR } \\
\text { or less }\end{array}$ & $\begin{array}{c}\text { 21-50 } \\
\text { EUR }\end{array}$ & $\begin{array}{r}\text { 51-100 } \\
\text { EUR }\end{array}$ & $\mathbf{1 0 1 - 2 0 0}$ EUR & $\begin{array}{c}\text { 200 EUR } \\
\text { or more }\end{array}$ \\
\hline Daily & 38.1 & 19 & 25.1 & 12.1 & 5.6 \\
\hline Several times a week & 27.6 & 26.8 & 22.2 & 13.0 & 10.3 \\
\hline Once a week & 7.3 & 31.7 & 4.9 & 24.4 & 31.7 \\
\hline Several times a month & 14.7 & 23.5 & 20.6 & 17.6 & 23.5 \\
\hline Once a month & 7.1 & 21.4 & 14.3 & 42.9 & 14.3 \\
\hline Several times a year & 35.7 & 14.3 & 14.3 & 35.7 & 0.0 \\
\hline Once a year & 33.3 & 33.3 & 0.0 & 33.3 & 0.0 \\
\hline Total & 29.3 & 23.6 & 21.6 & 15.1 & 10.5 \\
\hline
\end{tabular}




\subsubsection{Long-distance commuting}

A total of $20 \%$ (149 individuals) of those who answered the question about commuting made long-distance journeys by intercity or international train or bus or by plane. Almost a quarter (24.3\%) made such a journey every day or several times a week.

They lived in 13 countries - 21\% in Germany, $12.8 \%$ in the UK, $10.1 \%$ in Switzerland, $10.1 \%$ in Italy, $8.1 \%$ in the Netherlands, and the rest in other countries.

In terms of age, the composition of this set was similar to the overall sample.

In terms of gender composition, $66.4 \%$ were women, $28.2 \%$ were men and $5.4 \%$ were 'Other'. Men are long-distance commuters to a somewhat lesser extent compared with their percentage in the overall sample (32.4\%).

Unsurprisingly, however, long-distance commuting is more expensive. While in the overall sample, $15.1 \%$ spent between 101 and 200 euros per month and 10.5\% spent over 200 euros, for this group of long-distance commuters, the figures were $25.2 \%$ and $48.2 \%$ respectively.

\section{Chart 30: Monthly costs of long-distance commuting}

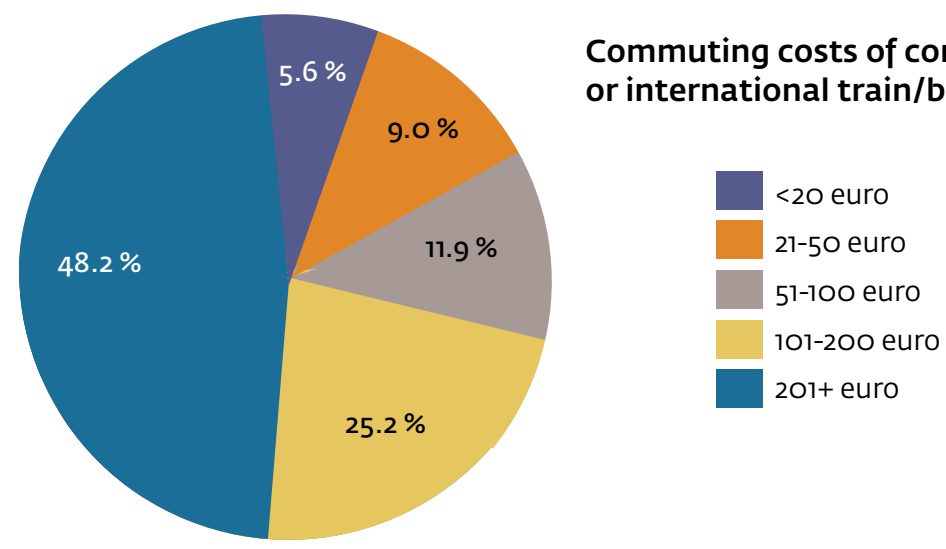

7.1.6 Air travel

A total of $8 \%$ (56 individuals) commuted to their place of work or study by plane. Within this subset, $33.9 \%$ travelled several times a month, the majority of them within the countries in which they lived, although a few lived and worked in different countries. ${ }^{75}$ This might not be a significant percentage overall, but it is quite an alarming percentage given the accompanying carbon footprint, especially when added to the carbon footprint of conference and fieldwork-related travel.

75 Of ten working in the UK, seven commuted within the UK, and one each lived in Greece, Ireland, and Italy. Of eight individuals employed in Germany, six commuted within Germany, one lived in Denmark and one in the UK. Five of those employed in Italy commuted by plane - three within the country, one lived in Belgium and one in Mexico. The rest were more isolated cases: three in the US, three in Switzerland, and two and less from other countries. 
Table 31: Frequency of commuting by plane, as percentages (\%)

\begin{tabular}{|lc|}
\hline Frequency of commute & Percentage \\
\hline Daily & 1.8 \\
\hline Several times a week & 5.4 \\
\hline Once a week & 7.1 \\
\hline Several times a month & 19.6 \\
\hline Once a month & 12.5 \\
\hline Several times a year & 44.6 \\
\hline Once a year & 7.1 \\
\hline Never & 1.8 \\
\hline
\end{tabular}

Those who commuted by plane were relatively evenly distributed in terms of age.

Table 32: Age of those commuting by plane, as percentages (\%)

\begin{tabular}{|l|c|}
\hline Age cohort & Percentage \\
\hline $\mathbf{3 0}$ or below & 16.1 \\
\hline $\mathbf{3 1 - 3 5}$ years & 14.3 \\
\hline $\mathbf{3 6 - 4 0}$ years & 21.4 \\
\hline $\mathbf{4 1 - 4 5}$ years & 19.6 \\
\hline $\mathbf{4 6 - 5 5}$ years & 19.6 \\
\hline $\mathbf{5 5}$ or above & 8.9 \\
\hline
\end{tabular}

\subsubsection{Summary}

Over two thirds of all participants commuted to their workplace either daily or several times a week, with women working more locally and sharing the tendency of not commuting as frequently as men, although the average remained approximately the same. The most frequently used means of transport, either alone or alongside other means, were public transport and bicycles. One out of 12 anthropologists participating in the survey reported commuting by aeroplane, and for one in three among those who did, this travel happened several times a month, albeit within the same country. A total of 123 Euros was spent per month on transportation to work or school on average, and the daily time spent commuting was on average 1 hour and 48 minutes. When combined with the conference and researchrelated travel, which the present study did not address, these numbers are still alarming when it comes to the carbon footprint of anthropology as a discipline, and academia as a career track more generally, vis-à-vis the impending ecological catastrophe brought about by climate change. 


\subsection{Academic mobility}

\subsubsection{International mobility}

Survey respondents were internationally highly mobile. As the following chart illustrates, more than $50 \%$ of respondents moved between countries in the five years before 2018 . Almost 20\% changed countries three or more times.

\section{Chart 31: Number of times that respondents moved countries over the five-year period \\ $0.20 \%$}

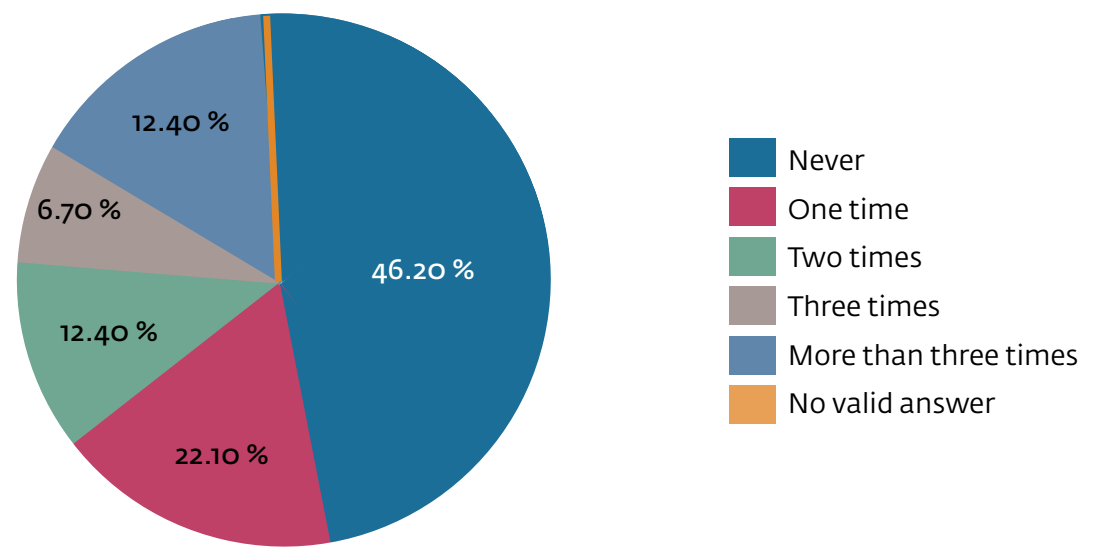

Note. 'In the last 5 years, how many times have you had to move between countries for work or for your education (fellowship, study, etc. but not including for fieldwork)?'

Among scholars working in ERC countries, the proportions remain the same.

\section{Chart 32: Number of times that scholars in ERC countries moved countries over the five-year period}

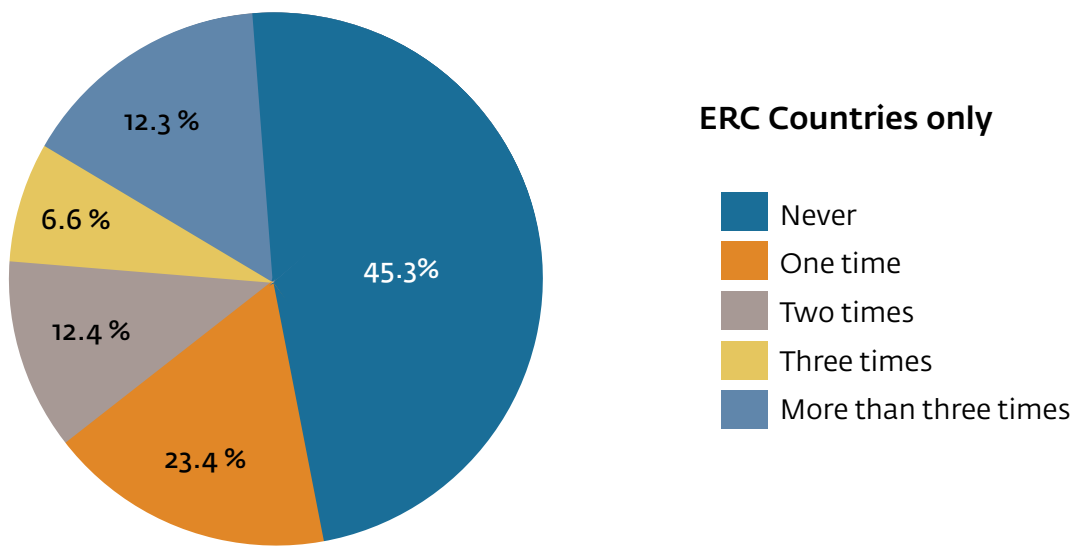

Note. 'In the last 5 years, how many times have you had to move between countries for work or for your education (fellowship, study, etc. but not including for fieldwork)?' 
There were no significant gender-based differences in levels of international mobility.

There were, however, differences between age groups as the following table illustrates:

Table 33: Frequency of moving between countries in the last five years according to age, as percentages (\%)

\begin{tabular}{|l|ccccc|}
\hline Age in years & Never & One time & Two times & Three times & $\begin{array}{c}\text { More than } \\
\text { three times }\end{array}$ \\
\hline $\mathbf{3 0}$ and younger & 34.5 & 26.2 & 17.9 & 8.3 & 13.1 \\
\hline $\mathbf{3 1 - 3 5}$ & 30.7 & 29.5 & 14.5 & 9.6 & 15.7 \\
\hline $\mathbf{3 6 - 4 0}$ & 38.4 & 27.9 & 13.4 & 9.9 & 10.5 \\
\hline $\mathbf{4 1 - 4 5}$ & 46.9 & 20.8 & 13.8 & 6.9 & 10.8 \\
\hline $\mathbf{4 6 - 5 5}$ & 65.7 & 12.4 & 9.5 & 0.7 & 11.7 \\
\hline $\mathbf{5 6}$ and older & 66 & 13.6 & 4.9 & 1.9 & 12.6 \\
\hline
\end{tabular}

If we put aside the group aged below 30, which includes a large proportion of doctoral students, the tendency to stay put increased with age. The cohort aged between $\mathbf{3 1}$ and 35 years was the most internationally mobile: Only $31 \%$ - less than one third - had not left their countries for work or education (excluding fieldwork) in the five years prior to the survey while one quarter - $25 \%$ - changed their countries of work three or more times. Interestingly, a significant portion of academics older than 45 years were also highly mobile: $32 \%$ of all people who moved more than three times were older than 45 years, with a slight increase over time.

Less surprisingly, there were differences in mobility levels between those employed on temporary contracts and those on permanent contracts. While only $\mathbf{3 9 \%}$ of academics on fixed-term contracts did not move countries at all in the five years prior to the survey, the proportion increased to $63.3 \%$ among the permanent staff. And while $28 \%$ of temporary faculty had moved once over the course of the last five years and $16.2 \%$ twice, the percentages more than halved when only permanent faculty were considered - to $13.8 \%$ and $6.7 \%$ respectively.

Interestingly, among those on permanent contracts, a large percentage of them had moved more than three times $-12.5 \%$ (in comparison with $9 \%$ among those on fixed-term contracts). Since we do not have information on the employment trajectories of these 28 individuals, it is impossible to say if their international movement occurred during their permanent employment or between temporary employments. 


\subsubsection{Interdepartmental mobility}

Mobility, both international and between institutions, has become one of the important pillars of the current research system, at least within the official discourse. In many countries, academics are discouraged - through unofficial and official practices - to remain at the department at which they attained their doctorates, and they are encouraged to seek experience elsewhere. In other countries, however, the opposite tendencies are at work.

Among the respondents, $\mathbf{7 2 . 1 \%}$ of those working in academia did not work at the same department at which they had obtained their highest degree. Only $14.5 \%$ of respondents had never left their alma mater, while $13.4 \%$ returned after a period spent elsewhere.

Below we chose countries for which we have at least ten cases, i.e. countries in which the bulk of the respondents were employed, or where departmental 'self-reproduction' was the highest and lowest. One needs to keep in mind, however, that many respondents did not answer this question. We therefore note the non-response rate as a percentage.

Table 34: Responses to the question 'Are any of your current contracts at the same department where you obtained your highest degree?' in selected countries, ${ }^{76}$ as percentages (\%)

\begin{tabular}{|lcccc}
\hline Country & 'No' & 'Yes. I never left' & 'Yes. I returned' & No response \\
\hline Austria & 33.3 & 20.8 & 33.3 & 12.5 \\
\hline Denmark & 65.2 & 8.7 & 21.7 & 4.3 \\
\hline Finland & 47.4 & 21.1 & 10.5 & 21.1 \\
\hline France & 60.0 & 4.0 & 8.0 & 28.0 \\
\hline Germany & 60.5 & 9.2 & 10.9 & 19.3 \\
\hline Ireland & 63.6 & 0.0 & 9.1 & 27.3 \\
\hline Netherlands & 48.6 & 8.6 & 17.1 & 25.7 \\
\hline Norway & 75.9 & 3.4 & 6.9 & 13.8 \\
\hline Poland & 37.5 & 16.7 & 20.8 & 25.0 \\
\hline Portugal & 48.6 & 17.1 & 8.6 & 25.7 \\
\hline Romania & 58.3 & 8.3 & 8.3 & 25.0 \\
\hline Spain & 48.3 & 13.8 & 10.3 & 27.6 \\
\hline Sweden & 51.9 & 14.8 & 0.0 & 33.3 \\
\hline Switzerland & 46.5 & 20.9 & 9.3 & 23.3 \\
\hline United Kingdom & 58.9 & 10.3 & 5.6 & 25.2 \\
\hline
\end{tabular}

It is also important to stress that most survey respondents were employed on temporary contracts, so the table above says nothing about long-term retention. There is also

\footnotetext{
${ }^{76}$ Included in the table are thus only countries for which more than two third of respondents answered, Sweden being the border case. In Italy, where $6.7 \%$ of respondents lived (the third largest cohort after Germany and the UK), there were as many as $50 \%$ of answers missing, and so it is not included in the table.
} 
no suggestion of ethical preference: institutional closure in hiring practices may be as problematic (e.g. in perpetuating dependency and power asymmetries) as radical openness (e.g. which more often than not privileges graduates from globally elite programmes to the detriment of locally trained graduates).

Bearing this in mind, it could be said that Austria and Norway lie at two poles. Austria demonstrated the highest level of departmental self-reproduction - only around $33.3 \%$ of staff had obtained their PhDs from departments other than the one at which they had an employment contract. Austria, Switzerland and Finland had the highest proportion of those who continued to work at the departments at which they had graduated - at around $20 \%$. Moreover, Austria, along with Denmark and Poland, had the highest proportion who had at some point returned to the departments from which they had graduated. In contrast, departments in Norway, Denmark and Ireland had the highest proportion of employment contracts with scholars who had not graduated from the departments (followed by Germany and France with 60\%). The majority had gained their doctorates within the respective countries: $59 \%$ in Norway, $78 \%$ in Denmark and $80 \%$ in Ireland. Norway could be thus said to be the most open as well as the most international (as with many countries, there was a strong UK bias: $67 \%$ of those who graduated outside Norway, that is, $28 \%$ of all respondents working in Norway, obtained their PhDs in the UK).

\subsubsection{Views on international mobility}

A large proportion of respondents were relatively geographically flexible, by choice or necessity, and many did not mind this in principle. As the table below shows, for more than one third $(36.5 \%)$, working in the same country in which they had worked or lived in $\mathbf{2 0 1 8}$ was unimportant (to a lesser or greater extent) as an aspect of their future working life. For $14 \%$ it was not at all important.

\section{Chart 33: Importance of continuing to work in the current country}

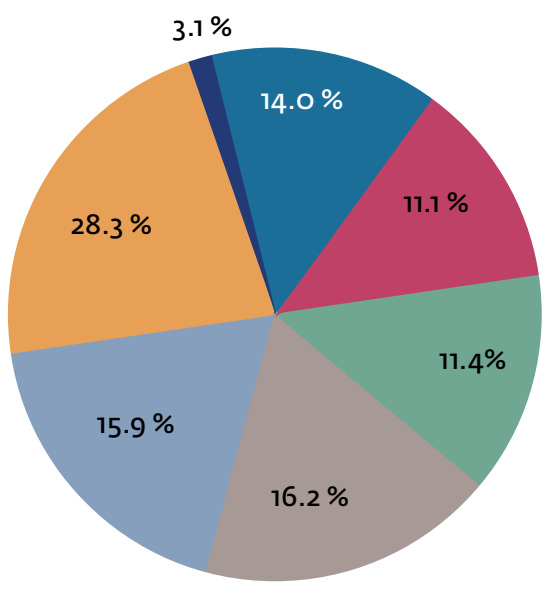

To work in the same country as I work/live currently

Note. 'When you think about the next five years, how important are the following aspects for your future working life?' 
The importance of working in the same country increased slightly with age: while it was 'very important' for $15 \%$ of those under 30 (and $55 \%$ chose answers $4-6$ ) and for $21.7 \%$ of those aged between 31 and 35 (56.7\% chose answers 4-6), it was 'very important' for $32.3 \%$ of those over 45 years old (in total $60.4 \%$ chose answers $4-6$ ).

As could have been expected, remaining in the same country in which one worked or lived was more important for those with children, although the difference was not huge: $67.2 \%$ of those with children chose answers $4-6$ (and it was 'very important' for one third - 34.5\%) as compared with $56.7 \%$ of those who had no children (and it was 'very important' for $27 \%$ ). There was, however, a significant difference in readiness to move countries between respondents who had a partner (or partners) and those without: $30.5 \%$ of those in a relationship thought that it was 'very important' to continue living in the same country in comparison with $19.9 \%$ of those who did not have a partner (or partners). This clearly shows that the respondents are aware of how ruinous academic mobility can be to the maintenance of relationships - the choice to move countries is influenced by and influences long-term relationships.

When we look more closely at the sample of those for whom working in the same country as they worked or lived in 2018 was unimportant (i.e. those who chose answers corresponding to 1 and 2 in the chart above), i.e. who did not mind moving, we gain the following insights:

- Younger people were somewhat more likely to find working in their present country unimportant: $59.4 \%$ were under 40 years old in comparison with $53 \%$ in the total sample.

- A total of $63.5 \%$ of those for whom remaining working in the present country was unimportant had not moved or had moved only once over the last five years (i.e. they did not suffer from moving fatigue).

- Only $40 \%$ of those for whom remaining in the same country was unimportant were on fixed-term contracts, while for the sample it was $71 \%$. In some senses, they were at lower risk of having to move, so the prospect for many could be treated theoretically.

- Women were slightly less willing to move: $58 \%$ of those for whom remaining in the same country was unimportant were women, while women represent $62.5 \%$ of all respondents.

- Having children also had an effect: $29.1 \%$ of those for whom remaining in the same country was unimportant had children (compared with $36.6 \%$ in the over sample, which suggests that people with children are less likely to find moving countries for work acceptable).

- Having a partner had some effect, as the percentages of those for whom remaining in the same country was 'very important' (answer 6 ) already revealed: $72.4 \%$ of those for whom remaining working in their present country was unimportant had a partner in comparison with $78.1 \%$ in the overall sample. 
Satisfaction with work-life balance was negatively influenced by the frequency of movement, as the following table shows. For instance, $48 \%$ of those who moved more than three times over the five years prior to 2018 clearly disagreed with the statement'l am completely satisfied with my work-life balance and/or school-life balance' (they chose answers 1 and 2 in Chart 33 ) in comparison with $36 \%$ of those who had not moved countries at all.

Table 35: Work-life/school-life balance satisfaction and frequency of changing countries over the past five years

\begin{tabular}{|l|cccccccc|}
\hline $\begin{array}{l}\text { Changing countries } \\
\text { over five years }\end{array}$ & \begin{tabular}{l} 
'I am completely satisfied with my work-life or school-life balance' \\
\hline
\end{tabular} & $\begin{array}{l}\text { Disagree } \\
\text { completely }\end{array}$ & $\mathbf{2}$ & $\mathbf{3}$ & $\mathbf{4}$ & $\mathbf{5}$ & $\begin{array}{l}\text { Agree } \\
\text { completely }\end{array}$ & N/A \\
\hline Never & 14.7 & 21.7 & 17.9 & 20.6 & 18.2 & 5.9 & 1.1 \\
\hline One time & 15.6 & 19 & 24 & 20.1 & 14.5 & 6.1 & 0.6 \\
\hline Two times & 19 & 26 & 14 & 25 & 10 & 5.0 & 1.0 \\
\hline $\begin{array}{l}\text { Three times } \\
\text { More than } \\
\text { three times }\end{array}$ & 18.5 & 37 & 14.8 & 14.8 & 9.3 & 3.7 & 1.9 \\
\hline
\end{tabular}

The people most dissatisfied with their work-life or school-life balance were those who had moved three times - almost 56\% were clearly dissatisfied and only $13 \%$ were satisfied with their work-life or school-life balance.

The following table looks at the relationship between a person moving countries and their life satisfaction:

Table 36: Work-life or school-life balance satisfaction and frequency of changing countries over the past five years

\begin{tabular}{|c|c|c|c|c|c|c|c|}
\hline \multirow{2}{*}{$\begin{array}{l}\text { Changing countries } \\
\text { over five years }\end{array}$} & \multicolumn{7}{|c|}{ 'All in all, I am completely satisfied with my life' } \\
\hline & $\begin{array}{l}\text { Disagree } \\
\text { completely }\end{array}$ & 2 & 3 & 4 & 5 & $\begin{array}{l}\text { Agree } \\
\text { completely }\end{array}$ & N/A \\
\hline Never & 3.2 & 10.2 & 16.8 & 23.0 & 35.0 & 10.7 & 1.1 \\
\hline One time & 5 & 11.7 & 17.3 & 27.9 & 27.4 & 10.1 & 0.6 \\
\hline Two times & 5 & 17.0 & 16.0 & 31.0 & 24.0 & 7.0 & O \\
\hline Three times & 3.7 & 11.1 & 18.5 & 31.5 & 29.6 & 5.6 & o \\
\hline $\begin{array}{l}\text { More than } \\
\text { three times }\end{array}$ & 4.0 & 17.0 & 26.0 & 21.0 & 27.0 & 5.0 & 0 \\
\hline
\end{tabular}


Again, there was some correlation between the frequency of a person moving between countries over the five years preceding the survey and their reported life satisfaction. In general, the more that people moved between countries, the less satisfied they were with their lives. Among those who moved more than three times, $21 \%$ were very clearly dissatisfied (corresponding to answers one and two in the above table) and $31 \%$ very clearly satisfied (answers five and six) with the rest lying in the middle. Among those who stayed put over the same period, clear dissatisfaction decreased to $13.4 \%$ and clear satisfaction increased to $45.7 \%$. Again, as with the question on work-life balance, those who moved three times are somewhat atypical: they were less dissatisfied (answers one and two) than any other group.

\subsubsection{Summary}

More than half of respondents moved between countries in the five years preceding the 2018 survey, and one in five respondents changed countries three or more times. One factor that correlated with mobility was age. The cohort aged between 31 and 35 years of age was extremely internationally mobile: only one out of three had not left their countries for work or education (except for fieldwork) in the five years prior to the survey, while one quarter had moved three or more times. Among academics older than 45, there was a large portion of highly mobile individuals: $11 \%$ had moved more than three times over the prior five-year period.

Another factor that influenced mobility was the type of contract people held: while only about one third of academics on fixed-term contracts had not moved countries at all within the five years prior to the survey, among those on permanent contracts the figure was two thirds.

Remaining in the same country in which one worked or lived was more important for those with children. While there was a difference in readiness to move countries between respondents who had a partner (or partners) and those without, this was not as definitive.

As concerns mobility, it is also important to note inter-institutional mobility. The survey shows that the myth of endogamy at European universities, is - if nothing more - a thing of the past, at least among those who responded to the survey (and by definition are EASA members) - and maybe there is a correlation. In any case, over two thirds of those working in academia did not work at the same department at which they had obtained their highest degree. Less than one in six respondents had never left their alma mater, and even less were given a chance to return after a period spent elsewhere, though there were significant variations between countries. 


\section{Workplace}

\subsection{Academic departments}

Most EASA members work in social-science departments.

Table 37: Departments at which respondents work, as percentages (\%) ${ }^{77}$

\begin{tabular}{lc} 
Department & Responses \\
\hline Anthropology/Ethnology or similar & 61.9 \\
\hline Social sciences & 15.6 \\
\hline Sociology & 6.1 \\
\hline Medicine & 3.6 \\
\hline Political science or similar & 3.3 \\
\hline Geography & 2.5 \\
\hline Psychology or similar & 1.2 \\
\hline Human resources or administration & 0.7 \\
\hline Library & 0.3 \\
\hline Other & 20 \\
\hline
\end{tabular}

As could be expected, the majority - two thirds - of respondents worked in departments of anthropology, ethnology or similar. Only around $5 \%$ of respondents worked in STEM departments, primarily in departments of medicine (3.6\%), but also in engineering (0.8\%) or life sciences $(0.5 \%)$.

Among the 'other' departments that respondents listed, the most frequent (about $3 \%$ of those who answered the question) were various interdisciplinary departments or institutes (sometimes private or project-based) and area studies departments (including indigenous studies). Another small group worked at departments of education.

\subsection{Workspace}

\subsubsection{Employer-provided services and infrastructure}

Respondents were also asked to evaluate the supporting infrastructure and services provided by their employers or educational institutions.

77 Respondents could choose all departments that applied to them and many hold several positions. Hence the sum is greater than $100 \%$. 
Table 38: Answers to the question 'How sufficiently does your employer provide you the following services, support and spaces?' as a percentage (\%)

\begin{tabular}{|lccccccc|}
\hline $\begin{array}{l}\text { Service or } \\
\text { infrastructure }\end{array}$ & $\begin{array}{l}\text { Not } \\
\text { provided }\end{array}$ & $\begin{array}{l}\text { Not at all } \\
\text { sufficient }\end{array}$ & $\mathbf{2}$ & $\mathbf{3}$ & $\mathbf{4}$ & $\mathbf{5}$ & Very sufficient \\
\hline $\begin{array}{l}\text { Working space } \\
\text { Common room }\end{array}$ & 5.9 & 8.5 & 8.5 & 6.5 & 10.4 & 21.1 & 39 \\
\hline $\begin{array}{l}\text { or kitchenette } \\
\text { Institutional email }\end{array}$ & 2.2 & 1.2 & 1.2 & 2.5 & 2.5 & 8.1 & 82.3 \\
\hline $\begin{array}{l}\text { Computer with s } \\
\text { internet acces }\end{array}$ & 7.2 & 3.2 & 3.4 & 4.5 & 4.5 & 10.7 & 66.5 \\
\hline $\begin{array}{l}\text { Access to library } \\
\text { and online } \\
\text { databases }\end{array}$ & 2.0 & 4.7 & 4.0 & 5.2 & 8.2 & 15.6 & 60.4 \\
\hline $\begin{array}{l}\text { Travel grants for } \\
\text { conferences }\end{array}$ & 14.1 & 13.6 & 10.4 & 13.6 & 14.6 & 15.6 & 18.3 \\
\hline $\begin{array}{l}\text { Funds to organise } \\
\text { workshops }\end{array}$ & 17.7 & 15 & 13.8 & 15.5 & 14.3 & 11.9 & 11.9 \\
\hline $\begin{array}{l}\text { Research funds } \\
\text { Funds for }\end{array}$ & 21.6 & 19.1 & 9.9 & 14.4 & 13.4 & 10.6 & 10.9 \\
\hline $\begin{array}{l}\text { publications } \\
\text { Career training }\end{array}$ & 26.9 & 16.6 & 11.5 & 15.9 & 10.5 & 10.5 & 8.0 \\
\hline & 16.1 & 12.6 & 16.6 & 16.8 & 16.4 & 13.8 & 7.7 \\
\hline
\end{tabular}

\subsubsection{Sufficiency of the workspace, access to facilities, and career development}

As concerns workspaces, although not entirely surprising, and potentially subject to rapid change in light of recent moves towards online teaching, it is positive that $\mathbf{9 4 \%}$ of those who responded to the question (594, or $73 \%$ of the overall sample) were provided with some sort of workspace by their employer or their university. At the same time, almost one quarter, $23.5 \%$, consider the workspace provided as insufficient to a greater or lesser extent, and $5.9 \%$ were not provided with any workspace. In other words, by adding up the answers 'does not provide' and answers 1-3 on the scale from 'not at all sufficient' to 'very sufficient', we can conclude that $\mathbf{2 9 . 4 \%}$ of respondents consider their workspace insufficient.

This workspace insufficiency is not a characteristic only of highly mobile scholars, or those affiliated with their institutions for a short period only. Out of those who do not have sufficient access to a workspace, $42 \%$ had not moved countries in the preceding five years and $23.9 \%$ had moved only once. In other words, they had been working at their department for several years. 
Moreover, two thirds of those who see their workspace as insufficient commute frequently to work: $26.1 \%$ of those who do not have a sufficient workspace commute daily and $40.9 \%$ commute several times a week.

Insufficient workspaces cannot be said to be typical of any one region: three out of four respondents (75\%) from Bulgaria, eight out of 12 (66.7\%) respondents from Romania, four out of seven (57\%) respondents from the Russian Federation, eight out of $17(47.1 \%)$ in Poland, six out of 13 respondents from Greece (46\%), and eight out of 22 (36.4\%) from the Netherlands, eight out of 24 (33\%) respondents from Austria, but also $28 \%$ of those working in the UK and Czech Republic, and $24 \%$ of those working in Italy, and finally $22.7 \%$ of those in Portugal did not have a workspace at all or had an insufficient workspace. The exceptions were Norway, Sweden and Germany: only $13 \%$ of those employed in Norway, $11.8 \%$ of those in Sweden and $10 \%$ of those employed in Germany reported an insufficient workspace.

\subsubsection{Student support and workspaces}

Students fared worse on the above-mentioned issues compared with other respondents. The largest difference between students and non-students was reported in terms of workspace: $\mathbf{4 4 . 7 \%}$ of students were either not provided with a workspace or deemed their workspaces insufficient (answers 1-3). This compares with $28 \%$ of the non-students and $29.4 \%$ of the overall survey sample.

There were also differences along other dimensions:

- $36.2 \%$ of students felt they were not provided with sufficient access to a common room or kitchenette, as compared with $29.7 \%$ of non-students.

- $10.6 \%$ were not satisfied with their institutional email compared with $6.8 \%$ of non-students.

- $21.3 \%$ felt their institution did not provide them with enough access to computers that had internet access, as compared with $18 \%$ of non-students.

- $10.6 \%$ were not provided with sufficient access to library and online databases, as compared with $16 \%$ of non-students.

- $70.2 \%$ did not receive sufficient career training as compared with $61.4 \%$ of non-students.

On the other hand, when compared with non-students, students reported receiving comparable and even more satisfactory support to develop their academic work. Still, it was unsatisfactory for both groups:

- $55.3 \%$ of students felt they were not provided with sufficient travel grants for conferences, as compared with $51.3 \%$ of non-students.

- $61.2 \%$ of students were not provided with sufficient funds to organise workshops, as compared with $61.9 \%$ of non-students. 
- $60.1 \%$ of students did not receive sufficient funds for research-related activities, as compared with $65.5 \%$ of non-students.

- $76.6 \%$ did not receive sufficient funds for publications (translation, editing etc.) as compared with $70.4 \%$ of non-students.

\subsection{Summary}

While the majority of EASA members are provided with some sort of workspace by their employer or their university, almost one in three consider their workspace insufficient, and two thirds of those commute frequently to work. The lack of sufficient workspace and also resources to support academic career development are most acute among students, almost half of which were neither provided with an adequate workspace, nor with sufficient access to computer facilities, career-training conference travel grants, or funds for research-related activities or publications. However, while this was a tendency more present among students, those working in departments, including those on permanent contracts, also faced similar challenges - albeit to a lesser extent. As most respondents and thus EASA members work in social-science departments, this strongly suggests that more support is necessary for scholars in such departments. 


\section{Discrimination}

\subsection{Experiences with discrimination, unfair treatment, harassment or abuse within academia}

In the survey, respondents were asked whether they personally experienced discrimination, bullying, harassment, unfair treatment, or verbal, physical or emotional abuse in the academic context. In total, $47 \%$ of the respondents chose the option'I have not experienced any discrimination, harassment etc.'We can thus surmise that more than half of the respondents $(53 \%)$ had personally experienced discrimination, unfair treatment, harassment, bullying or verbal, physical or emotional abuse.

Table 39: Personal experiences with discrimination, harassment, abuse and unequal treatment as percentages (\%)

\begin{tabular}{|l|c|}
\hline Kind of discrimination etc. experienced & Percentage who reported it \\
\hline Gender & 21.1 \\
\hline Citizenship/nationality & 14 \\
\hline Age & 12.2 \\
\hline Pregnancy/family obligations & 10.6 \\
\hline Social class & 8.9 \\
\hline Ethnicity & 3.7 \\
\hline Race & 2.6 \\
\hline Sexual orientation & 2.1 \\
\hline Religion & 1.7 \\
\hline Disability & 1.1 \\
\hline Other (please specify) & 15.7 \\
\hline
\end{tabular}

Note. The survey question read: 'Responses to the questions In the past five years have you personally experienced discrimination, bullying, harassment, unfair treatment, verbal, physical or emotional abuse in your academic context (including within professional associations, at job interviews and so on)? If yes, for what reasons? Select all that apply'.

Besides those who felt discriminated against for reasons listed in the table (including 'other'), $7.8 \%$ felt they had been discriminated against, harassed or treated unfairly, but stated that they did not know what this reason was.

From the given set of choices, the most frequently reported experiences of discrimination, harassment, unfair treatment or abuse within the academic context were those based on gender and citizenship. Interestingly, 'other' was the third most chosen answer.

A total of $\mathbf{2 1 . 1 \%}$ of our respondents had experience of gender-based discrimination, harassment, unfair treatment or abuse in academia. Women and those who preferred 
to self-describe in alternative or non-binary ways reported experiencing genderbased discrimination more often. Of the $21.1 \%$ with such experiences, $88.9 \%$ were women; $1.8 \%$ self-described in alternative ways; and $5.8 \%$ preferred not to reveal their gender. Men were less affected: $3.5 \%$ reported such experiences.

Of the 54 individuals who have officially been diagnosed with a disability, nine individuals (17\%), experienced discrimination, unfair treatment, harassment etc. within the academic context.

In total, $8.9 \%$ reported discrimination, harassment, unfair treatment or abuse in the academic context on the basis of their social class. We looked closer at the class composition of this set, which we, for comparative purposes, approximated via parents' levels of education. Such form of discrimination, bullying, harassment etc. was distributed across the classes. For instance, of those who reported experiencing such treatment, $11 \%$ of their fathers had attained doctoral or equivalent degrees. Fathers of the same percentage of respondents were on the other side of the spectrum - they had not completed primary education. On the other hand, academics from a working-class background experienced such treatment to a disproportionally large degree in the sample. A total of $35.4 \%$ of fathers and $40 \%$ of mothers of individuals who had experienced class-based discrimination or other unfair treatment had attained lower secondary education or below. In the sample, equally $18.9 \%$ of fathers and mothers had lower secondary education or below.

Of course, the categories of discrimination given were not exclusive: for instance, $52 \%$ of those who reported being discriminated against or otherwise abused or unfairly treated on the basis of their race also reported being discriminated against according to their ethnicity, and $57 \%$ according to their nationality.

\subsection{Other reasons for discrimination, unfair treatment, harassment and abuse within academia}

A total of $15.7 \%$ reported being discriminated against or having received unfair treatment in academia for 'other' reasons than those listed. Sadly, but not unexpectedly, this included sexual harassment or being discriminated or otherwise unfairly treated as a consequence of objecting to such harassment on their own or others' behalf.

Among 'other' reasons given, the most prominent were power and status differentials that arise from the academic hierarchy: several reported having been treated unfairly or bullied because of their temporary or part-time contracts, and others because they were low in the academic hierarchy in their departments. Some reported being put under pressure to work harder, even when they felt they were themselves productive, or being penalised when they refused to take on unpaid work, which they could ill afford to due to their precarious status. 
Other prominent reasons for such treatment had to do with the internationalisation of academia: many reported not being given equal opportunities or being professionally abused due to their nationality or citizenship status (14\%), while others listed language barriers or their accents as reasons for such treatment. On the other hand, many felt that they were rejected by the academic system in their home countries, because they had international experience. Some felt they had been treated unfairly because their degrees were not from the 'right' countries, or because gaining degrees abroad meant that they had no functional network and senior professors who would support or otherwise vouch for them. What all these experiences show is that there are limits to international mobility and that opportunities that such mobility may present nevertheless conflict with existing hierarchies and dynamics (e.g. the perceived worth of different degrees, or patronage networks).

In addition to all these reasons, some have felt they were discriminated against, unfairly treated, bullied etc., because they worked in non-anthropology departments or research teams.

Others felt discriminated against, harassed or abused due to their political convictions.

\subsection{Witnessing discrimination, unfair treatment, harassment or abuse within academia}

While $53 \%$ of the sample had personally experienced discrimination, unfair treatment, harassment, bullying or verbal, physical or emotional abuse, 63\% had witnessed such treatment in relation to a colleague or a student in their academic context (including within professional associations, at job interviews and so on). Only $37.1 \%$ were positively convinced that they had not witnessed such a situation.

Table 40: Witnessing discrimination, harassment, abuse and unequal treatment in the academic context as percentages (\%)

\begin{tabular}{|l|l|}
\hline Kind of discrimination etc. witnessed & Percentage who reported it \\
\hline Gender & 31 \\
\hline Citizenship/nationality & 18 \\
\hline Pregnancy/family obligations & 19.3 \\
\hline Age & 15.7 \\
\hline Race & 16.2 \\
\hline Social class & 14.6 \\
\hline Ethnicity & 14.5 \\
\hline Sexual orientation & 8.9 \\
\hline Religion & 6.9 \\
\hline Disability & 6.1 \\
\hline Other & 11.4 \\
\hline
\end{tabular}


Note. The question read 'In the past five years have you witnessed discrimination, unfair treatment, harassment, bullying, verbal, physical or emotional abuse of a colleague or a student in your academic context (including within professional associations, at job interviews and so on)? If yes, for what reasons? Select all that apply'.

Besides the above reasons, $8.5 \%$ had witnessed such situations but did not know the reasons (including 'other' reasons) behind them.

It must be noted that the values in the two tables are not directly comparable (e.g. several people could be witnesses to the experiences of the same colleague). Nevertheless, both gender and nationality remain the main reasons for unequal or degrading treatment. Despite featuring in different orders, they are followed by age and family obligations/ pregnancy, and then by race, class and ethnicity. ${ }^{79}$

'Other' forms of discrimination, unfair treatment and abuse witnessed by respondents differed slightly from those that individuals reported direct experience of. There is a difference in the perceptions of impacts of international mobility, as discussed above.

Respondents did not report witnessing discrimination directed at their colleagues or students due to the lack of functional networks, the origins of their degrees, or international experience. The language barrier was also perceived as less of a problem. They also did not list working as an anthropologist with non-anthropology colleagues as reasons for discrimination, harassment etc.

\subsection{Power and inequality in academia}

More prominent, however, was the general sense of bullying and mobbing due to power differentials: 'for alleged poor performance'; of 'taking advantage of junior staff [who] fear precarity'; of 'exploitation of teaching assistants' and of 'young women [who] - when they are submissive in personality - are totally exploited at their workplace and bullied verbally by older male or female colleagues'; of 'harassment/bullying by superiors/faculty towards academics (PhDs, temporary staff) of lower rank'. All of these issues concern power relations within academia. 'Your categories here are misleading', wrote one respondent. 'Some if not most discrimination is on the basis of the clientelist structure of the academic system and

\footnotetext{
79 It was beyond the scope of this survey to probe further into the different ways in which discrimination around gender, ethnicity, and nationality was experienced and expressed among anthropologists, but we hope the statement of the prevalence of these issues will inspire other colleagues to do further work in this direction.
} 
it involves strong/big man/woman bullying some people on the one hand while promoting others to gain power'. ${ }^{80}$

Several respondents noted that such dynamics were often related to, and exacerbated by, academia's restructuring. 'Unfair treatment, verbal and emotional abuse towards colleagues, related to conflicts and restructuring happening in my institution', as one wrote. In other cases, reorganisation was used as a way of, or excuse for, getting rid of some people.

Respondents reported that the pressure to publish and write grants led to bullying by superiors. Heads of departments were seen by some as exerting pressures on unreasonable publication plans. Shrinking resources gave rise to departmental infighting, at times between cliques of colleagues. The structure of big grants handed over power to the PIs: 'The PI and other senior faculty bullied their PhD students to conduct our research (fieldwork and analysis) in a way that would achieve particular results. They also expected to be coauthors on all our articles, even though they did not contribute to the work', wrote one. After the students complained, 'the PI went into victim-mode, and the bullying became worse'. 'The risk [of voicing a complaint] is too high', added another tersely. 'People who tried to make changes would be singled out and denied conference/research funds. And harassed emotionally and intellectually', explained one respondent. This respondent went on to explain that'l just stopped going to work as much as possible to avoid it and tried to support people in different ways'.

'It's a profoundly disempowering experience', said another about a conflict within a project that employed them, where among other things they were asked to work on topics unrelated to the project, and they were barred from publishing freely, 'and my colleagues know about it, but permanent colleagues don't want to challenge my PI because the PI has power and brings in money'.

These are not mere quibbles: 'I found out I was paid less than male colleagues', as one respondent hired on a seasonal basis wrote. But they never complained about it, as they worried that they would not be offered another such contract in the future. Others had problems with the reimbursement of fieldwork costs, which made economic survival difficult.

\footnotetext{
${ }^{80}$ More qualitative research is needed that would unravel these dynamics. For one good example see Peacock, V. (2016). Academic precarity as hierarchical dependence in the Max Planck Society. HAU, 6(1), 95-119.

https://doi.org/10.14318/hau6.1.006. As the late David Graeber observed: '[Ethnographic texts] are written at universities. Reflexive anthropology, however, almost never had anything to say about the power relations under which these texts were actually composed. [...] While one is writing his or her dissertation, one is, typically, a penniless graduate student, whose entire career could very possibly be destroyed by one impolitic interaction with a committee member. While one is transforming the dissertation into a book, one is typically an adjunct or untenured Assistant Professor, desperately trying not to step on any powerful toes and land a real permanent job. Any anthropologist in such a situation will, in fact, mostly likely spend many hours developing complex, nuanced, and extremely detailed ethnographic analyses of the power relations this entails, but that critique can never, by definition, be published, because anyone who did so would be committing academic suicide. [...] One can only imagine the fate of, say, a female graduate student who wrote an essay documenting the sexual politics of her department, let alone the sexual overtures of her committee members, or, say, one of working-class background who published a description of the practices of Marxist professors who regularly cite Pierre Bourdieu's (1993) analyses of the reproduction of class privilege in academic settings, and then in their actual lives act as if Bourdieu had been writing a how-to book instead of a critique.' Graeber, D. (2009). Anarchism, academia, and the avant-garde. In R. Amster, A. DeLeon, L. Fernandez, A. J. Nocella, II, \& D. Shannon (Eds.), Contemporary Anarchist Studies: An Introductory Anthology of Anarchy in the Academy (pp. 119-128). Routledge. See also Bourdieu, P. (1993). The field of cultural production: essays on art and literature. Polity Press.
} 
The abuse of power can also break academic careers. Projects and ideas are appropriated, and access to events for which one fundraised or wrote project proposals is denied: 'My name was left out as an author from a journal publication I substantially contributed towards'. One respondent, in a similar case was offered a complaint procedure, but 'for fear of a worse working relationship, I didn't continue to pursue it'.

\subsection{Summary}

More than half of the respondents had personally experienced discrimination, unfair treatment, harassment, bullying, or verbal, physical or emotional abuse, and two out of three have witnessed such treatment in the case of a colleague or a student in their academic context. The most frequent experiences of discrimination, harassment, unfair treatment or abuse were those based on gender and citizenship, but among the free text answers, a general sense of bullying and mobbing due to power differentials in the academic hierarchy was very prominent as well, such as those relating to unreasonable work demands or the excessive power of PIs within big grants. 


\section{Representation of interests}

\subsection{Representation of interests in one's department}

About the same percentage of respondents ( $46 \%$ ) felt that their interests were sufficiently represented in their workplaces as the percentage of those who felt they were represented insufficiently (47.6\%).

\section{Chart 34: Representation of one's interests at the workplace}

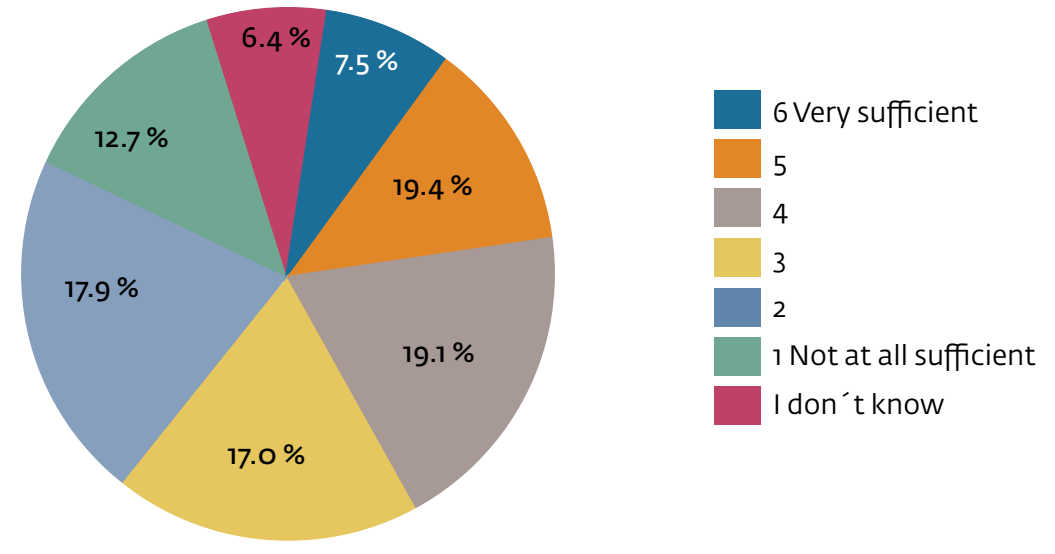

Note. 'How sufficiently are your interests represented in your department/school?'

The interests of about half of the respondents - $49.6 \%$ - were represented at their departments or institutes by elected officials and of $24.2 \%$ by unelected representatives.

Worryingly, in $15.9 \%$ of cases there was nobody who represented their interests at their department or school and in $18.6 \%$ of cases they were unaware of the existence of such representatives ${ }^{81}$ There is therefore scope for improvement and the heads of departments should be made aware of this issue.

At the same time, some respondents were doubtful of what such representatives could do. In their brief descriptions of the cases in which they raised complaints, which they were able to write about in the survey, several noted that although the elected representatives were sympathetic to their situation, there was nothing they could do.

\footnotetext{
${ }^{81}$ The sum is greater than 100 since several answers could be chosen.
} 


\subsection{Trade unions}

\subsubsection{Union membership}

Overall, only $\mathbf{3 5 . 8 \%}$ (289) of respondents were members of trade unions. In total, $44.1 \%$ of those employed in academia and $23.1 \%$ of PhD students were unionised. This severely limits the possibilities of respondents to defend their rights or to create pressure so as to improve their situation.

Looking at countries for which we have at least ten answers for this particular question, we can conclude that those working in the Nordic countries were the most unionised, significantly above average; the German-speaking countries and South West Europe lie below the average; and East Central Europe (Poland and the Czech Republic) lie significantly below the average.

Table 41: Union membership according to country, as percentages (\%)

\begin{tabular}{lc} 
Country & Percentage of unionised respondents \\
\hline Denmark & 95.7 \\
\hline Finland & 84.2 \\
\hline Norway & 82.8 \\
\hline Sweden & 77.8 \\
\hline UK & 53.3 \\
\hline Romania & 41.7 \\
\hline Ireland & 36.4 \\
\hline Sample average & 35.8 \\
\hline Portugal & 37.4 \\
\hline USA & 37.3 \\
\hline Greece & 30.8 \\
\hline Belgium & 30 \\
\hline Austria & 29.2 \\
\hline Netherlands & 28.6 \\
\hline Spain & 24.1 \\
\hline Germany & 23.5 \\
\hline Czech Republic & 15.4 \\
\hline Italy & 14 \\
\hline Switzerland & 14 \\
\hline Poland & 4.2 \\
\hline France & 4 \\
\hline
\end{tabular}


Union members tended to agree that their unions more or less represented their interests, although a relatively high proportion of members (almost 8\%) had no opinion.

\section{Chart 35: Views on union representation}

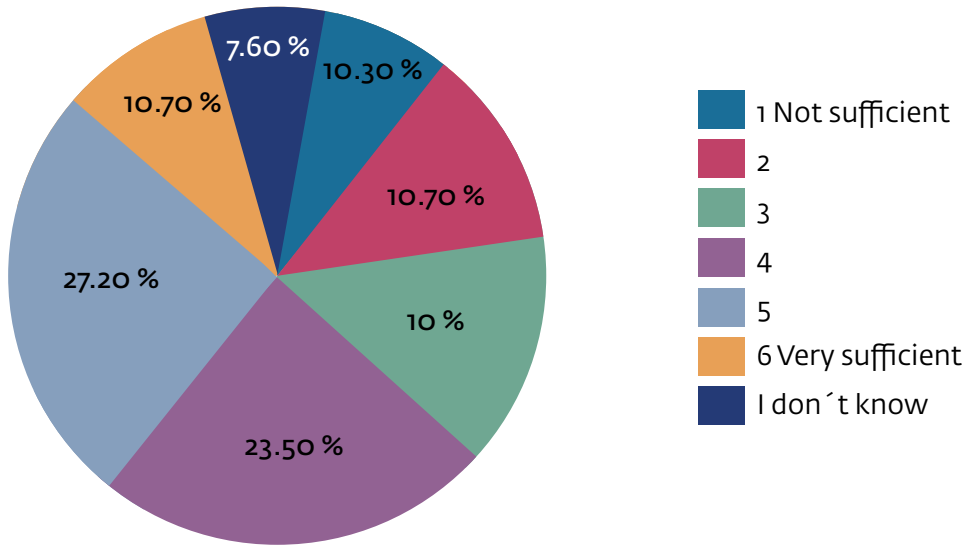

Note. 'How sufficiently are your interests represented by the union?'

\subsubsection{Reasons for not joining a union}

As the table below illustrates, the most important reason for not joining a trade union was the lack of knowledge, a feeling that the union would not represent their interests well, and the fact that their current category did not fit the union classifications.

Table 42: Reasons for not being a union member as percentages (\%)

\section{Reason}

Fees are too high

Language barrier

It does not represent my interests or necessities well

Contractual category does not fit any union classification

Lack of knowledge about unions in the country of employment

Other

\section{Percentage}

8.9

3.9

24.4

22.9

30.6

24.9

Note. Responses to the question 'Why are you not a [union] member? Select all that apply.'

The answers of respondents who elaborated on their reasons corresponded with the answers listed in the table in many ways, but also brought some further insights. The most frequently stated reason for non-membership was that there were no unions in their workplaces. Alternatively, as students, retired academics or unemployed, they were not able to apply for union membership, even though some respondents in these categories used to be union 
members in the past. Several mentioned a disillusionment with the work of the union and the lack of support in the past, or the lack of political identification with the union or their policies.

For many precariously employed academics, an important reason for not joining the union was that 'current unions do not represent exploited academics', as one respondent put it, or that they were dominated either by senior professors or by university administrative staff:

I can only join the professors' union in the country where I work, and it does not seem to do anything useful at all.

Unions in Germany rather defend the interests of research/university administrative staff with permanent contract and school (i.e. not academic) teachers.

Relatedly, many could not join the union because as their status was equated to that of civil servants, they were not allowed to join a union, or no union effectively existed.

Often, those on grants, research fellowships and temporary contracts argued that they could not apply for union membership. Those on fixed-term contracts also felt that it made no sense to join the union. Statements such as: 'Not sure if I will stay in academia, I will join once I am on a permanent contract', 'changing jobs too often across countries' or 'just recently moved here and still working to find a union' are fairly representative of the general views. For others it was a question of time: 'No time to engage in further activities, I'm on the limit of the manageable' or 'too much work and keep postponing joining!'

\subsubsection{Summary}

In total, $36 \%$ of respondents were members of a union; this says something about the union involvement of those EASA members who responded to the survey and does not reveal a great deal regarding levels of unionisation in particular countries. Respondents in the Nordic countries were the most unionised, while colleagues in the German-speaking countries and South West Europe are around the average, while those in East Central Europe fall significantly below the average, with the exception of Romania. Besides a lack of (knowledge about) union representation at their workplaces, many EASA members - and especially those precariously employed - stated as reasons for not joining or trusting unions the fact that many academic unions did not represent the interests of exploited academics as they were often dominated by senior professors or by administrative staff. Insecurity about staying in academia, or the lack of eligibility to join a union as a student or early career research worker, were other reasons for not joining any union.

\subsection{Raising complaints}

In total, $11.6 \%$ of respondents (94 individuals) have filed a work-related complaint with their academic employee(s) or colleague(s) past or present; the non-response 
rate to this question was low $-0.4 \%$. Certainly, many had reasons to raise work-related complaints, but decided against it. 'I would not dare to', one respondent wrote, 'Although laws are robust, what goes on hidden inside small academic departments means there is no means of obtaining proof for the complaint'.

A total of 106 respondents (13\%) also shared their experiences with their employer organisations' formal complaints procedures, the role of labour unions and other actors. Most of the complaints were against one's employer for unpaid salaries, unfair dismissal or employment conditions that violated labour laws. Others were against one's supervisors, such as PhD supervisors or project PIs, and ranged from verbal and emotional abuse to conflicts over data. Some involved lawyers, HR departments, ombudspersons or union representatives.

Besides lawyers, union representatives were found helpful and supportive whenever they became involved:

They followed our case closely, and provided us with support, resources, and clear information every step of the way.

The union was very involved and key to the outcome, though at the beginning they were slow to act. It led to an appreciation that formal grievances actually deliver positive outcomes compared to the informal processes preferred previously.

In many cases, however, the support was limited:

The labour union was sympathetic, but could not do anything. They arrange courses for PhD students about how to become more efficient and such, and seem to have totally appropriated the ideology of the corporate university.

Union supportive, but case dismissed by university in order to protect a professor.

In another case, which ended up in this respondent leaving the department:

The unions were there to assist me (and the other person), but all they could do is find small temporary solutions to get me out of the worst of it, they could not make the abuse stop fully.

Many respondents, however, described how even when advised to file a complaint, they ultimately decided against it, such as this respondent:

I did not file an official complaint about the harassment I experienced and witnessed out of fear of retaliation and irreparable damage to my career.

Equally worryingly, others were discouraged from raising such a complaint:

The university administration strongly discouraged me from filing a complaint. They would not protect me against punitive actions by my supervisor. Out of fear of these repercussions, I did not file. 
Many who did not file an official complaint tried to deal with things informally, but often found that it did not lead anywhere. Several voiced their conviction that institutions were there only to protect themselves and that given their precarious position and dependency on senior scholars for promotion - or in the context of PhD supervision, against a background of shrinking opportunities - they had few opportunities left, for as one respondent explained:

I did not do anything about it [the breaking of contractual obligations on the side of the department] as I was hoping to get a permanent contract with the department at a later point.

Another anthropologist rhetorically observed:

Why is none of this being considered elite modern slavery? - where slaves look washed, well dressed, articulate, intelligent, literate/highly intelligent. We are the elite intelligentsia living 'under' the poverty line. None of the students or their parents know what is going on. We have to be complicit in the 'secret' in order to keep getting small jobs to put on the CVs to justify why we don't have a full-time lectureship yet.

\subsection{The role of EASA}

The survey was conducted among the EASA membership in order to map the respondents' employment situation in a systematic manner and to open the discussion on the respondents' changing structure of employment.

As indicated in the introduction, the survey dataset is slightly skewed towards early career researchers - people mostly aged between 31 and 45, who represented 52\% of the EASA membership in 2018 , and $59.1 \%$ of the sample. Almost $55 \%$ of respondents had become EASA members between 2013 and 2018 and almost $78 \%$ after 2007. It should be remembered that many of those who joined (or re-joined) in 2018 (22\%) did so in order to attend the conference and may not have remained members after the conference.

The survey asked what role EASA could play as a professional association. One of the last questions asked: 'What do you think EASA, as a professional organisation, could do for its members in terms of defending their labour rights?'

In total, $59.45 \%$ of respondents replied to this question. The answers could be grouped as follows (illustrated by representative statements):

- A minority thought that EASA was a scholarly association and that its mission was not to get engaged in the fight for labour rights. It should not do anything. Alternatively, due to different situations across countries, there was little EASA could do. Defending labour rights was a 'job to be done here in our country'. 
- For many, EASA could be involved in EU-level advocacy, for instance, in helping to create an awareness at EU level about the precarious situation within academia. EASA could also make visible the skills that anthropologists have, improve the recognition of the discipline and promote an awareness of why anthropology matters. It could work with funding agencies to make them aware of the specific problems: 'EASA should lobby with the EU and national governments to transform the current policies about employing academics', is a statement that fairly represents these sentiments.

- EASA could collaborate with other institutions. It could work with other professional organisations to 'lobby governments for fairer working conditions' or with 'local anthropology associations to lobby on specific agendas', which the latter identifies as pertinent to their countries. 'There might be some benefit to disciplines working together to uphold shared values', and EASA could'represent anthropology in the European context'. It could also 'be more active at WCAA to build a strong world network of anthropological associations'.

- EASA could be involved in creating structures that would enhance labour protection, such as trade unions ('Creating a transnational labour union? That's the only way to deal with academic predatory precarity'), reporting and monitoring mechanisms ('monitoring surveys of working and employment conditions of its members'), or advocacy structures ('some kind of collectivisation initiative for early career scholars across institutions to advocate for better conditions', 'creating a legal framework, uniting as many European universities as possible'). It could also coordinate 'response, discuss and engage with the issues and problems' that emerge 'such as the ones currently surrounding HAU'.

- EASA should attempt to influence the work of anthropology departments through, for instance, 'direct contact to the departments where EASA members work'. It could suggest 'good working practices'. It could 'shame institutions that use zero-hours contracts' or develop 'a kind of departmental scorecard - gender balance, contract type etc'. It could promote an 'exchange between department leadership, so also they can i) consider that non-permanent staff matters are their concern, and ii) exchange positive methods for assuring rightful procedures'.

- EASA should open and lead a discussion on generational divide and class scissors opening within departments: 'The senior staff who comfortably got their permanent positions before these conditions came in place and have no idea how hard we work and what this uncertainty and precarity does to our lives and the level of stress it generates'. And also: 'EASA members who are professors and enjoy the privilege of having permanent positions need to be self-reflexive about their own situations and devote more time and energy to not only defend the labour rights of their junior colleagues but also generate new jobs and lobby with the governments to improve working conditions'.

- EASA should also directly influence the behaviour of its members. Discussing survey results could be a starting point: 'Maybe a workshop or even conference theme could 
critically investigate the issues this survey is dealing with. After all, current professors do hold the power to change working conditions and do fairly little about it'.

- EASA could materially support early career researchers and 'offer more grants for research and conference participation'. 'One of the things I have admired in another organisation I'm part of', wrote another, is 'the funding and development opportunities they offer for early career researchers'.

- It should raise awareness of good practices. It could 'provide some guidelines of good, supportive working environments, perhaps give a sketch of working conditions in various countries'. EASA could do well by 'speaking up against precarious labour (in journals, teaching and research jobs), and drafting guidelines for all institutions and journals', including guidelines on big projects.

- It should disseminate the results of the survey. This statement summarises such sentiments well: 'I think this research is a great idea, and using the report to create some practical recommendations, publish and promote it widely, hold some public discussions, and have meetings with senior people in the field would be a great way to press for change'.

Overall, while people were careful when proposing quick solutions, and were aware of the limits of a scholarly association, most seemed to coincide with the statement of one respondent that 'EASA could put this problem [employment and precarity] on its agenda and give it as much attention as possible'. 


\section{Conclusions and recommendations}

In light of the above findings, there are a number of recommendations that we as authors direct equally at EASA and at department-, institutional-, national- and European-level decision-makers.

- A career framework is needed. It should standardise the progression towards tenure for anthropologists across the continent, starting with guidelines like those of the UK Concordat to Support the Career Development of Researchers. ${ }^{82}$ It can follow existing examples that have been developed on a number of levels: the standardisation of labour contract types, payment scales according to national standards, and requirements for career progression that benefit the employees. Each country should introduce and encourage standards of receiving tenure as a result of a subsequent number of teaching or research contracts. An EU-wide monitoring process and award could be developed for best employment practices in hiring and permitting career progression for precarious faculty members. Employers should be incentivised, provided with resources, and monitored to reinforce such progression, and take responsibility in guaranteeing career progress inside their institutions. Within this framework all contractual categories should be tightly monitored by institutional and national bodies, and reported in their own rights, not as full-time equivalents. These categories should be made to fit trade-union classifications and should be eligible for fully fledged trade-union membership and protection.

- PhD programmes should be fully resourced - governments, institutions, and departments should collaborate and set a framework for doctoral studies that provides employment contracts and salaries for all PhD students. Employment contracts should include contributions towards unemployment, medical insurance, a pension and other benefits that create a level of social protection equal to that of research workers with that level of qualification. PhD students in anthropology should be granted access to fieldwork funding in particular, as well as - just as for PhD students in other disciplines - access to funds for conference attendance and career development. Student fees and debt-inducing student loans should be fully discouraged at PhD level.

\section{- Cyclical project funding and structural overtime should be reduced to a minimum}

- the amount of overtime, unpaid extra work spent on grant applications, job applications and class preparation is a waste of human and time resources that needs to be curtailed, in anthropology and academia more widely. Funding bodies and institutions must seriously rethink the current research-funding infrastructure. They should prioritise long-standing, well-resourced, strategic grants to institutions and departments with discretion over how research budgets are spent over time. Departments should reduce overtime and not

82 Vitae (2019). Concordat to support the career development of researchers. Retrieved from https://www.vitae.ac.uk/policy/concordat 
push employees into unpaid work. While the number of funding-related fixed-term parttime contracts should be gradually reduced, departments should make a particular effort to adequately pay colleagues on such contracts (sessional workers especially).

- The increasing responsibilities of EASA and other professional associations While not legal bodies or trade unions in their own right, EASA could and should prioritise lobbying activities aimed at mitigating the effects of a multiplicity of economic, ecological and social crises - exacerbated by the COVID-19 pandemic - on their members. EASA should commission further research into prominent issues such as the nature, structure and effect of cyclical research funding, and introduce and sanction standards of good practice to be observed by individual members and institutions. EASA has to recognise the fact that its members do not all have the same stakes in their workplaces, they are not always automatically allies, and that in fact (as working-class colleagues have known all along), there is a multi-layered class conflict within anthropology departments and projects: between working-class academics and middle-class academics, and between precariously hired early career researchers and senior faculty on permanent contracts. EASA will ignore these dynamics only at its own peril. 